Florida International University FIU Digital Commons

FIU Electronic Theses and Dissertations

University Graduate School

4-16-2001

\title{
The maintenance of tracking : the role of organizational culture
}

Dora Acherman-Chor

Florida International University

DOI: $10.25148 /$ etd.FI13101521

Follow this and additional works at: https://digitalcommons.fiu.edu/etd

Part of the Educational Sociology Commons

\section{Recommended Citation}

Acherman-Chor, Dora, "The maintenance of tracking : the role of organizational culture" (2001). FIU Electronic Theses and Dissertations. 1101.

https://digitalcommons.fiu.edu/etd/1101

This work is brought to you for free and open access by the University Graduate School at FIU Digital Commons. It has been accepted for inclusion in FIU Electronic Theses and Dissertations by an authorized administrator of FIU Digital Commons. For more information, please contact dcc@fiu.edu. 


\section{FLORIDA INTERNATIONAL UNIVERSITY}

Miami, Florida

THE MAINTENANCE OF TRACKING:

THE ROLE OF ORGANIZATIONAL CULTURE

A dissertation submitted in partial fulfillment of the requirements for the degree of

DOCTOR OF PHILOSOPHY

in

SOCIOLOGY

by

Dora Acherman-Chor 
To: Dean Arthur W. Herriott

College of Arts and Sciences

This dissertation, written by Dora Acherman-Chor, and entitled The Maintenance of Tracking: The Role of Organizational Culture, having been approved in respect to style and intellectual content, is referred to you for judgment.

We have read this dissertation and recommend that it be approved.

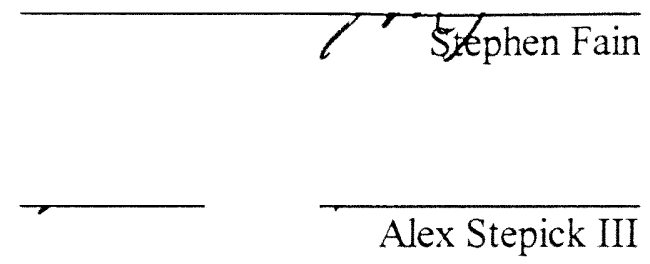

Dennis Wiedman

Betty Heărn Morrow, Major Professor

Date of Defense: April 16, 2001

The dissertation of Dora Acherman-Chor is approved.

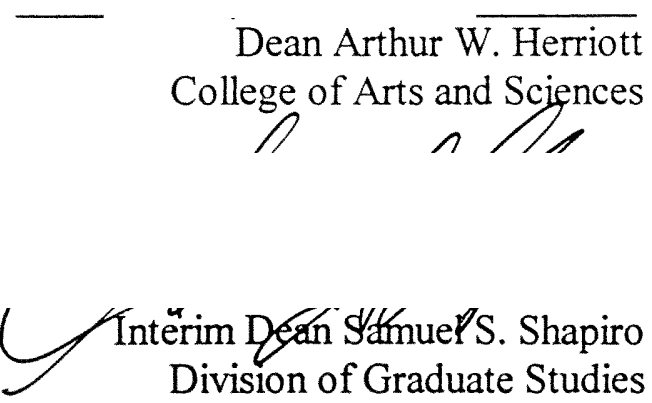

Florida International University, 2001 
(C) Copyright 2001 by Dora Acherman-Chor

All rights reserved. 


\section{DEDICATION}

I dedicate this dissertation to my parents, who taught me the love of learning, and to Henrique, Daniel, and Felipe, who teach me the love of living. 


\section{ACKNOWLEDGMENTS}

I wish to thank the members of my committee for their insightful comments, and patience.

To my major professor, Dr. Betty Morrow, a special thank you for her support, insight, encouragement, advice, and endless patience. 


\section{ABSTRACT OF THE DISSERTATION \\ THE MAINTENANCE OF TRACKING: \\ THE ROLE OF ORGANIZATIONAL CULTURE \\ by}

\section{Dora Acherman-Chor}

Florida International University, 2001

Miami, Florida

Professor Betty Hearn Morrow, Major Professor

Modern comprehensive high schools do not formally track students into different programs, but schools offer different curricular sequences with important and stratified consequences for students' post-secondary education. This study used qualitative methodology to examine how schools' organizational cultures influence the maintenance of tracking practices in four comprehensive high schools in Miami. The methodology included long-term participant observation in each of the four schools, unstructured and semi-structured interviews and the collection of written documents produced by the district. A framework based on the concepts of environment, mission, information, strategy, and leadership was used to analyze the data.

It was found that school cultures shared deeply held beliefs that regard ability as a fixed trait. This prevented schools from providing access to information about the consequences of course selection to the majority of the student body, with the exception of those students defined as "college bound." State and County level policies that reward achievement in standardized tests combined with school overcrowding, resulted in organizational cultures that favored the adoption of strategies stressing efficiency, as 
opposed to a challenging education for all students. Only one of the four schools in the study had a policy requiring students to attempt courses that were more challenging. The practice was resented by both teachers and counselors, since it was perceived as interfering with other goals of the institution, i.e.: graduating students in four years.

The culture of the schools stressed college as the only legitimate post-secondary option; consequently, the majority of counselors did not encourage students-even those already defined as "not college material"- to consider other alternatives, such as vocational education. The elimination of formal tracks in these comprehensive high schools resulted in the school culture lacking a clear mission in regards to non-college bound students. Findings are discussed in relation to current theoretical explanations for educational policy and equality of opportunity. 
$\begin{array}{ll}\text { Setting } & 73\end{array}$

$\begin{array}{ll}\text { The School District } & 73\end{array}$

$\begin{array}{ll}\text { Programs Offered } & 78\end{array}$

$\begin{array}{lr}\text { Student Membership } & 81\end{array}$

The School Staff $\quad 83$

\section{FINDINGS}

Environment

The Outside Environment: The Educational System

and Society in General $\quad 87$

The Internal Environment $\quad 92$

Acceptable and Unacceptable Discourse in School's

Organizational Cultures $\quad 100$

$\begin{array}{ll}\text { Mission } & 102\end{array}$

How Is the Mission Defined? 102

How Is the Mission Articulated? Accountability and Tracking 103

High School Mission as College or "Other" 105

$\begin{array}{ll}\text { Strategy } & 107\end{array}$

$\begin{array}{ll}\text { Funding Policies and Strategies } & 107\end{array}$

Vocational Programs $\quad 109$

Information $\quad 114$

Physical Access to Information $\quad 114$

Subject Selection Procedures $\quad 117$

Overview of Findings 123

The Centrality of the Concept of Ability 123

Overcrowding, Resource Distribution, and Differential Access

To Information $\quad 123$

The Influence of the External Environment 126

$\begin{array}{ll}\text { Summary } & 127\end{array}$

V. CONCLUSION

After the "Unremarked Revolution:" Organizational Culture

and the Maintenance of Tracking 129

Indicators of the Maintenance of Tracking 129

Emic and Etic Perspectives on the Use of the Concept of "Ability" 130

The Unifying Role of Comprehensive Schools 131

The Stigmatization of Vocational Education 132

The Role of Information 133

School Mission $\quad 135$

The Focus on College and the Organizational Culture of Schools $\quad 136$

Theoretical Implications $\quad 136$

Social Reproduction or Social Mobility 136

The Effects of Tracking: Unequal Selectedness and Meritocracy 137

Educational Policy and School Change 137 
REFERENCES CITED 


\section{INTRODUCTION}

"Be kind to the honor roll students. You will probably be working for one of them someday." (Poster by the honor roll list on the wall of main office at Lincoln Senior High)

What if the curriculum was a fetish?

(Silva 2000)

This dissertation is a study of the organizational cultures of four comprehensive high schools in Dade County, Florida. Its main concern is the manner in which these organizational cultures set the parameters that help or hinder the implementation of educational policies aimed at providing students with equality of educational opportunity. By definition, comprehensive high schools are not supposed to track students into vocational and academic tracks. However, they have continued to offer different curricular sequences in practically every subject, resulting in stratified opportunities to learn for the students (Stevenson, Schiller and Schneider 1994). Because opportunities to learn are not offered equally to all students, these opportunities become a limited resource. Those who control access to this resource-primarily guidance counselors and teachers - - then act as gatekeepers in a process of social stratification. This dissertation is a study of the ways in which the organizational culture of these schools determines whether or not, or to what extent, educational policies that aim at expanding educational opportunities to all children become reality. 


\section{General Statement of Problem Area}

The last fifty years have witnessed an increase in educational policies intended to improve access and equality of educational opportunity for groups previously discriminated against in one form or another by the educational system. Proponents of these policies argued that they needed to be implemented if the educational system was to become one where success is truly based on merit, not other factors. The Brown versus Board of Education decision in 1954 paved the way to additional lawsuits that resulted in mandates aimed at influencing the way schools distribute educational opportunities. When AfricanAmericans achieved the right - even if only legally and not in reality - to receive the same quality of education as whites, the decision became the legal basis for action by other groups also disenfranchised within the educational system (Rippa 1997).

The decades that followed the Brown decision saw the recognition of the rights to equal opportunity of several other groups. Native Americans fought to achieve more control over their children's education and to education that is more culturally appropriate (Rippa 1997). Hispanic and other minority students fought to be placed in higher-level classes (Oakes 1995), and limited English proficient students achieved the right to "understandable" or bilingual education (Office of Bilingual Education and Minority Language Affairs 1997). Handicapped and disabled students became entitled to be educated in the least restrictive environment (Rippa 1997), and girls gained the right to be treated equally in science and math classes. Female athletes gained rights to similar proportions of college scholarships as males (Rippa 1997). Some of these rights, recognized only after lengthy legal processes, resulted in the courts mandating schools to change the way they conduct their business. 
Legally mandated school reforms, however, more often than not failed to produce the expected results (Cuban 1990; Oakes 1986; Sarason 1996; Tye 2000). Educational researchers have been suggesting explanations for these failures since policy-makers started mandating school reforms. Some of these reforms, if properly implemented, would have affected the distribution of important educational resources among students from different racial and socioeconomic backgrounds, and would have had implications that extend well beyond school gates regarding issues of access, equality of opportunity and social mobility (Oakes 1994). An example of such a reform is the development of comprehensive high schools; particularly regarding the specific features intended to prevent the tracking of students into academic and vocational tracks in secondary education (Lucas 1999; Wraga 1998).

Comprehensive high schools supposedly offer different types and levels of classes to serve students' needs according to their abilities and interests "under the same roof" (Hallinan 1994; Wraga 1998, 1999). The original designers of comprehensive schools intended to prevent American schools from following the English and German models that tracked students into formal and separately housed academic and vocational tracks (Wraga 1998, 1999). Educational policymakers in America wanted the comprehensive school to provide all students with the general knowledge required for citizenship in American society. In addition, comprehensive schools should offer college preparatory courses that prepared "deserving" students for college and vocational skills for students whose interests were not academic (Gamoran 1987; Oakes 1982, 1983, 1985, 1986, 1987).

Although not formally separated into vocational and academic tracks, students in comprehensive high schools are placed in classes that belong to different curricular 
sequences. In a comprehensive school, most courses are offered in at least three levels at each grade: Remedial, regular and Honors. The majority of students are placed into curricular sequences that belong to either one of two patterns. The first, more prestigious pattern involves academically demanding college-preparatory classes that emphasize critical thinking skills, courses that build upon skills acquired previously, and high performance expectations. The second pattern involves classes where demands for critical thinking skills are few, challenges practically non-existent, and minimal teacher expectations (Gollub and Sloan 1978; Oakes 1985, 1995; Pallas et al. 1994). While in theory "remedial" classes are supposed to help students catch up with their peers who are learning at what is considered grade level in that subject (Hallinan 1994), in practice students placed in remedial classes rarely move up to other levels (Gamoran and Berends 1987; Oakes 1994; Rosenbaum 1976).

The practice of placing students in different levels and class sequences, therefore, although not considered by the school system as "tracking" per se, has de facto long-term implications. It results in stratified and differential opportunities for social mobility (Lucas 1999; Oakes 1983, 1985). Theoretically, students in a comprehensive school should be able to follow their interests and abilities by taking advanced classes in the field of humanities, for example, while taking a less demanding curricular sequence in science and math, if they so desired. Prestigious colleges, however, examine students' records of studies carefully, accepting students who take more advanced level courses (Honors or Advanced Placement) and rejecting students who took the less demanding classes. Thus, despite the absence of formal tracks and the existence of policies against tracking students, comprehensive 
schools in fact have continued to track students (Hallinan 1994; Oakes 1982, 1990, 1994, 1995; Pallas et al. 1994).

Complicating this situation further, research on comprehensive high schools has shown time and again that minority and lower class students are disproportionately placed in the lower level, less prestigious, and less demanding classes (Mehan et al. 1994; Oakes 1982, 1985; Pallas et al. 1994; Rosenbaum 1976; Vanfossen, Jones and Spade 1987). Criteria used to make placement decisions are often unclear since policies mention concepts such as "ability," "interest," and "motivation" without defining them. Standardized achievement tests-SATs, usually referred to as stanines, the way they are measured - commonly used by placement decision makers are constantly accused of bias against ethnic and linguistic minorities (Gould 1996). Tests intended to measure intellectual ability have had a problematic history since their creation, as shown by Gould (1996). Intelligence and ability tests in general have been misused and misinterpreted, oftentimes intentionally, in order to support someone's preconceived ideas about different groups of people. These findings are particularly problematic in relation to the practices of comprehensive high schools since they pose a real threat to the meritocratic and equity principles that play crucial roles in American beliefs about educational opportunity. This belief in turn is an important piece of the American self-concept as a democratic nation with "freedom and opportunity for all."

\section{Research Purpose}

This dissertation is a qualitative study of tracking - placement practices - in four comprehensive high schools in Eastville County; Franklin, Russell, Darwin and Lincoln 
High Schools. ${ }^{1}$ Many studies of tracking use quantitative techniques to analyze what kind of students are placed in what kind of classes, whether there is mobility in terms of levels, or whether students tend to be placed in all lower level or higher level classes ${ }^{2}$. In contrast, this study focuses on the organizational culture of schools and how it affects the manner in which placement decision makers (mainly guidance counselors and teachers) deal with the demands placed on them in large urban comprehensive high schools. The organizational culture of the school sets the parameters within which policies and rules are implemented and includes both the written policies and the unspoken rules regarding the sorting and selecting of students.

An important question is how placement decision makers, as members of an institution committed to providing equality of opportunity, understand and explain the application of these rules, particularly in regards to sorting and selecting students. Schools are not only institutions with their own organizational cultures. They are also places upon which the culture of the wider society places contradictory requirements (Wilcox 1988). Comprehensive high schools are expected to provide equal opportunity to students. At the same time, they must sort and select students and place them in courses within curricular sequences that will have long-term implications for students' opportunities for social mobility. These demands generate contradictions that have to be dealt with by the educational system's organizational culture. Placement practices need to be understood within the context of the wider society that gives meaning to these practices. Thus, a larger question underlying this study concerns the ways in which schools' organizational cultures

\footnotetext{
${ }^{1}$ Pseudonyms were used as names of places, neighborhoods, schools, and people in order to protect the identity of those involved.

${ }^{2}$ See Lucas (1999) for a recent example of statistical analysis of tracking.
} 
react and adapt to these contradictory requirements placed on them by the culture of the wider society.

The definition of culture was addressed using a theoretical approach from the field of organizational sociology, as opposed to definitions commonly used in the fields of business management or administration. The difference between the approaches resides, most of all, in the use of the more sophisticated and encompassing concept of culture as "the fabric of meaning in terms of which human beings interpret their experience and guide their action" (Geertz 1973:145). Humans, however, do not create this "fabric of meaning" in a vacuum: Issues of power affect the cultural sphere, just as they do the social and political spheres. Thus, hegemonic and counter-hegemonic definitions of situations will exist in any organization, reflecting both the distribution of power in society at-large as well as the distribution of power at the organizational level (Bobbio 1982; Giroux 1992).

As used here, organizational culture implies not only the observed regularities of behavior of that organization, but more importantly the underlying, often unspoken, beliefs, values and myths that guide that behavior (Martin 1992; Sarason 1996; Tye 2000). Thus, the organizational culture of a school has certain characteristics:

- It is located within the broader context of the wider society and behaves in relationship to it (Tye 2000).

- It has elements that can be widely shared, being almost universal, that can be analyzed from an integrative perspective (Martin 1992).

- It has other elements that make it fragmented, including the different subcultures of the participating groups: Administrators, teachers, students, counselors, and parents, 
to name a few. These elements need to be analyzed from a differentiated perspective (Martin 1992).

- These subcultures are not static. They are socially constructed and re-constructed within the constraints of the larger socio-political and economic context (Tye 2000).

Studies of school reform failure often focus on problems with the policies themselves, that is, the recommended change did not result in the desired effect. Cuban (1990) notes that the dominant model to explain school reform failure, which he calls the "rational model of organizational action," asks whether the right problem was attacked, whether the solution really fit the problem, and whether the policy was implemented as planned. Other attempts to explain failure to change on the part of schools are based on a psychological model and often find fault with teachers or administrators for resisting change, either due to pure conservatism and fear of innovation or to avoid increased workloads (Sarason 1996).

The goal of this dissertation is to look at how the organizational culture of schools affects the implementation of educational policies requiring schools to provide equal opportunity to all students. Such policies also require high standards of education for every student, while at the same time schools are required to provide education to every student "at their own level." Each school with its organizational culture must react and adapt to these contradictory requirements of "excellence" and equity.

Data analysis followed a framework suggested by Tierney (1988) framework for the study of organizational culture of an educational institution. The framework includes six essential concepts: Environment, mission, strategy, leadership, information, and 
socialization. Each of these concepts leads to a number of questions that are be used to guide the researcher. This study focused on four of these concepts: Environment, mission, strategy, and information. The two additional concepts in Tierney's framework, leadership, and socialization, are analyzed indirectly in relationship to the other four concepts.

\section{Research Questions}

- How does the organizational culture of schools support the maintenance of tracking practices despite an official discourse stating that schools are not supposed to track students?

- How does the organizational culture of schools legitimize the maintenance of tracking practices in face of the commitment to not track?

- How does the organization define its environment, external to the schools (the educational system and the wider society in general) and internal, and how do these definitions influence tracking practices?

- In the absence of formal academic and vocational tracks, how is the mission of the schools defined, and how is it articulated in practice, particularly in regards to those students who are perceived as non college-bound?

- What are the strategies available within the organizational culture to people occupying different roles in the schools (principals, teachers, counselors) and how do these strategies affect tracking practices?

- What kinds of information are available to students in the schools? Is information uniformly or differentially distributed, and how does this distribution of information relate to the maintenance of tracking? 


\section{Overview of Methodology}

This research is an extension of a larger project called "The Academic Orientation of Native-born and Immigrant Minority Adolescents" headed by Dr. Alex Stepick (1995). The larger project is a longitudinal study of six immigrant-ethnic minorities (AfricanAmericans, Haitians, West Indians, Cubans, Nicaraguans and Mexicans) in four different Miami-Dade county high schools. ${ }^{3}$ The district granted the permission to conduct the research in those four schools. Additional permission was granted in person by the principals in each of the four sites. The larger project focused on issues pertaining to immigrant students' experiences at home and at school and their effects on students' academic orientation.

Sample

The sample consisted of four public high schools in the same district in a Southeastern urban area. Although they share similarities, each of these schools is located in a region with different demographics. While the population in all four schools is made up of mostly minority students, largely immigrant, each school serves a different population. One school is located in a rural area and has a large percentage of MexicanAmericans. Another school is located in the inner city, with a predominantly Haitian immigrant population. The other two are urban schools: One is predominantly Hispanic and mostly Cuban, the second school currently serves predominantly black populations from different national and ethnic backgrounds: The majority of students are either African-American or Haitian, with many others coming from other Caribbean countries.

3 The larger project was supported by National Science Foundation Grant SBR-9511515, the Andrew Mellon Foundation and the Carnegie Corporation. 
All four schools were functioning over capacity during the period when the research was conducted.

\section{Methodology}

Many scholars of education (Apple and Weis 1983; Karabel and Halsey 1977b:61) have criticized the positivistic emphasis and overreliance on statistical procedures of the "achievement tradition," asking for "an approach that would combine an investigation of day-to-day curricular, pedagogic, and evaluative activities of schools with generative theories of the school's role in society" (Apple and Weis 1983:4). By focusing on the organizational culture of schools, this study is an attempt to respond to such requests for a research program that connects interpretive studies with structural analysis.

The methodology used in this project was primarily qualitative, with the extensive use of semi-structured and unstructured interviews with school principals, assistantprincipals, teachers, department-heads, and counselors. Principals and assistant principals were interviewed once in each school. Interviews with principals were conducted in conjunction with a senior member of the larger research project, Dr. Carolyn Herrington, from Florida State University. One of the principals was replaced at the end of study. I met the new principal on the first week of class, and observed two meetings with the staff, but did not interview him.

Observation with counselors and the staff who interacted with students in the guidance area of the student services department makes up the largest set of data. This data provided information from the guidance offices, where most decisions regarding opportunities offered to, or withheld from, students, course-taking patterns, and career 
decisions are made. Some counselors allowed me to sit in during meetings with parents, but not all. In a few instances, since I was there as a volunteer, I was asked to translate for nonEnglish speaking Hispanic parents, and in a few others I was asked to make phone calls to the home or work of students who had attendance problems to ask parents to meet with counselors.

A second source of information came from the content analysis of documents describing educational policies relevant to the issues of tracking and career decisions. Documents analyzed include county level documents such as School Board Rules, school level documents such as mission statements and Curriculum Bulletins.

This triangulation of methods was used as a means of compensating to a certain degree some of the limitations of each particular method, such as the lower reliability that is normally associated with participant observation. An important component of this investigation was its focus on schools' organizational cultures. Each school had its own history, served a particular population, and developed its own self-identity. Although they are all within the same county, there might be variations in policy implementation.

\section{Significance of the Study}

This is a study of the implementation of educational policies requiring high schools to be comprehensive and to refrain from "tracking" students into vocational and academic tracks. This study's contribution lies in its focus on the organizational culture as a means to explain the maintenance of tracking. The methodology constitutes a departure from the quantitative methods traditionally used in the study of issues of tracking and stratification in education. 
Despite the mandatory "de-tracking" of high schools ${ }^{4}$ and the professed commitment of educational systems to the comprehensive school model, the number of programs providing professional training in "academies" within the comprehensive school, tech-prep programs, and magnet programs, are becoming more prevalent every year. Most of these programs accept students only during the first year of high school, the $9^{\text {th }}$ grade, and require students to take a set curriculum, with less room for choices in classes. This trend may be indicative of an even greater tendency towards specialization, a tendency that counters the comprehensive model of high schools theoretically espoused by the American educational system. It is expected that the study's findings will have implications for educational policy.

\section{Summary of Chapters}

Chapter 1 introduced the reader to the general area where this study belongs: It described the importance of public education and the concepts of equality of opportunity and meritocracy in the American belief system. Chapter 2 begins with a historical background that focuses on the development of the meritocratic ideal in the American culture, particularly in regards to education. The chapter reviews main current theories on the role of education in society, particularly the reproduction versus mobility debate.

Chapter 2 also reviews and summarizes the theory and research on tracking and relates it to issues of equality of opportunity. In addition, it discusses the concept of organizational culture and how it is used in analyzing educational settings. Chapter 3 describes the setting

\footnotetext{
${ }^{4}$ The Smith Hughes legislation from 1917 established comprehensive schools, and was recently reinforced by the Charles D. Perkins act of 1984. For more details, see Wraga, William G. 1998. "The Comprehensive High School and Educational Reform in the U.S.: Retrospect and Prospect." The High School Journal 81:121-126..
} 
and the methodology in further detail. Chapter 4 contains the results from the analysis of data collected in interviews, observations and secondary documents from the schools and the county. Chapter 5 discusses some implications of the analysis of the data and relates the findings to the literature previously discussed. 


\section{Chapter II}

\section{LITERATURE REVIEW}

\section{Overview of Chapter}

Organizational cultures cannot be understood outside of their historical and sociopolitical context. To understand the organizational culture of contemporary high schools, therefore, it is necessary first to understand the historical context that produced them. Particularly relevant is the role that the belief in equality of educational opportunity plays in determining this organizational culture. The literature review begins by placing comprehensive high schools, their placement practices, and their resulting organizational cultures in the context of the larger culture.

The review then links the role of tracking in differential achievement and the relation between differential achievement, social stratification, and the two paradigms in social theories of schooling: Schools as agents of social mobility or of social reproduction. Each of these paradigms is related to an approach to understanding curricular tracking, with educational researchers divided between those who consider curricular tracking as a neutral and efficient way to serve the needs of students and those who see tracking as a mechanism used inside schools to reproduce the social stratification of the larger society. The chapter also reviews empirical studies of tracking and detracking, including some studies on their effects on schools as institutions.

The chapter then examines the literature on organizational culture, focusing on the study of schools' organizational cultures and stating the framework used in the analysis of 
the data in this study. A brief review of some empirical studies of school culture, with an emphasis on school culture and change concludes the literature review.

Background of the Study: American Education in Historical Perspective

\section{Education in Colonial America}

Early settlers in colonial America brought with them an intellectual heritage derived from Old World traditions. Geographic forces, such as the need to survive in the new environment, as well as social forces such as the racial interaction faced in the New World, had a strong and selective influence on imported European ideas. To understand the development of American education, one needs to take into account the ways in which the New World changed European traditions. S. Alexander Rippa (1997:4), an education historian, notes: "Colonial America did not understand the meaning of democracy." Moreover, despite the fact that many of the first settlers were escaping religious persecution, tolerance could not be farther away from their minds. Settlers wanted freedom from interference by opposing sects or political authorities, but "once in America, those who had been persecuted in Europe soon began feverishly to expel the heretics from their own political domain" (Rippa 1997:8).

English-speaking settlers constituted not only a numerical majority, but also had a larger role in political leadership in the New World. They also had closer ties with their motherland than other immigrants in colonial America. Thus, the English model of education played an influential role in the development of American education (Rippa 1997). In colonial America, discipline in schools was rigid since the dominant attitude was that children were already born in sin and tended to human degeneracy. Learning was 
always through rote memorization from textbooks, reading was merely a tool to allow people to read the Bible, and education beyond the level of basic reading was only for the few rich boys, who learned Latin and Greek and went on to Harvard to become clergy or statesmen.

Despite the New World's religious and nationality differences, most groups shared the common fear that their children would lapse into barbarism in such a primitive environment. Education, therefore, was seen as a weapon against this feared descent (Rippa 1997). The Franklin and Southern colonies, however, had quite different views of who should be educated and who should be financially responsible for children's education. In the Franklin colonies, under mostly Puritan influence, the Puritan clergy's belief that every child should be able to read the Scriptures made education a civil and religious responsibility.

The Southern colonies, on the other hand, with their plantation-based way of life, considered education primarily a private and individual matter (Rippa 1997). Huge distances from one plantation to another made private tutoring of children a better option than sending them to school. In addition, wealthy planters were not inclined towards educating all children regardless of class origin. The education of their own children was very important, but that of the poor was none of their business. Neither did the dominant Anglican Church view the state as having any responsibility in the education of the poor (Rippa 1997). In the southern colonies, therefore, the education of the poor was left in the hands of religious and philanthropic societies that provided charity schools. In the middle colonies, with their variety of languages (French, German, Dutch and English) and religious groups (Dutch Reformed Church in New York, Catholics in Maryland, and 
Quakers and Mennonites in Pennsylvania) and sparsely settled areas, education also developed along sectarian lines without state support (Rippa 1997).

Despite these differences in their approaches to education, social distinctions were as important in the more urban New England puritan society as they were in the agrarian southern colonies. Although neither of the two versions of the New World aristocracies fit the leisure pattern of their European counterparts, colonial Americans did not neglect social stratification and hierarchy (Rippa 1997). With very few exceptions, schools in colonial America "were designed not to open the paths to social opportunity, but rather to develop in the pupils a passive acceptance of the existing political and religious patterns" (Rippa 1997:37). How then, did America become, at least in its idealistic self-conceptions, a meritocratic "land of opportunity" with "justice and freedom for all?"

\section{The Development of the Meritocratic Ideal in Education}

Secular ideas from the European Enlightenment gradually arrived at the New World's shores, and had an impact on America's beliefs about education. Religious dogmas and ideas about predestination and supernaturalism were, in many places, superseded by a belief in reason, science, and human control. The ideas of the Enlightenment suited quite well the needs of some of America's new growing urban middle class involved in mercantile activities. Education followed these needs, with a shift from a focus on classical knowledge towards more scientific, practical, and applicable types of knowledge: mechanics, electricity, and astronomy. The conception of children also changed, influenced by the ideas of philosophers such as John Locke and Jean Jacques Rousseau. They were no longer sinners with evil tendencies in need of control, but were 
conceived as going through a developmental process. Educators, then, should suit the educational process to children's developmental stages (Kliebard 1995).

The end of the colonial period brought some important changes to the American cultural and ideological landscape. Analyzing the influence of the colonial tradition on the development of American education, Rippa (1997) notes that it was the frontier society that brought the ideals of democracy and meritocracy into the American political culture. The availability of land and the flexibility of frontier life allowed individuals to disregard traditional restraints to social mobility such as religion, family, and social origin.

Almost four hundred years later, Americans still want to believe that America is a land of unlimited opportunity. One needs to go no further than the judges who presided over the Brown versus Board of Education lawsuit in 1954 to see the importance of the ideal of equality of opportunity in shaping American history: The judges concluded that racially segregated education was unacceptable because separate inevitably also meant unequal. The issue that prompted the judges' decision was that of equality of opportunity in education. Had the lawyers arguing for the maintenance of segregated schools been successful in proving that racially separated schools were not inherently unequal and thus a threat to the meritocracy principle, America might still have officially segregated, "colored" schools in its educational system.

The Modern Comprehensive High School

During the 1900's, two main factors led to the expansion of compulsory public education. The first factor was the economic need for a minimally trained yet literate workforce. The second factor was the belief in the role of public schools in the 
transformation of immigrants into "modern American citizens" who could not only speak English, but also would understand and share the basic "modern" democratic ideology and thus become members of this new nation (Lucas 1999; Tye 2000; Wraga 1998).

Initially, high schools in America resembled the European models of curricular placement: Students were placed into an explicit curricular track around the time they entered secondary school. While in Europe the different tracks (academic and vocational) were housed in different schools, the specific needs of assimilating the growing number of immigrants led American policymakers to develop a school that offered differentiated curriculum while keeping students under the same roof. The different tracks allowed for differential cognitive preparation and socialization for the future roles students would have in their lives (Kliebard 1995; Lucas 1999). The majority of high schools eventually used a system with explicit overarching tracks; some school systems named their tracks according to the preparation they would give students, e.g. college preparatory, general, generalcommercial, secretarial-commercial, while others would name tracks based on level: Honors, regular, essential and basic (Lucas 1999). Underlying tracking was a core pedagogical belief broadly shared in the professional culture: That intellectual ability is a fixed individual trait that varies widely in students (Erickson 1987).

The comprehensive high school is a product of American history, a "peculiarly American phenomenon" (John Gardner, President of the Carnegie Corporation, as quoted by James Conant (1967:3). 
Each community under the authority delegated by the state government was expected to provide free schools. As the high schools developed more than fifty years ago, it gradually became accepted doctrine that instruction should be provided for youth with a variety of ambitions and abilities. In only a few cities did the European idea of separate selective academic high schools take root. Rather, an elective system as contrasted to a selective system became characteristic of American schools (Conant 1967).

Conant (1967) notes that compulsory attendance laws contributed to an increase in the numbers attending high school as well as in the heterogeneity of the student body. This heterogeneity has been recognized by the wider American culture as an advantage; the underlying belief was that by bringing youth from different backgrounds to come to know each other and share at least some part of their educational experiences, they would also come to understand each other. Thus

One might almost say that the justification of the American system as contrasted to the European must be in terms of social and political ideals. The comprehensive high school attempts to accomplish these ends: it endeavors to provide a general education for all future citizens on the basis of a common democratic understanding; and it seeks to provide in its elective offerings excellent instruction in academic fields and rewarding first-class vocational education (Conant 1967:4).

Cuban (1990) describes the introduction of the comprehensive junior and high school as "a workable compromise" between competing definitions of equal educational opportunity. On one side is a definition of equality as "academic excellence" for all, in the form of traditional academic subjects that need to be taken by all students. On the other side of this society versus child debate is a progressive definition of equality as "fitting the curriculum to the student," in terms of ability, interests, or vocational future.

Wraga (1998, 1999), a staunch defender of the concept of comprehensive schools, states that to be considered truly comprehensive, schools must perform two functions: A 
unifying and a specializing function. The goal of the unifying function is to create a citizenry for the Nation, with a shared commitment to democratic principles and other fundamental values of American life. The goal of the specializing function is to serve a "diverse array of students' educational needs." According to Wraga, however, the comprehensive school has seldom been implemented as intended, with the specializing function constantly taking precedence over the unifying function, thus undermining the "truly democratic nature of the comprehensive model" (Wraga 1998). Wraga seems to miss the contradiction between what he calls the specializing function and equity. Rather, he failed to question the assumption regarding students" "diverse educational needs" and the manner in which these needs would be best served.

The civil rights movement in the 1960's, however, clearly noticed that the tracking of students was inextricably linked to their social class and/or minority status, and was therefore inequitable, serving as a mechanism of social reproduction (Moore and Davenport 1988). Furthermore, the idea that intelligence or academic ability was unitary and fixed also came under attack, undermining a basic principle upon which the formal tracking system was based (Lucas 1999). In at least one case (Hobson versus Hansen in Washington, D.C.), the judge ordered school administrators to abolish tracking (Hayes 1990). As Lucas (1999) notes, the mere threat or possibility of litigation may have been enough to encourage administrators to change the formal tracking system.

Somewhere between the late 1960's and early 1970's, the majority of school systems eliminated formal tracks (Lucas 1999; Oakes 1981). As a result of the Hobson v. Hansen 1967 ruling, attention shifted toward issues of busing and racial balancing (Hayes 1990), with students now assigned to courses that were tracked as Honors, regular, or 
remedial. Lucas (1999) calls this change in school practices the "unremarked revolution," not because the change went unnoticed, but because its implications were not fully recognized. The elimination of formal overarching tracks was intentional and meant to reduce the role of schools in the reproduction of social inequality (Kliebard 1998; Lucas 1999). However, the result of the new structure that substituted formal tracks, as Lucas suggests,

may have been to actually reduce students' and parents' ability to effectively seize the opportunities for individual upward mobility that schools provide. In fact, the change in school practice also may have increased the tendencies to individualize failure and thus heightened the difficulties of generating transformative collective action (Lucas 1999:1).

Opponents of the comprehensive school model have long questioned the viability of the enterprise, citing "the well-known and powerful resistance to change, which has made the high school largely impervious and impossible to improve" (Raywid 1999:306).

Placing the current organization of schools in its historical context is fundamental if one wants to understand what happens inside schools today. It is only within the context of the culture of the larger society, of the beliefs about the importance of equality of educational opportunity as well as beliefs about individual opportunity, that one may attempt to explain the difficulties faced by those who want to change schools. As Sarason (1996) notes, school reform in America has been mostly dictated by the courts, or mandated by the districts many times in fear of litigation. As mentioned before, the abolition of the overarching, formal tracks in high schools is no exception to this rule. It is also true that planned change is resisted by schools. The issue of resistance to reforms faced by anyone who attempts to change schools has interested educational researchers for a long 
time (Binder 2000; Sarason 1996; Tye 2000). The importance of cultural phenomena is now accepted, if not as a complete answer to the puzzle, as at least an important part of it.

When schools resist change, they do so as organizations. Even though individuals in schools may oppose certain educational policies, the implementation of school reform depends on more than individuals, or even individual schools. The next section of this chapter reviews the theoretical background for the study of schooling. The use of an approach focusing on organizational culture of schools is suggested as an alternative to the two traditional sociological models that see schools either as agents of social mobility or of social reproduction.

Schooling and Equality of Opportunity: A Theoretical Overview Considering the importance of the belief in equality of opportunity in American culture, it should not come as a surprise that educational scholars have been concerned with the persistence of racial, ethnic, gender and social class differential achievement in education. Authors differ in the type of differential achievement they focus on. Some have looked mostly at social class (Bernstein 1975; Bourdieu and Passeron 1977; Bowles and Gintis 1976), while others concentrated mainly on issues of race and ethnicity (Achor and Morales 1990; DeVos 1980; Gamoran and Berends 1987; Gibson and Ogbu 1991; Kalmijn and Kraaykamp 1996; McDermott 1987; Ogbu 1974; Pallas et al. 1994; Trueba 1987). Underneath these differences, though, scholars have strived to explain the persistence of differential achievement by class and ethnicity despite the official commitment to democratic and meritocratic principles. 
The debate over curriculum and tracking practices fits into the issue of the role of education in social stratification: Educational practices such as tracking and curriculum differentiation constitute processes of in-school stratification that affect educational attainment, which in turn is related to an individual's adult socio-economic status. For this reason, tracking and curriculum differentiation have been subjects of numerous investigations (Finley 1984; Kelly 1975; Lucas 1999; Mehan et al. 1994; Oakes 1982; Wells and Oakes 1996).

Scholars differ in terms of their theoretical approaches depending on whether they used a conception of society based on the presence or absence of conflict. Most studies of schooling can be traced to either one of two theoretical approaches based on the question of whether or not they perceive conflict as a key issue.

\section{The Functionalist Tradition}

One approach mostly ignores the issue of conflict, considering its existence largely dysfunctional. This approach, based on a functionalist perspective, expects the gap in student achievement (by class or ethnicity) to decrease in time, and conceives schools as instruments of social mobility. Studies guided by this approach usually focus on the effects of aptitude, expectations, race, gender and socioeconomic status on educational attainment, emphasizing individual attributes as the source of inequalities and neglecting the role of educational organizations (McDonough 1998). The tradition affirms the neutrality of public schools, defining schools "as a democratic institution that functions to improve the social position of all students - including, if not especially, those groups that are subordinated to 
the system" (McLaren 1998:190). The conception of schools as agents of social mobility is based on a conception of schools as "great equalizers" (Kliebard 1998; Wilcox 1988).

The functionalist approach in sociology of education has spawned a tradition of quantitative research that attempts to find whether social mobility is increasing in societies that have undergone an educational expansion. Within this approach, status attainment theory affirms that western nations distribute status and material rewards in a meritocratic fashion. Schools play the role of sorting and selecting students according to ability and motivation, offering the most able an education that will entitle them to occupations of higher status and financial rewards. According to this line of thought, there is an expectation of individual attainment with only limited correlation between parents' occupational status and students' status. Overall, research has not supported these optimistic expectations (Saha 1987).

Large-scale surveys looking for an explanation for differential achievement have relied on concepts such as "ability," mostly defined as an Intelligence Quotient (I.Q.) ${ }^{5}$ as well as aspirations and peer pressure. Findings have been consistent, pointing to the importance of student characteristics in school success, as opposed to school characteristics. ${ }^{6}$ The functionalist model has been criticized for measuring ability at an age when students have already been exposed to extensive (and differential) schooling (Hurn 1993), as well as for not working well with black students. Ability test scores do not predict

\footnotetext{
${ }^{5}$ IQ is usually measured at age 14 , at a time when children can already be reflecting the influence of previous schooling including that of ability grouping. See Hurn, Christopher J. 1993. The Limits and Possibilities of Schooling: An Introduction to the Sociology of Education. Boston: Allyn and Bacon.

${ }^{6}$ For a recent example of this type of approach, see Rumberger, Russel W., and Katherine A. Larson. 1998. "Toward Explaining Differences in Educational Achievement among Mexican American Language-Minority Students." Sociology of Education 71:68-93..
} 
Black students' achievement as they do for whites (Gottfredson 1981). The model also does not look at what happens inside the schools, keeping it a "black box" which bears no responsibility in the making or the maintenance of social inequality (Barr and Dreeben 1983; Karabel and Halsey 1977a).

\section{The Conflict Tradition}

In contrast to the functionalist perspective, the conflict tradition sees conflict as an inherent characteristic of social life, portraying schools as instruments of social reproduction. Differential achievement should be expected because schools are a product of a capitalist society based on inequality, and therefore schools are set up in ways that reproduce social inequalities (Bourdieu and Passeron 1977; Bowles and Gintis 1976; Ogbu 1990). Schools and the curriculum reflect the values of the dominant class, rewarding the types of knowledge, behaviors, and cognitive skills typical of the hegemonic group and ignoring the existence of other forms of knowledge. Some reproduction theorists describe schools as rewarding the cultural capital of the hegemonic class with academic success and denying legitimacy to the types of knowledge of other classes (Bourdieu and Passeron 1977; Kalmijn and Kraaykamp 1996). Others focus on the fact that schools emphasize different skills and attitudes for children from different socio-economic backgrounds, teaching children the thought patterns, and attitudes deemed appropriate to their class position in the job market (Bowles and Gintis 1976; McLaren 1998; Willis 1981).

Due to the assumptions about the role of schooling in the reproduction of social inequality, research in the conflict tradition goes beyond the issue of correlation between variables. The focus is on understanding the mechanisms by which the curriculum and the 
organization of schooling interact with the cognitive and behavioral styles of students from different socio-economic and cultural backgrounds, leading to either success or failure. As a result, the tradition has produced an entirely different line of inquiry, from both its Marxist and its non-Marxist branches. Within this paradigm, a tradition of research on tracking as a mechanism of gatekeeping has emerged. Under the cloak of separating students by ability to better serve their needs, researchers have found that schools actually segregate students by class and ethnicity and differentially distribute access to valuable cultural capital (Gamoran 1987; Gollub and Sloan 1978; Kalmijn and Kraaykamp 1996; Kelly 1975; Lucas 1999; Oakes 1981, 1985, 1990).

The Marxist point of view is best known through the work of Bowles and Gintis. Their central idea is the correspondence principle: The social organization of the classroom mirrors the social organization of work. This happens through the explicit curriculum (what is taught in the classrooms), but mainly through the hidden curriculum (the attitudes and personality traits taught in school, as well as general knowledge about life and one's place in society). The correspondence principle asserts that schools prepare students from different backgrounds to assume different occupational roles in society: While elementary schools emphasize rule-following by limiting and channeling the activities of students, high school education allows for more independent activity and less overall supervision. At the higher level, a more open atmosphere emphasizes the internalization of societal norms (such as punctuality, neatness, organization) while giving students much more freedom. Within each of these levels of education, different programs also offer different types of training. Evidence of this comes from the fact that gifted programs in general offer more opportunities for independent and creative work while children placed in regular classes 
and particularly in the lower ability groups are expected to learn through rote repetition, and a strong emphasis on discipline (McDermott 1977; Rist 1970).

Bowles and Gintis' work has been criticized (as many other Marxist works) for its economic determinism (Cole 1988). The assertion that children of parents with upper socio-economic standing often achieve upper socio-economic status, while children of lower socio-economic parents acquire a correspondingly lower socio-economic status cannot explain why some children cross over from the status of their parents. The correspondence principle does not provide an answer to the question of how schools help transmit the status and class positions of the wider society. "Social reproduction, as it turns out, is more than simply a case of economic and class position; it also involves social, cultural and linguistic factors" (McLaren 1998:190).

Another classic work in the social reproduction paradigm is that of Pierre Bourdieu (Bourdieu and Passeron 1977), whose central focus is not economic but what he labels cultural capital. Bourdieu, as well as others (Apple and Weis 1986), emphasizes the explicit curriculum in the effects of schooling. Schools, in Bourdieu's view, teach the superiority of a particular form of culture, in this case classical, European "high" culture. In France, the emphasis is on the study of Latin and Greek, and on a specific way of using language. Students reared in homes and broader social environments that expose them to "high culture" (classical literature, classical music, classical dance, and museums) speak and write in the fashion endorsed by the schools. Thus, children of the upper classes profit from their "cultural capital" in general and even more from their "linguistic capital" or an ability to communicate in the very specific form used in schools. In his research in France, Bourdieu found that most students who lacked this kind of knowledge were not promoted 
to the higher tracks or the elite schools, and were thus eliminated from the competition for the most prestigious occupations. Those few students from the lower classes who made it into the most prestigious tracks performed better in terms of their grades and achievement than their upper class peers. This is due to a process of "unequal selectedness." If only a very small group of people from low socioeconomic backgrounds is "selected" into higher tracks, they are usually more qualified than those from the dominant group (Bourdieu and Passeron 1977).

Two hundred years separate Jefferson's proposals for a selective system of public education (Conant 1963) from Bourdieu's critique of the process of unequal selectedness. Jefferson's proposals were too progressive for their time, and did not happen during Jefferson's life. Radical changes in the cultural construction of what it means to be a democratic modern nation are at the root of the system of thought of Bourdieu's critique of public education. Thus, while the conflict tradition views the educational system as an agent of social reproduction, it is important to notice that the critique itself is only possible within a system of thought that is more attuned to the need for increased opportunity than it was originally.

\section{Limitations of Models of Schools as Agents of Mobility or Reproduction}

Sirotnik (1998) summarized these opposing viewpoints by arguing that social mobility theorists are "those who see schools as benign agents of socialization, as places where Mannian and Jeffersonian notions of preparing all the nation's youth both to serve and reap the benefits of their society are played out" (59). Social reproductionists are "those 
who see schools as malevolent agents of social control, as convenient places where society can reproduce racist and sexist attitudes and socio-economic stratifications."

Both the social mobility and the social reproduction paradigms have been criticized for lacking a place for human agency. Both models in a certain way attribute "intention" to schools as institutions and are thus prevented from seeing schools as places of intense struggle and negotiation between social classes, ethnic, and interest groups. At the theoretical level, both models focus on structure-one through function, the other through class domination - and ignore human agency in establishing or changing the social role of school.

The idea of a "hidden curriculum" has also been criticized. One critic notes that the hidden curriculum thesis claims more than it can substantiate, and suggests that the order, discipline and hierarchy that underlie the hidden curriculum stems from the nature of large organizations, rather than from political reasons (Merelman 1980).

An attempt to reconcile these opposing views, suggested by Saha (1987), states that both social mobility and social reproduction are opposite sides of the same coin, and that mobility is offered to a small number of the non-dominant groups while reproduction for the majority. Thus, social mobility is constantly happening, reinforcing the myth of schools as places of equal opportunity, while for the majority the reality is one of social reproduction. Saha distinguishes between social mobility that is offered to individuals who are members of a disenfranchised group and social mobility that is available to the group or the class as a whole. While certain schools offer the possibility of mobility to specific individuals, schooling does not offer the possibility of mobility to the working class as a whole. Social mobility through education is an option available to individual members of 
non-dominant groups whether they are working class majority or ethnic minority. However, that does not alter the structure of domination. Success stories of specific individuals within the educational system serve to reinforce the belief in equality of opportunity, while social reproduction is the rule for the majority of the students. Enough students from "disadvantaged backgrounds" succeed to reinforce the belief in the neutrality of public schools and the perception that the allocation of educational resources and the distribution of opportunities to learn (Stevenson, Schiller and Schneider 1994) are actually based on objective criteria.

Saha's theory is congruous with ideas first posed by Gaetano Mosca (1939) regarding the circulation of elites. In this case, schooling and the ideas of meritocracy are modern democratic nations' equivalent to Mosca's "political formula;" a "great superstition" or "universal illusion" that everybody believes in, including the ruling class (Mosca 1939). Interestingly, Mosca predicted the essence of what many sociologists of education in the conflict tradition would be writing about fifty years later. Even when access to power is theoretically open to people from other social classes, as is the case in a society that preaches "equality of opportunity" and offers free public education, there is great difficulty in overcoming the special advantages that individuals socialized within the ruling class acquire throughout their lives. Mosca does not see this difficulty as a result of the children of the elite inheriting their parent's intelligence, but rather of the long preparation, ${ }^{7}$ connections, and kinships (social capital), that set an individual in the right road (Mosca 1939). The lower classes are kept out, not by law or hereditary privilege, but

\footnotetext{
${ }^{7}$ The acquisition of the "right" cultural capital, particularly a specific type of linguistic competence, as shown in the work of Bernstein, Basil. 1975. Class, Codes and Control. London: Routledge and Keagan Paul..
} 
by "a silken thread of subtlest fiber-a difference in education, in manners, in social habits" (Mosca 1939:114). ${ }^{8}$

American schools differ from French schools in their degree of enforcement of elite high culture. American public schools are more open, at least in theory, ${ }^{9}$ and pay lip service to the idea of multicultural education ${ }^{10}$ (Freedman Lustig 1997). Knowing how the educational system functions and understanding the implications of the tracking system are just as important as linguistic capital, in terms of the kind of "cultural capital" required by American schools. Lower class and minority students whose parents did not attend college, or dropped out of high school, as well as recent immigrants, find themselves at a disadvantage in terms of both of these kinds of capital (Lucas 1999).

Educational anthropologists view education as part of a process of socializing children to adult life done by every society, whether in the form of an educational institution or not. While noting that accepting a view of schools as transmitters of culture has problematic implications in regards to issues of equality of opportunity, educational

\footnotetext{
${ }^{8}$ This sentence describes what Pierre Bourdieu later would term habitus; recurring patterns of class outlook, inculcated by families and reproduced over time. See Bourdieu, Pierre. 1979. Outline of a Theory of Practice. Cambridge, U.K.: Cambridge University Press.

${ }^{9}$ Although there have been compromise regarding multicultural add-ons, these do not change the basic fact that History is taught from a basically white European point of view, and does not give equal weight to the perspectives of other peoples. Neither has the notion that there is a core of knowledge that should be required of every student been seriously questioned. See Kohl, H. 1994. I Won't Learn from You and Other Thoughts on Creative Maladjustment. The New Press.

${ }^{10}$ Multicultural education is supposed to decrease interethnic conflict and increase minority achievement by diminishing their sense of alienation from the dominant culture found in the school. Freedman Lustig, D. 1997. "Of Kwanzaa, Cinco de Mayo, and Whispering: The Need for Intercultural Education." Anthropology and Education Quarterly 28:574-592, argues that superficial multicultural programs actually exacerbate interethnic conflict.
} 
anthropologists, such as Wilcox (1988), criticize social reproduction theorists who expect schools to socialize children for membership in "some ideal society."

Much of the writing about education and equal opportunity in the U.S. is grounded in some serious misconceptions about the role of schools in society and about the role of teachers in the classroom (Wilcox 1988:271).

Wilcox's critique is directed particularly at some of the more radical critical theorists. Critical theorists belong in the conflict perspective and see schools as agents of social reproduction, but claim that this need not be so. True education has the potential for bringing about social change. From this perspective, schools can be more than agents of social mobility for a few selected students; schools can themselves become the agents of liberation from oppression and 'conscientização' (Freire 1987).

The polarized discussion between mobility and reproduction ignores other key sources of disagreement concerning education, such as debates over the curriculum (Beyer and Apple 1998; Kliebard 1998; Sirotnik 1998). What actually happens inside schools and inside the classrooms is very much related to the types of knowledge deemed relevant and necessary for a person to be deserving of a certificate or diploma. The curriculum is far from a neutral element in education.

\section{Curriculum Tracking}

One of the principal ways in which schools distribute differential opportunities is through the practice of grouping students and assigning these groups to different curricular sequences based on students' alleged abilities, performances, or aspirations. In elementary schools, this is done mostly through ability grouping where students are assigned to different groups inside the same classroom, working at different levels and 
paces (Pallas et al. 1994; Rist 1970; Rosenthal and Jacobsen 1968). Another way schools distribute differential access to more prestigious types of knowledge is by offering programs such as "gifted" programs, which emphasize more critical thinking and independent learning (Sapon-Shevin 1993). At the secondary level, this is done through curriculum differentiation where students are assigned to different classes that lead into different sequences and different opportunities to learn (Oakes 1994; Stevenson, Schiller and Schneider 1994).

In the past, secondary school students were assigned to academic, general or vocational tracks that led to different programs that either allowed access to higher education or limited one to going on to the job market. Courses within those tracks prepared students either for college or for work. With the elimination of track categories and the change to the model of "comprehensive high schools," schools can now claim to offer equal educational opportunity. However, in most of these schools students continue to be assigned to different course levels, such as advanced, Honors, regular, or basic courses and also follow different course sequences. ${ }^{11}$ Higher level, and in some cases, regular courses, are loosely equivalent to academic tracks, while basic and lower (remedial) courses are equivalent to the general tracks ${ }^{12}$ (Hallinan 1994). Although some vocational tracks may be available, acceptance into the more prestigious vocational tracks that offer good job perspectives also requires high levels of academic performance.

\footnotetext{
${ }^{11}$ This is particularly true for math and sciences.

${ }^{12}$ Regular courses can either belong to sequences that are required for college, such as chemistry and physics, or they can belong to sequences that simply fulfill the requirements for graduation, such as environmental science, marine biology, ecology, informal geometry.
} 
The denial of the existence of tracking on the part of the educational system makes it harder for students to resist or reject the track in which they have been placed (Lucas 1999). It is much harder to oppose something that has no recognized existence.

Theoretically, students in comprehensive schools choose their courses. The presence of tracking in a system with no formal tracking can be explained by the concept of hegemony (Bobbio 1982): The hegemonic discourse shifts the responsibility for students' lack of social mobility from the educational system to the individual, at the same time that it suppresses resistance but denying the existence of the oppressive act itself.

Educational researchers who see schools as agents of social mobility consider curriculum differentiation as a neutral organizational practice whose aim is to facilitate instruction and increase learning. According to its proponents, the practice permits teachers to tailor instruction to the ability level of their students (Hallinan 1994). The assumption underlying the theory of curriculum differentiation is that there are differences in ability levels of students and that they can best be instructed at a specific level. Different instructional treatments are therefore not only necessary because of their efficiency, but also morally justified as fair and democratic (Hallinan 1994). A less often mentioned assumption is that bright students are held back by sitting in classrooms with less able peers. Within the social mobility perspective, placement in different curricular sequences is determined mostly by academic criteria, but also includes motivation, generating homogeneous classes with respect to ability and effort (Hallinan 1994). The underlying assumption is that schools are actually able to objectively classify students according to their learning potential. 
Within the social reproduction tradition, tracking is seen as one of the mechanisms through which schools selectively distribute access to more highly valued types of knowledge (Bourdieu and Passeron 1977; Oakes 1986). Schools are therefore not providing equality of educational opportunity, but instead are sorting and selecting students to receive differential educational opportunities. In the more radical view of Bowles and Gintis (1976), tracking does more than simply distribute differential academic opportunities. It fosters a completely different set of personality traits, according to one's future place in society.

For social reproductionists, vocational and general tracks emphasize rule-following and close supervision, while the college track tends toward a more open atmosphere, emphasizing the internalization of norms concerning work behavior. These differences in social relationships among and within schools, in part, reflect both the social backgrounds of the student body and their likely future economic positions. Thus, blacks and other minorities are concentrated in schools whose repressive, arbitrary, generally chaotic internal order, coercive authority structures, and minimal possibilities for advancement ${ }^{13}$ mirror the characteristics of inferior job situations. Similarly, predominantly working class schools tend to emphasize behavioral control and rule-following, while schools in well-todo suburbs employ relatively open systems that favor greater student participation, less direct supervision, more student electives, and, in general, a value system stressing internalized standards of control. These differences do not occur by accident; rather, they

${ }^{13}$ Due to the smaller number of advanced classes offered and the tight gatekeeping that leaves most students out of the more challenging courses. 
reflect the educational objectives and expectations of teachers, parents, the administration, and the community (Cole 1988).

Opponents of tracking affirm that it has a negative effect on the self-esteem of students categorized as being of "low ability" (Kelly 1975). Tracking is said to influence students' future educational plans both by affecting the students' self-perception as well as teachers' expectations (Alexander, Cook and McDill 1978). The argument for detracking affirms that not only is tracking deleterious for most students, ${ }^{14}$ but also that heterogeneous grouping and the cognitive diversity that it creates is an effective teaching technique on its own (Oakes 1994). Opponents of tracking argue that it cannot be treated as a disembodied practice; rather, the inequalities that tracking reinforces are an inherent part of the practice of curriculum tracking itself (Oakes 1994). The structure of tracking is embedded in cultural and political contexts. Historically, tracking has been associated with providing education that will fit students "equally well for their particular life work" (Lazerson 1974; Oakes 1994). Tracking is related to social inequality in terms of preparing supposedly differently-abled students to different careers, and as such, it has never been a "neutral" method for the organization of instruction.

These different views of tracking in relation to equality of opportunity have generated a heated debate. Riordan (1997:184) compares the debate on tracking and detracking to the one regarding policies of integrated and segregated schooling. Furthermore, the idea of detracked schools raises a fear of "bright flight," much in the way that desegregation created "white flight" towards suburbia. Since curriculum tracking

\footnotetext{
${ }^{14}$ Even though some say that the brightest students profit from their advanced courses, there are those who believe this to be incorrect because they lose touch with the "real world" of other students.
} 
results in within-school segregation, with minorities making up the majority of lower track classes and majority students concentrated in the upper track classes, there is an expectation that detracking might lead a large number of high achieving white students to transfer to private schools (Hallinan 1994).

\section{Empirical Research on Tracking}

\section{Instructional Effects: Tracking and Student Achievement}

Although in theory the educational experiences of students in different tracks should lead to improved achievement for all groups, empirical research on the effects of tracking on learning reports positive effects only with high achievers (Alexander, Cook and McDill 1978; Hallinan 1994; Oakes 1983; Rosenbaum 1976). Controlling for ability, students in higher tracks show greater gains through time and their scores become increasingly differentiated (Alexander, Cook and McDill 1978). Ability grouping and tracking have been shown to affect students' learning through quantity, quality and pace of instruction (Gamoran 1987; Gamoran and Berends 1987; Pallas et al. 1994). Students in lower ability groups are taught less material, their curriculum is less challenging, and the pace of instruction is slower, so that the gap between the lower ability groups and the higher ones is constantly increasing. Lower track classes not only provide fewer learning opportunities, but teachers in these classes expect less of students (Oakes 1985; Rist 1970). Students in these classes are exposed to a curriculum that is more restricted in scope and in exposure to resources and opportunities (Gamoran 1987; Gamoran and Berends 1987; Oakes 1995; Stevenson, Schiller and Schneider 1994). Because both contents and methods of instruction vary between tracked classes, students in the high tracks have access to 
knowledge that is more highly valued in society, thus increasing their cultural capital and opportunities for social mobility (Bourdieu and Passeron 1977; Gamoran and Berends 1987; Oakes 1983).

Summarizing knowledge on the effects of grouping and tracking in secondary schools, Gamoran and Berends (Gamoran 1987) find that despite inconsistencies in survey analyses, the balance of ethnographic evidence suggests that they do affect achievement. A survey analysis of a nationally representative sample from the High School and Beyond dataset led Gamoran and Berends (1987) to conclude that the difference in achievement between tracks exceeds the gap between students in school and dropouts. These findings suggest that students' choice of courses in school may be even more important for the development of cognitive skills than whether one is in school or not (Gamoran and Berends 1987).

Placement practices are a problematic area for supporters of tracking. Hallinan(1994), while defending the practice of tracking, admits that actual placement practices produce groups that are far from homogeneous, and suggests a stricter enforcement of "objective" measures of ability and achievement. The evidence indicates that the classification process is rarely well defined or consistently carried out. Indeed, there may be no valid objective measures. Standardized tests of achievement or aptitude are problematic because they are inappropriate for students with language or cultural differences and their use results in many minority students being inappropriately placed in lower tracks (Oakes 1983; Zehler et al. 1994).

Both sides on the debate recognize that, in practice, placement of students reflects more than strictly academic considerations such as grades, standardized test scores, and the 
recommendations of teachers and counselors. Defenders of tracking mention course conflicts, co-curricular and extra-curricular schedules, students' work demands, and teacher and curricular resources as non-academic factors influencing placement (Hallinan 1994). After controlling for achievement, the race-ethnicity and income effect on track placement decreases, but does not disappear (Hallinan 1994), a clear indication that race, ethnicity and income discrimination influence track placement (Oakes 1994). Stevenson, Schiller, and Schneider (1994), for example, found that the level and topics of math that students take in eighth grade are closely related to what they take in high school, regardless of their academic performance.

In most cases, placement criteria are not publicized ${ }^{15}$ and many parents and students are not well informed regarding either placement criteria or the consequences of placement. Again, the practice discriminates against low socioeconomic and minority parents who are not as likely to exert pressure on the school regarding their children's placement (Oakes 1994). Foreign parents are seldom aware of the implications of track placement and are not likely to not know that they can override school placement decisions. A study on parental involvement in children's education found that it tends to decrease in schools with higher concentration of minority students (Carey, Lewis and Farris 1998). Another study focusing on Limited English Proficient (LEP) students reports that according to teachers interviewed, their parents are substantially less involved in school functions, as classrooms or school volunteers than parents of non-LEP students (Fleischman and Hopstock 1993). The study also found that, similar to majority parents, LEP parental involvement is highest

\footnotetext{
${ }^{15}$ This is particularly relevant for foreign-born parents who do not know English and even when they do, they may not be familiar with the U.S. tracking system. When information is translated, it is usually in an abbreviated form.
} 
in elementary school and gradually decreases in secondary school. In addition, given the current debate over anti-immigrant legislation, it is reasonable to assume that parents who are not legally in the country are resistant to contact the school system, and all the more so reluctant to express disagreement with school practices.

The lack of uniformity and objectivity in track placements is clear in the finding that ability-group placements are not reliable. Two related findings support this assertion. The first one is that children with comparable levels of academic performance can be found in tracks that rank anywhere from the top of the class to near the bottom (Hallinan 1994; Oakes 1994; Pallas et al. 1994). The second finding is that the distribution of achievement in tracks overlaps the distribution of the adjacent tracks (Hallinan 1994; Oakes 1994).

In what seems to be the most thorough analysis of tracking practices, Lucas (1999) found that despite the dismantling of formal tracks, tracking practices continue to exist in comprehensive high schools. His statistical analysis indicates that the majority of students take courses of similar levels. Therefore, the expectation that the elimination of formal tracks would enable students to take course of discrepant levels according to their ability and motivation in each individual subject did not materialize. Social class still plays a role in determining student course placements, even after controlling for achievement, aspirations, race, and gender. Therefore, despite the change in school practice, "the system remains unmeritocratic in important ways" (Lucas 1999:59). In addition, Lucas also found that in-school stratification still matters in terms of educational attainment; it affects college entry and cognitive achievement.

Lucas attributes the maintenance of the social class effect to the parents' knowledge of how the system functions and the importance of taking "the right classes" for their 
children's future opportunities. The dataset used in his research, however, does not contain information for verification of this suggestion. Lucas thus leaves this suggestion concerning the role of access to information regarding course selection as a hypothesis open for testing.

\section{$\underline{\text { Socialization Effects }}$}

Another important finding of Lucas' work is that school environment also has an impact on how the elimination of formal tracks has been implemented. Schools with a higher level of socio-economic diversity present higher levels of association between students placement in different subjects. Again, it appears that middle-class parents use both their political power as a group, and their knowledge of the system as individuals, to maintain a more tracked system in schools where they fear loss of privilege if their children share classes with the children of less privileged groups (Lucas 1999).

Lucas found no systematic effects of track location on interest in school, a socialization outcome. In addition, the fact that most students were found in discrepant level courses made it difficult for schools to practice differential socialization, since students are exposed to more than one level of class during their academic lives.

\section{Institutional Effects of Tracking, Detracking and Untracking}

Another line of inquiry on the effects of tracking looks at how the practice affects or is affected by organizational features of schools. One example is how tracking practices create a hierarchy of teaching. Finley (1984) found that, at the institutional level, tracking

serves the schools' needs to reward personnel. Teachers compete for high achieving students in higher track class assignments (Finley 1984). Low track teaching assignments are less preferred by teachers and are usually left for the newcomers in the schools, who 
often are the least experienced teachers or are not certified to teach assigned subjects (Oakes 1983, 1990).

The dismantling of the tracking system in a single school system in one sweeping effort is usually referred to as detracking (Oakes 1983) or heterogeneous grouping (Cooper 1996). In a qualitative study of a school undergoing reform that included detracking, Datnow (1997) found that detracking was perceived by teachers as changing the distribution of power and privileges of teachers as well as of students. In a quantitative study of a California high school, Cooper (1996) found that the institutional culture - that is, the norms and ethos that drive the policy and practice within an institution such as the school - can be either a barrier or a facilitator of change. The process requires effort on the part of the teachers to learn and implement new methods of teaching appropriate for heterogeneous classes. When the principal and administrative staff did not devote enough time and resources to help teachers develop the techniques and strategies needed, the process of detracking was undermined (Cooper 1996).

In addition to the institutional culture, detracking efforts also reach a point where they are opposed by some groups of parents. In a national, three-year, multiple site qualitative case study of schools undergoing detracking, Wells and Oakes (1996) found that parents of high achieving or identified "gifted" students demanded greater differentiation between what their children learned and what was offered to other students. Detracking efforts are undermined by these issues if they are not taken into account when planning for changes (Datnow 1997).

Mehan et al.(1994) report on an alternative solution to the problems of tracking that avoids some of the pitfalls of detracking. Untracking is the process of assisting a small 
number of students to move from general and vocational tracks to the college preparatory track. The process included providing increased support by explicitly teaching low-income students the implicit culture of the classroom and the hidden curriculum of the school. Mehan et al. (1994) suggest the use of untracking as an initial step in a detracking effort.

After a rigorous analysis of tracking practices after formal tracks were eliminated in the majority of American schools, Lucas (1999) concluded that de facto tracking continues, since students continue to occupy similar course locations in different subjects. Despite the fact that mobility is now theoretically possible, Lucas found in actuality there is little mobility and most of it is downward. ${ }^{16}$ The removal of overarching tracks, the signposts of the curriculum, actually increased the advantages of the middle class students who possess information about the system, hurting those who already entered the system in disadvantage. Surprisingly, however, Lucas disagrees with those who favor de-tracking, siding with Hallinan, who suggests that it is preferable to correct the misapplications of curriculum differentiation than to eliminate it. Because of the unintended effects of the elimination of formal tracks, Lucas fears that de-tracking might lead to re-tracking inside the classrooms. If teachers are not convinced that de-tracking is logistically manageable and pedagogically sound, they will resist it (Lucas 1999). Parents can also undermine such efforts by individually moving their children to private schools and other forms of political action, such as voting for politicians who favor voucher systems. For Lucas, "it is possible

${ }^{16}$ Even though there is enough upward mobility to reject previous suggestions that schools was similar to tournament mobility, where winning allows one to move to the next round and losing disqualifies the person forever. For a detailed discussion of the tournament mobility metaphor, see Lucas, Samuel Roundfield. 1999. Tracking Inequality: Stratification and Mobility in American High Schools. New York, N.Y.: Teachers College Press. 
to have a differentiated curriculum and not have tracking" if "access to the full variety of classes is based purely on achievement, and given sufficient achievement, interest" (Lucas 1999:147).

This theoretical detour into different ways of understanding schools and the analysis of the ways in which processes of in-school stratification relate to issues of social stratification leads us back to the issue of how schools react to mandated change. Bearing in mind the complex relation between schools and the wider society, we can now turn to the issue of how the schools deal with policies that attempt to change the way they go about the business of educating the nation's children.

Placement happens in the school, but mostly outside of the classroom. Placement decisions are made by individuals based on policies and practices determined at the district and school levels. This study attempts to overcome some of the limitations of the functionalist and conflict approaches - particularly the issues of lack of human agency and the inability to account for change — by looking at schools' organizational cultures and tracking patterns.

\section{Organizational Culture: A Theoretical Framework}

Organizational culture approaches have been used more often in the study of other types of institutions such as corporations. Educational researchers have shown less interest in using the approach; a bias that might be attributed to the frequent use of studies of organizational culture by researchers whose motivation was "managing" culture with an eye to increasing productivity and profit (Martin 1985; Smith 1993). In contrast, historians of education as well as those in the field of educational administration have long tinkered 
with concepts derived from organizational analysis in general and organizational culture in particular to look at educational institutions. The organizational culture perspective has been an important one for those attempting to understand schools' resistance to change (Corbett, Firestone and Rossman 1987; Sarason 1996), particularly to changes that are supposed to increase equality of opportunity (Binder 2000; Cuban 1987, 1990, 1995; Finley 1984; Oakes 1985; Tye 2000; Wells and Oakes 1996).

Researchers of organizational culture work from different definitions of culture; while some argue that organizations can be understood as cultures, others argue that culture is something organizations have (Smircich 1983). According to Nord (1985), these conceptual differences are the source of the disagreement over whether or not culture can be managed. Martin explains the differences between authors' definitions of culture as:

Some emphasize deeply rooted, even unconscious sources of culture, whole others emphasize relatively superficial cultural manifestations, such as espoused values, reward structures, and dress codes (Martin 1985:96).

In synthesizing studies of organizational change-including studies of failed attempts at culture change - Nord (1985) found that all authors had adopted an approach that centered on culture as a managerial tool. The approach led to a focus on the constraints organizations may face when leaders attempt to change culture. A partial list of these constraints included "life cycles, conflicting interests, a lack of willingness on the part of some actors, different saliences attached to issues, different meanings, poor communication, lack of subordinate development, bad timing, a leader getting trapped by his or her own rhetoric, and complexity" (Nord 1985:193). Managerial views of culture as a tool often are based on a metaphorical view of culture as "glue" that keeps the part of the 
organization together. A main limitation of this approach is that it leads to a static view of culture that fails to dignify the importance of countercultures, conflicting values, perceptions and interests that are characteristic of more complex organizations, producing "less dynamic models than may be warranted" (Nord 1985:195). Using Martin's (1992) terminology, Nord's critique of the "glue" metaphor is a critique of the tendency to overemphasize the integrative elements of the organization's culture in detriment of the differentiated and fragmented views. Nord suggests the use of a magnetism metaphor as an alternative:

Adequate conceptualization of the bonding process that holds complex organizations together must be able to encompass repulsion as well as attraction; it must allow for changes in the parts; and it must treat the patterning among the parts (e.g., coalitions). If there is such a force, magnetism seems to be a better analogy than glue. The magnetic metaphor encourages examination of the dynamics through which the various parts arrange themselves in the field, of how various parts attract some parts and repel others, of how the magnetic field itself (via induction) may change the structure of the individual components, of the operation of some elements that are nonmagnetic, and of others that are antimagnetic and that may lead to the destruction of the field. (...) If culture is seen as a powerful integrating force in complex organizations, viewing it as glue is apt to lead to understatement of the autonomy of the parts and thus to understatement of the causal roles they play (Nord 1985:195).

\section{Defining School Culture}

An initial difficulty with the concept of organizational culture derives from the difficulties inherent in the definition of culture (Cusick 1987; Erickson 1987). Sarason (1996), one of the first to use the concept of culture in relation to difficulties in changing schools, has been criticized by scholars who are dissatisfied with his treatment of culture as an undifferentiated entity; as "the overall character or ethos of an educational setting" 
(Erickson 1987:11). For Erickson, such a definition of culture is too vague and fails to provide guidance for the researcher.

In trying to overcome this initial difficulty, Erickson compares three different conceptions of culture. The first conception, following Goodenough (as quoted in Erickson 1987:13) sees culture as consisting of many chunks of knowledge stored as a large pool of information within the social group, with no single member possessing all of the knowledge possessed by the group as a whole. The second conception follows Geertz (1973) and sees culture as "a more limited set of large chunks of knowledge-conceptual structures," or core symbols, that frame what is taken as "reality" by members of a group (Erickson 1987:13). In both of these conceptions, culture is transmitted across generations through socialization. The third conception of culture, coming from the work of conflict theorists, such as Giroux (1992) sees culture as intertwined with social structure, with patterns of differential sharing of cultural knowledge in the social unit. This conception emphasizes social conflict as a fundamental process by which patterns of cultural knowledge vary within a population (Erickson 1987). In all three conceptions, culture is ideational, seen as "knowledge and as a framing for meaning, rather than as social behavior or its artifacts" (Erickson 1987:22). Erickson thus agrees with Schein's (1992) definition of the essence of culture. Erickson prefers the third conception to the first two for its comprehensiveness and ability to account for change as well as stability.

\section{Studying School Organizational Culture}

Education is part of a process of socializing children to adult life done by every society, whether in the form of an educational institution or not (Spindler 1955; 1988; 
Wilcox 1988). Schools are institutions with the purpose of socializing children to adult life in modern societies. Schools match some of the general definitions of organizations found in classical organizational theory, but clearly not all. According to Schafritz and Ott (1987), organizations are "social units with some particular goals and purposes," and schools fit the definition.

Classical organizational theory states that organizations exist to accomplish production-related and economic goals, and that there is one way to organize for production, which can be found through systematic, scientific inquiry. Furthermore, people in organizations act in accordance with rational economic principles, and production is maximized through specialization and division of labor (Shafritz and Ott 1987:1). In stark contrast to business and military organizations that have clearly defined products and outcomes, educational organizations

lack consensus on describing the desired product, cannot directly observe the production process, and have trouble explaining how they create products. Such organization cannot specify what their key staff must do or what the desired outcomes should be... (Cuban 1995:6).

It is crucial to note these differences between educational institutions and other types of organizations. Schools are organizations where the definition of what they ought to produce-what we expect from a high school graduate- -is constantly contested territory (Cuban 1995). As a result, schools are coping organizations: "Ruled by procedures and beliefs that conform to the expectations of those constituencies that supply political and financial support" (Cuban 1995:6). Features of the organization of schools include governance - how authority is used to govern; formal structures - the formal building blocks that give structure to the organization; and the organizational 
culture itself-informal features that influence how people behave within them (Cuban 1995).

Despite these differences, many of the basic definitions used by those who theorize on organizational culture can be used in reference to schools. Schein defines the culture of a group as

A pattern of shared basic assumptions that the group learned as it solved its problems of external adaptation and internal integration, that has worked well enough to be considered valid and, therefore, to be taught to new members as the correct way to perceive, think, and feel in relation to those problems (Schein 1992:12).

The power of these shared assumptions resides in the fact that they operate outside of our awareness, to the extent that people find it awkward and inappropriate to discuss them (Schein 1992). Schein distinguishes between three levels of culture: 1) the more superficial level of visible organizational structures and processes, of artifacts-material culture; 2) the level of espoused values or justifications-the one that sets the strategies, goals and philosophies; and 3) the deepest one, the level of basic assumptions. An important distinction is made between espoused values that become part of the behavior, i.e.: they inform solutions that are turned into practice and that work. In contrast, espoused values that are not based on prior practice may predict what people will say in different situations, but not what they will do (Argyris and Schon 1978). Key to the study of organizational culture, thus, is whether espoused values are congruent with basic assumptions, or alternately, rationalizations, or simply aspirations for the future (Schein 1992).

The distinction between espoused values and basic assumptions is somewhat parallel - though not completely overlapping - to the distinction between emic and etic 
perspectives: Values are equivalent to emic - the insider's interpretations and approaches; and basic assumptions-which participants are unaware of - are equivalent to the etic perspective, the outsider's view (LeCompte and Schensul 1999). It is possible for an organization to hold values that are mutually contradictory. This is an important point in regards to studying public schools. As public education is required to be responsive to its different constituencies, it espouses contradictory values such as "encouraging critical thinking" and "providing for order in the schools," or "meritocracy" and "equality of opportunity" (Sirotnik 1998).

Culture manifests itself at the level of behavior and espoused values. Schein, however, would rather have the term culture reserved for the deeper level of basic assumptions, or "theories-in-use" (Argyris and Schon 1974): Implicit assumptions that guide how people perceive and feel about things, thus guiding behavior. This, for Schein, is the essence of culture. This "essence" matches Geertz's (1973) definition of culture as web, the fabric of meaning that people use to make sense of their lives. At this level, alternative ways of doing things become invisible, beyond the "thinkable."

Schein's theory also emphasizes the role of organizational leaders, an issue often neglected in sociology of education. Founder-leaders create the climate that precedes the existence of a group culture, while in later stages the leader's role changes to one of deciding what is important. What leaders pay attention to, measure, and control on a regular basis is of fundamental importance in an organization. An important point in Schein's theory is that leaders who are aware of this process are systematic and consistent in what they pay attention to, in the criteria they use to allocate scarce resources, in how 
they react to critical incidents, and in how they recruit, select, promote, and allocate rewards and status or punishments (Schein 1992).

Any organizational culture of a certain size will also develop functional subcultures (Schein 1992), and conflict between different subcultures within an organization is to be expected. This is an important point in the case of analysis of schools and their different constituent groups, ranging from those who are totally immersed in the school—-teachers, students, administrators-to those who are related to the activities in the school but do not "live" the organization in the same sense-parents, school board members, district administrators. Nevertheless, Schein notes that most organizations have common assumptions that come into play when a crisis occurs, or when a common enemy is found.

DiBella (1994) and Martin (1992) mention three main theoretical approaches to the study of organizations:

- An integrative perspective based on a functionalist conception of society that conceives culture as unified.

- A differentiated perspective that draws upon conflict theories, and looks at organizational cultures as multicultures generated by groups with conflicting interests.

- A fragmentation perspective that draws from phenomenological conceptions of society, where reality is socially constructed and daily recreated and re-constructed.

Martin suggests that the three perspectives cannot be integrated, but should be used as complementary lenses to analyze reality. 
The approach taken in this study is based on the assumption that organizational culture must be understood with reference to aspects of the wider culture (Moore 1985). Thus, organizations generate meaning by drawing and learning from the fabric of the host society. As mentioned before, public schools are a particular type of social institution, upon which the wider culture places contradictory expectations (Wilcox 1988). Moreover, public schools are intimately connected to the American ethos, to its selfimage as the land of opportunity. Thus, the relationship between the organization's culture and the wider culture is all the more relevant in regards to schools. Using Schein's (1992) concept of "espoused values," the contradictory expectations described by Wilcox are reflected in the contradictory espoused values found in public education. The wider culture sets the parameters of that which is possible, at the same time that it sets what is out of bounds, that which is unthinkable within a particular cultural system. It sets the "paradigm" within which social action happens (Kuhn 1962). Within this paradigm, a variety of things can happen, depending on leadership and local conditions. While the unit of analysis in studies of organizational culture is the organization, group culture is a result of a social learning process where individuals as actors are involved in the process.

The Organizational Culture of Schools and School Change

\section{Theoretical Framework}

Tye (2000) states that despite the apparent disagreements Americans seem to have about schooling, there exists a deep structure of schooling that prevents most changes from happening: 
This deep structure of schooling, I now believe, is composed of the values and assumptions about education that are widely shared throughout our society. Despite our traditions of local control, Americans do not vary greatly in their views of desirable and appropriate educational experiences for children and young people. (...) These values and assumptions are also shaped by conventional wisdom, by tradition, by vested interests - and by a certain amount of institutional inertia. At this point in time, what we Americans expect of our schools includes the physical similarity of classroom; the overall control orientation of policy, program, and pedagogy; the general similarity of curriculum and of schedules; patterns of resource allocation; faith in test scores as measures of success; and the practices of age-grading and the labeling and sorting of students (Tye 2000:3).

This deep structure, Tye notes, is not a new discovery. In 1971, Sarason (1996) discussed "The Culture of the School and the Problem of Change." Sarason defined the culture of schools as the "regularities" of schooling; behaviors, beliefs, and assumptions so deeply ingrained in those within the schools (or any other organization) that they prevent awareness of alternative ways. This difficulty faced by those within a culture to see their own culture for what it is leads Cuban (1995:6) to call features of the organizational culture of schools "the hidden variable." These informal features influence how people behave within the organization - including governance, formal structures, and cultural processes - and are obstacles to change in schools.

Tye's definition of deep structure posits that stability is inevitable in a schooling system unless the surrounding culture changes, leading to changes in schooling (Tye 2000:176). From this perspective the changes in the wider culture caused by the civil rights movement discussed in the previous section should have led to a real increase in opportunity. The majority of the empirical research on tracking does not support this claim (Lucas 1999; Oakes 1981, 1990). A hypothesis that could explain this lack of change in the 
schools despite the change in the wider culture can be derived from Schein's distinction between espoused values and basic assumptions. In this case, the wider society has espoused the agenda of the civil rights movements, but basic assumptions about ability have not changed.

Binder (2000) suggests that curricular challenges have a better chance to succeed when they tap into two logics of the institution: 1) the school's cultural understandingsbasic assumptions - about education, and 2) the organizational practices of the institution. In other words, the greater the discrepancy between the suggested change and the existing conceptions of the way school life is, or should be, the greater the resistance to that proposed change will be (Corbett, Firestone and Rossman 1987). Corbett et al. distinguish between two types of norms and beliefs held by teachers. Sacred norms are those at the core of teachers' professional purpose, those that teachers perceive as their 'raison d'être.' These sacred norms determine expectations for behavior that the staff needs to follow. Schools have both sacred and profane norms. Profane norms establish the way things are done in a given school, but are not fundamental for the teachers' self-identity, do not define their core. When proposed changes constitute attacks on sacred norms, they face resistance on a different level than that faced by changes that constitute attacks on profane norms. According to Corbet et al., although high schools appear to have substantially similar cultures, different schools present subtle but important differences in norms, beliefs, and values (Corbett, Firestone and Rossman 1987).

An important aspect of the organizational culture of schools is the fact that such cultures have adapted to living with, or ignoring, paradoxical or contradictory situations. As in the case of beliefs in equality of opportunity that live side by side with tracking 
practices that sort and select students, or curricular goals that emphasize critical thinking as well as order and control, inside schools the existence of several different curricula is also ignored. Thus, the implemented (taught) curriculum is different from the official curriculum, as noted by Sirotnik (1998). In addition, as Cuban notes, the learned curriculum is different from that which is taught. The learned curriculum includes what Dewey called collateral learnings-ideas children pick from classmates, teachers' or other adults they meet in school - as well as the hidden curriculum — what children learn from experiencing school practices (Cuban 1995). Finally, there is also the tested curriculum, a limited part of what was intended by policymakers, taught by teachers and learned by students, done usually with the purpose of sorting high achieving students from their lowerachieving peers (Cuban 1995).

Despite the existence of several theoretical works dealing with organizational culture (Hamada 1994; Schein 1992; Shafritz and Ott 1987), the writings that deal with organizational culture aspects of educational organizations are mostly empirical. Several authors such as Sarason (1996), Cuban (1990, 1995, 1998a), Tye (2000) and others (Corbett, Firestone and Rossman 1987), have noted the connection between phenomena at the level of schools' organizational cultures and difficulties in implementing school reform. A framework for the study of organizational culture in educational institutions, suggested by Tierney (1988) outlines essential concepts, or key dimensions of culture, which generate questions to guide the researcher of organizational culture (Table 1). These questions were used as guidance in the analysis of the data in this study. 


\section{Table 1 A Framework of Organizational Culture}

\begin{tabular}{|c|c|}
\hline Environment & $\begin{array}{l}\text { How does the organization define its environment? } \\
\text { What is the attitude toward the environment? } \\
\text { (Hostility? Friendship?) }\end{array}$ \\
\hline \multirow{4}{*}{ Mission } & How is it defined? \\
\hline & How is it articulated? \\
\hline & Is it used as a basis for decisions? \\
\hline & How much agreement is there? \\
\hline \multirow{3}{*}{ Socialization } & How do new members become socialized? \\
\hline & How is it articulated? \\
\hline & $\begin{array}{l}\text { What do we need to know to survive/excel in this } \\
\text { organization? }\end{array}$ \\
\hline \multirow{3}{*}{ Information } & What constitutes information? \\
\hline & Who has it? \\
\hline & How is it disseminated? \\
\hline \multirow{4}{*}{ Strategy } & How are decisions arrived at? \\
\hline & Which strategy is used? \\
\hline & Who makes decisions? \\
\hline & What is the penalty for bad decisions? \\
\hline \multirow{3}{*}{ Leadership } & What does the organization expect from its leaders? \\
\hline & Who are the leaders? \\
\hline & Are there formal and informal leaders? \\
\hline
\end{tabular}

From Tierney, W.G. (1988) Organizational Culture in Higher Education: Defining the Essentials. Journal of Higher Education 59 (1):2-21.

\section{Empirical Studies of Organizational Cultures of Schools}

In general, research shows that the American public continues to express expectations that schools should impart basic literacy, respect for authority, and "proper moral behavior" to students (Cuban 1998b; Tye 2000). In addition to attending to the academic, vocational, civic and personal development of students, Americans also expect their schools to take care of children and young people during the workday. This custodial function, however, is seldom acknowledged or discussed (Tye 2000).

McQuillan's (1998) cultural analysis of an urban American high school serving mostly blue-collar and minority students found that maintaining control and order was a much higher priority than academic concerns. The ability of the school to deal with many 
of the problems that plagued the school (high drop-out, failure, and suspension rates, disproportionate numbers of low-income, limited-English proficient and special education students) was undermined by the basic assumptions that guided the school's practice. The predominance of behavioristic assumptions in the school's organizational culture led the school staff to ignore the fact that rewards and punishment are socially constructed, and therefore not necessarily universal. The school persisted in distributing rewards and punishments that were meaningless and ineffective for many of its students. Teachers allowed students to engage in active non-learning in exchange for peace and order. Another basic assumption in the school was the belief in rugged individualism, denying the difficulties faced by the students in and out of the school, and leading to a belief in the existence of equal educational opportunity when actually very little education was being imparted (McQuillan 1998). These basic assumptions constantly undermined attempts to change the school, regardless of whether they came from the outside, such as the experiment in collaboration with a University, or whether they were internally generated, as in the case of changes suggested by staff committees.

"Organizations generate their collections of meaning by drawing on and adopting (learning) the mores, archetypes, metamyths, and values which form the fabric of the host society" (Moore 1985:277). McQuillan's ethnography of Eastville High is an empirical example of this principle concerning the relationship between organizations and the wider society at work. Despite mounting evidence to the contrary, inside the school educational opportunity continued to be taken for granted, even when in reality for the majority of the students there was no education being imparted (McQuillan 1998). Beliefs common in the wider society regarding individualism and personal choice are maintained inside schools, 
which continue to portray themselves as neutral places (McLaren 1998) where students make choices as individuals, even in the face of evidence to the contrary.

Enomoto (1994) used Martin's model of three discrete lenses in the analysis of a school's organizational culture and how it dealt with changes in its truancy policy. The integrative lens looked at how and why members were unified in their definitions of truancy, the differentiation lens of subcultures highlighted the contradictions between different subcultures in the school-students, teachers, administrators- and the fragmentation lens looked at issues that individual members shared and disputed. While everyone agreed that truancy was a problem in the school, enforcement of rules was far from uniform, as Enomoto discovered. While part of the staff saw the school as a "fair and just" place, i.e.: rule directed, consistent in policy and practice and maintaining law and order-others had an image of the school as a "caring" place, i.e.: individual-directed, flexible and accommodating. Differences in perceptions of how rules should be enforced originated in different subcultures as well as in different personalities. Enomoto concluded that the inconsistency in the actions of the attendance office undermined the implementation of the new policy, and neither care nor punishment was actually delivered.

As in the case of the disciplinary policy described above, organizational features can be obstacles in the implementation of curricular changes as well. The elimination of $d e$ facto tracking in schools has been hindered by organizational features of schools. Siskin's (1994) work points to the strong role of academic departments and their centrality to teacher identification as one obstacle to reforms attempting to eliminate tracking in schools. A differentiated curriculum that would not be hierarchically organized would radically alter 
the distribution of power among departments and teachers, and such change faces resistance by groups of teachers.

The division of subjects into separate departments is an organizational feature related to difficulties in implementing changes in pedagogy: Team teaching and interdisciplinary approaches are pedagogical innovations that have proven successful but difficult to implement, in part due to organizational features (Cuban 1987, 1990, 1995). Cuban finds that despite all the research attesting to the benefits of a student-centered pedagogy, teacher-centered instruction remains the dominant mode of instruction due to structural conditions, organizational incentives and the modes of teacher socialization. Structural conditions include the physical organization of schools and the classroom, and tradition. The organizational incentives include the manner in which teachers are hired and promoted. In public schools, teachers are assigned to a probationary position. If they succeed in maintaining order, documenting that they have covered the required content, and behaved professionally as defined by the prevailing norms in the school-especially on the few occasions when the principal or assistant principal visits, they are granted tenure. Finally, most teachers teach in the same way they were taught (Cuban 1987).

Even when teachers buy into progressive pedagogical changes, organizational features can hinder schools' attempts to implement these changes. Leslie Hurst's (1991) ethnography of a junior high school in Berkeley, California, provides an insight that can probably be applied to other schools across the country. Hurst found a culture in the school that emphasized a separation of spheres, which she called the "political-economy of the body." According to this political economy, there is a separation and division of function between the school, the teachers, and the family. The student's physical body, its 
whereabouts and safety, are the domain of the school. The school administration is responsible for making sure the students stay inside the school, perform activities on time and in the appropriate area, and that outsiders do not come in the school. The student's mind, the intellectual part of it, is the responsibility of the teacher in the classroom. The student's soul — the heart, the will, personal values, and attitudes - is the domain of the family or someone else outside the school. The student is expected to come to school with values, attitudes, and a sense of decorum that is supposed to be provided at home by the family. Within this context, Hurst (1991) found the teacher's authority so reduced that teachers had to spend most of their time negotiating with students from a very weak position, and little learning occurred as a result. In Hurst's case, the school staff was philosophically committed to a democratic, student-centered pedagogy. What undermined the ability of that pedagogy to function was an organizational culture influenced by values of the wider society (such as parental rights, a student's right to privacy), which emphasized the separation of spheres between mind, body and soul.

Implications of the Literature Review for this Study

The theoretical approach used in this study follows the interdisciplinary tone established in the preceding literature review. This review indicates the high level of complexity of issues involving change in educational organizations and their cultures. The elimination of formal tracks in high schools did not lead to the expected results, as shown by the empirical work to date. Much of this work, however, has used quantitative approaches, and has provided suggestions as to why comprehensive schools have failed to eliminate tracking practices. This study addresses this question through its use of a 
qualitative methodology and the use of a conceptual framework involving the role of organizational culture.

From a theoretical point of view, this study is innovative in its attempt to integrate concepts from sociology of education dealing with issues of social mobility and reproduction with theories of organizational culture. Recognizing the limitations of conflict and functionalist approaches, the study follows Saha (1987) in viewing social mobility and social reproduction as complementary processes. From the field of organizational culture, the study uses Schein's (1992) distinction between espoused values and basic assumptions, as well as two of the lenses suggested by Martin (1992), the integrative and the differentiated. In addition, it uses Tierney's (1988) key concepts in his proposed framework for analyzing educational institutions. Finally, a major assumption on which this study is based is that education needs to be understood within the historical socio-political context of the wider society in which it is inserted (Wilcox 1988). 


\title{
Chapter III
}

\section{METHODOLOGY AND SETTING}

\author{
Methodology
}

This research developed as an extension of a larger project (Stepick 1995) focusing on issues pertaining to immigrant students' experiences at home and at school and their effects on students' academic orientation. The larger project involved a number of research assistants assigned to investigate different groups of immigrant students in each of the schools. My role in the larger project was to investigate the implementation of educational policies that affected the placement of immigrant Limited English Proficient (LEP) students, and the data collected in that framework constituted the basis for a Master's thesis. While conducting that research, I became interested in tracking as it affects the entire population of high school students, and extended data collection well beyond the scope of the initial project. Thus, a project initiated from an interest in placement policies designed for immigrant students grew to encompass the relation between placement of all students and the organizational cultures of schools. In time, the project developed into an interest in how organizational culture relates to the current mission of comprehensive high schools, an issue inextricably linked to the wider society's expectations from education and the role that education fulfills in modern society.

The methodology used in the study involved mainly direct observation, and when possible, participant-observation. Unstructured and semi-structured interviewing techniques were used to interview counselors, the English and math department heads in each of the schools, school principals and assistant principals. Other qualitative methods 
included content analysis of documents, such as School Board Rules concerning the evaluation and placement of students, particularly in math and science courses. Written policies and statements regarding the expressed objectives of state and county programs created for students were also examined. School curriculum bulletins and other relevant school publications were used as additional data sources.

\section{Why Choose a Qualitative Methodology?}

Educators, particularly, are concerned because the tried-and-true methodologies and research designs used most widely in educational research have failed to answer pressing questions. These experimental and correlational approaches that isolate variables from context and overlook the all-important dimensions of meaning in human behavior have been overworked (Spindler 1988:3).

This study used mostly qualitative research methodologies to address the question of how the practices engendered by the organizational cultures of schools interact with policies that eliminate formal tracking. The choice of a qualitative methodology was dictated by the focus of the project. Particularly influential in the decision was an interest in studying the differences between espoused values and basic assumptions, along with an awareness of the co-existence of contradictory values and assumptions in the organizational culture of schools (Kliebard 1995; Wilcox 1988). The decision to look at the organizational culture of schools using both the integrative and the differentiated perspectives also suggested that qualitative approaches would best fit the purpose and questions of this project.

Although it is possible to use quantitative methodologies to study culture, ethnographic studies have much to offer in terms of validity. While surveys and 
quantitative analysis offer reliability and are an indispensable tool for obtaining descriptive information, qualitative methods offer the advantage of the in-depth understanding of the essence of the issue at hand (Spindler 1988). Yet, while there exists an extensive body of literature with quantitative analysis of tracking (Gamoran and Berends 1987; Lucas 1999; Oakes $1982,1987,1990)$, qualitative analysis is nearly absent. This absence combined with the appropriateness of qualitative approaches to the project's research questions to determine the choice of an ethnographic (direct observation) approach. The appropriateness of any method, however, does not affect in any way the limitations of that method. Each research methodology has its inherent limitations, with ethnography being no exception to the rule. The following section addresses some of the limitations inherent in the use of ethnographic methods.

\section{The Researcher as Research Tool}

In each school, I volunteered to help in the schools as needed, and a few opportunities for participant-observation indeed occurred. Most of the data, however, was collected as an observer. As Spindler notes:

This does not always mean participant observation. While participant observation is frequently possible in traditional anthropological fieldwork, it is particularly difficult for most adults in such situations as classrooms, playgroups, and other characteristic settings in the ethnography of schooling (Spindler and Spindler 1988:65).

As a research method, direct observation involves the same issues associated with participant observation, issues of subjectivity resulting from fact that the researcher is also the research tool. Peshkin notes that 
a close association exists among the four Rs of research: (1) researcher (who, in terms of personal qualities and background, is doing the study; (2) research (what is studied); (3) researching (how the study is conducted); (4) results (what is found in the data). This association may be merely an interesting speculation to the many scholars who consider their work to be essentially objective. However, for those of us who are doing ethnographic research - those of us who are committed to objectivity but still acknowledge the subjective nature of our work - understanding the association is essential (Peshkin 1988:50).

The first two chapters of this dissertation addressed the issues concerning the second $\mathrm{R}$, or the research itself-its purpose, its questions, its theoretical assumptions - and the next two chapters address the fourth $\mathrm{R}$, the results. This chapter offers information on the first and third Rs, that is, the researcher and the research process. It also begins to address the fourth $\mathrm{R}$, results, by providing some information about the process of data analysis.

The "researcher as research tool" in this particular case is a foreigner with an idiosyncratic accent. While this might have been a disadvantage, in my case this constituted an advantage in several ways. The first advantage of foreign status was that I was a real stranger to the system. While an American educational researcher using ethnographic methods would have to make an effort to make the familiar become "strange," comprehensive high schools were "exotic" to me. The second advantage came from the fact that most people had some difficulty in "placing" my accent. That provided subject for conversation, particularly during the initial weeks in each of the sites, when some people tended to be more suspicious. Being Brazilian as well as Jewish proved an added bonus. My "ethnic capital" was instrumental in the field, at times providing subject for conversation about "amenities," and at other times enabling people to feel more at ease 
because they were talking to a fellow Latin, or to a fellow Jew. The fact that I am white is probably what made one counselor feel comfortable enough to comment on "how these people behave in Church"-in a majority Black school.

The third advantage came from the possibility of sharing how different the educational system was from the one I attended. Letting people know that my experience with the American educational system was restricted to graduate school enabled me to ask what otherwise might have been perceived as stupid questions. I was able to compare high school practices here with those in a small private religious school in Brazil, where I graduated from high school with a class of 19 , or with those in public schools in Israel, where I had also lived. This allowed me to engage people in conversations and question them about many features and practices that might have been "transparent" to me, had I been part of the cultural system.

\section{Researching the Schools}

This project focused on those who have the greatest involvement in students' placement; primarily the guidance counselors and others working in the student services area. That was where most of the observation (both direct and participant) took place. In addition to the informal conversations I held with school staff while volunteering or just "hanging around," I had one formal, taped interview with each of the guidance counselors, the College Assistance Program (CAP) advisor, and the TRUST (To Reach Ultimate Success) ${ }^{17}$ counselor in each school. Sometimes it was possible to write field notes during the day; observations were often tape-recorded while driving home. Interviews with

\footnotetext{
${ }^{17}$ TRUST Counselors deal with students' personal issues, particularly regarding drug and alcohol abuse and teenage pregnancy.
} 
department heads, principals, and assistant principals ${ }^{18}$ were semi-structured and taped, with the exception of the principal at Franklin who refused permission to tape.

Although I entered the field as a researcher, I offered to work as a volunteer in each one of the schools. This offer was accepted to a greater or lesser extent at each school site, either by a counselor or a department head. Data collection began in October 1996, with short visits to the middle schools in the feeder patterns of the schools in the project. ${ }^{19}$ Between January 1997 and June 1999 I engaged in more intensive fieldwork, first at Franklin High and from September 1997 to May 1998 at Lincoln High. I continued visiting Franklin High, although less intensively through the beginning of the 1997-98 school year. In September of 1998, I moved on to Russell High, while still visiting Lincoln High on an occasional basis. In January of 1999, I moved on to Darwin High, where I stayed until the end of the school year, June 1999.

When I was actually helping a counselor with some particular project, as was the case at Franklin, where I helped the counselor who was test chairperson during testing season, I came to the school site on a daily basis for an average of five hours per day. On some occasions, such as subject selection week at Franklin, I spent the whole week in the school for the major part of the school day. During periods when nobody needed help, I would normally come to the school site two to three times a week. Whenever I knew of

${ }^{18}$ Interviews with all four principals and the Math and English department heads in two of the schools (Franklin and Lincoln High) were conducted with Dr. Carolyn Herrington, from Florida State University, who was a co-investigator in this project. Dr. Herrington was also instrumental in obtaining information through personal communication with a high-ranking district administrator. This administrator explained to us the district's reasoning behind the decision-making process in principal selection for the schools in question.

${ }^{19}$ I was able to visit the middle schools while accompanying Dr. Rosa Castro-Feinberg, who was then a School Board Member and a consultant to the larger project. 
some special event that seemed to be of particular interest, e.g. career week, visits from college representatives, articulation meetings, I made sure I attended it.

In all high schools, I became familiar with all guidance counselors, the CAP Advisor, and the TRUST counselor. In each school, usually one or two counselors were open and allowed me to spend significant parts of the day in their offices. The majority of counselors and several teachers and administrators generously shared their thoughts, worries, frustrations, and even their personal lives, sometimes getting a little help with translation to or from Spanish, typing a letter, or checking a list of names. More often than not, people shared their thoughts about what was happening just because they found an interested listener. In each school site, however, one or two counselors never overcame their suspicions, remaining constantly "on guard." Once given the opportunity to discuss issues they found important, most counselors were very willing to share their thoughts. Each site presented different opportunities and difficulties, some of them resulting from the physical plant of the school, others from the characteristics of their organizational cultures.

Each school has a testing chairperson who is responsible for carrying out all functions related to standardized tests at that site. In any given year, several tests are conducted, including the High School Competency Test (HSCT), the Scholastic Aptitude Test (SAT), the Florida Comprehensive Assessment Test (FCAT) and the Florida Writes, and others. Only one of the four school sites in the project, Franklin, denied me access to observing counselors working with students in their offices. However, since I spent several weeks working in the office of the guidance counselor who was the school's testing chairperson and who desperately needed help, I was still able to do a fair amount of observation there. Other opportunities arose during Subject Selection Week, when all 
students went to the cafeteria to complete their subject selection sheets, as well as during the few weeks when I helped the head guidance counselor by alphabetizing subject selection cards.

At Lincoln, Russell, and Darwin I was allowed to spend time with individual counselors and observe them as they worked in their offices. In most cases, we would agree that the counselor would let me know if the issue at hand was personal, rather than placement and subject selection, and I would leave. In fact, this rarely happened, and usually I would stay with one counselor for most of that day. Counselors always introduced me to students as "a graduate student interested in education" and asked them if they had any objections to my presence. No student ever had a problem with it. At both Russell and Darwin High I spent several days in the CAP advisor's office, and on several other days I "shadowed" the CAP advisor throughout most of the day. Spending full days with one counselor provided several opportunities for them to share their thoughts on their work, students, and education in general.

Transforming Data into Results

All recorded tapes were transcribed ${ }^{20}$ and combined with the information from the written notes. The resulting documents were later coded and analyzed with the aid of QSRNUD*IST, a computer assisted qualitative data analysis software. My use of the software was limited to the functions coding data and producing reports based on coding categories. While I am aware of the existence of other possible uses of the program, I found that these

\footnotetext{
${ }^{20}$ Several of the tapes were transcribed by a professional transcriber, with support from a grant provided by the Graduate Student Association at F.I.U.
} 
procedures provided me the information I needed to answer the questions posed in this project.

To a certain extent, the methodology used followed what LeCompte and Schensul (1999:67) call "analysis from the bottom up." Although the project began with a formative research model, it had no preexisting codes or categories beyond the most obvious ones, such as students, teachers, counselors, subject selection, policy, tracking. LeCompte and Schensul, however, make it clear that the results that emerge from the qualitative research process of collecting words through interviews, descriptions of observations, quotations, and documents, however, is far from mystical:

Although seemingly mysterious, the emergence of patterns actually occurs because the researcher is engaged in a systematic inductive thought process that clumps together individual items at the specific level into more abstract statements about the general characteristics of those items as a group (LeCompte and Schensul 1999:68).

Data collection was guided by an interest in educational policies and whether or not they were able to affect tracking practices. The literature and my knowledge-at the time quite limited-of public schools in the U.S. told me that although students needed teacher recommendations to register for higher level courses, tracking in a more general sense happened also outside of the classroom. Thus, I chose to study those adults who were more actively involved in what the district defines as "the student's decision-making process."

The decision to examine organizational features of the schools was informed by the preliminary analysis of the data. The patterns that emerged indicated that the conditions under which people made decisions were as important as, or even more important than, the values and principles they or the institution professed. The "emergence" of categories and 
and codes used in the final analysis of the data, however, did not follow LeCompte and Schensul's (1999) model. Instead, coding categories in this work were informed by a framework suggested by Tierney (1988) for the analysis of organizational culture in educational institutions. Although his work deals with institutions of higher education, the categories he suggests proved relevant and appropriate for the data in this project. The resulting coding categories were adapted from Tierney's framework to allow for the distinction between espoused values and basic assumptions, a distinction that is not critical in Tierney's framework.

The analysis of the data focused on four of the six categories in Tierney's framework: environment, mission, strategy and information. Issues of leadership, socialization, and information were incorporated into these three categories. While all six categories are important, the category of mission emerged as the most problematic.

\section{Setting}

\section{The School District}

The school system where this study was conducted is among the largest public school systems in the country. Between 1988 and 1998, its student body grew at a rate ranging between 2 and 5 percent a year. The district has the one of highest percentage of foreign-born residents among major U.S. cities, estimated at 45 percent. As a result, a high percentage of the student body is also foreign born, approximately 20 percent, ${ }^{21}$ with over a hundred different national origins represented in it. According to the district's estimates, more than half ( 58 percent) of its students speak a language other than English at home.

\footnotetext{
${ }^{21} 1998-99$ data.
} 
The rate of eligibility to receive free or reduced-price lunch in the district exceeds 59 percent. Principals, counselors, and teachers attested that these immigrants are no exception to their predecessors in their aspirations for social mobility. The students also believe that a college education is the key to this mobility. ${ }^{22}$

The high percentage of foreign-born population leads to a high number of students classified as Limited English Proficient (LEP) in the school system. For 1996-97, the first year of data collection for this study, 15 percent of its students ${ }^{23}$ were classified as LEP. Districtwide, at the high school level, 10.2 percent of students were classified as LEP. These numbers have grown steadily, and county officials expect the trend to continue. Within the LEP population, an estimated 84 percent are of Spanish language origin and 14 percent are of Haitian-Creole origin. The remaining two percent represent diverse language backgrounds.

As in some other large U.S. school districts, such as New York and Los Angeles, white non-Hispanic students account for less than half of the student body. More than half of the student population in the district is classified as Hispanic, a label that includes anyone descended from native Spanish-speakers. Thirty-four percent of the districts' students are classified as Black, without regard to issues of national origin. Therefore, most district statistics regarding Black students include African-American and Haitian-born students, as well as English-speaking West Indians.

\footnotetext{
${ }^{22}$ In addition to information from the counselors and teachers interviewed, quantitative and qualitative data confirming these high aspirations of students in these schools have been collected in the larger project.

${ }^{23}$ Aggregate information for the county, unless otherwise stated, regards Kindergarten through $12^{\text {th }}$ grade.
} 
This study was carried out in four schools: Lincoln High, Franklin High, Darwin High, and Russell High. Lincoln High is located in a racially segregated neighborhood with one of the largest African-American concentrations in the county. Nearly 85 percent of the population is Black, and about 13 percent are Hispanic, mostly recent arrivals from Central-America and the Dominican Republic. The school is located in an inner city area that is home to some of the city's poorest residents. Adjacent to this neighborhood, and still part of the Lincoln's boundary zone, is another area with a large concentration of Haitians, including many recent arrivals.

Franklin High is located in an older suburban neighborhood not far from Lincoln High. An overwhelmingly white area through the 1970 's, beginning in the early 1980 's it has become increasingly minority populated. African-American and Caribbean Blacks, as well as Hispanics have settled in the area. The neighborhood's population is predominantly middle-class, and the area is a desired destination for many of those living in Lincoln High's boundaries who can afford to move up to a "better" area (Stepick 1995). Franklin had the smallest percentage of students in the free/reduced lunch program in the sample.

Despite the differences mentioned regarding ethnic background and national origin of the majority of their students, schools in the sample share important characteristics. First, all four schools are large, with between 2500 and 4000 students, and all were functioning above capacity at time of this study. Second, three of them have quite large percentages of Limited English Proficient students, with the exception of Russell High. Third, all schools have a high percentage of students who qualify for the "Free and Reduced Lunch Program" indicating a generally low socio-economic status of a large proportion of the school's population. Fourth, guidance counselors' caseloads in each school range between 600 and 
700 students, with the exception of the head of the student services office, who usually has a smaller caseload (approximately 450 students). In addition to guidance counselors, each school had one TRUST counselor, one College Advisor, and one Occupational Placement Specialist, regardless of size or specific needs of the population served. In short, schools in the sample were all overcrowded and understaffed. Although the average class size provided in county statistics follow usual recommendations of 23 to 25 students per class, in reality all schools in the sample had several extremely large classes with 40 to 60 students, as well as several Special Education classes with six to ten students each. Subjects taught in these larger classes included core courses such as Algebra, Biology, and Chemistry. Table 2 shows selected statistics for each school. 


\begin{tabular}{cccccc}
\hline & COUNTY & FRANKLIN & LINCOLN & RUSSELL & DARWIN \\
\hline $\begin{array}{c}\text { Total N }{ }^{\mathrm{o}} \text { of } \\
\text { Students }\end{array}$ & 85,825 & 3,390 & 2,397 & 2,619 & 3,919 \\
School Capacity & N/A & 2,967 & 2,220 & 2,268 & 2,538 \\
$\begin{array}{c}\text { Percent } \\
\text { Utilization }\end{array}$ & N/A & 113 & 106 & 115 & 153 \\
$\begin{array}{c}\text { Percent LEP } \\
\begin{array}{c}\text { Percent } \\
\text { Free/Reduced } \\
\text { Lunch }\end{array}\end{array}$ & 32.3 & 17.5 & 22.2 & 4.9 & 10.4 \\
$\begin{array}{c}\text { Mobility Index } \\
\text { (95-96) }\end{array}$ & 34 & 42 & 52 & 41 & 38.5 \\
$\begin{array}{c}\mathrm{N}^{\mathrm{o}} \text { of } \\
\text { Counselors }\end{array}$ & 230 & 5 & 7 & 7 & 27 \\
\hline
\end{tabular}

\section{Notes:}

a-Mobility Index: An index of movement computed by dividing the number of students, without regard to how many times an individual student enters or withdraws, who have entered or withdrawn from a location during the regular school year by the aggregate number of students in membership at that location during the year. b-The number includes one College Assistance Program (CAP) Advisor, one TRUST counselor, and one Occupational Placement Specialist in each school. These counselors do not provide advice with subject selection.

At the beginning of the data collection, both Lincoln and Franklin schools were included in the state's list of "critically low performing schools." Both schools were later removed from the list due to their performance in one of the State's standardized tests used to determine such placements. In general, their results in standardized tests are below 
district's averages, which in turn are below the state's averages. Table 3 shows national, state, district, and school median percentiles for 1996 in the High School Competency Test (HSCT) and the Grade Ten Assessment Test (GTAT), and mean scores in the College Board Scholastic Assessment Test (SAT I). Each of these tests has a verbal and a math component.

Table 3 Indicators of School Performance 1996

\begin{tabular}{cccccccc}
\hline Location & $\begin{array}{c}\text { HSCT }^{\mathrm{a}} \\
\text { Comm. } \\
\text { Percent } \\
\text { Passing }\end{array}$ & $\begin{array}{c}\text { HSCT }^{\mathrm{a}} \\
\text { Math } \\
\text { Percent } \\
\text { Passing }\end{array}$ & $\begin{array}{c}\text { GTAT }^{\mathrm{b}} \\
\text { Reading }\end{array}$ & $\begin{array}{c}\text { GTAT }^{\mathrm{b}} \\
\text { Math }\end{array}$ & $\begin{array}{c}\text { SAT I }^{\mathrm{c}} \\
\text { Verbal }\end{array}$ & $\begin{array}{c}\text { SAT I }^{\mathrm{c}} \\
\text { Math }\end{array}$ & $\begin{array}{c}\text { Number }^{\mathrm{t}} \\
\text { tested }^{\mathrm{d}}\end{array}$ \\
\hline National & N/A & N/A & 50 & 50 & 505 & 508 & N/A \\
State & 77 & 75 & 47 & 54 & 498 & 496 & N/A \\
County & 67 & 66 & 31 & 38 & 461 & 465 & 6,007 \\
Franklin & 63 & 64 & 22 & 26 & 440 & 456 & 226 \\
Lincoln & 38 & 38 & 13 & 13 & 344 & 380 & 77 \\
Russell & 60 & 57 & 25 & 26 & 404 & 409 & 114 \\
Darwin & 83 & 86 & 37 & 50 & 438 & 452 & 267 \\
\hline
\end{tabular}

Notes:

a-High School Competency Test, required by the State for graduation. The exam is offered each September to all $11^{\text {th }}$ grader regular high school students. The HSCT measures the application of basic skills in communications and mathematics to everyday life situations. b-GTAT: Grade Ten Assessment Test, a nationally standardized, norm-referenced achievement test that measures the performance levels of $10^{\text {th }}$ graders in the subject areas of reading and comprehension. The numbers provided are the median national percentile rank.

c-38 percent of $12^{\text {th }}$ graders took the SAT I exam in 1996.

d-Number of students who took the SAT I.

\section{Programs Offered}

The county has developed federally funded Magnet Programs (and Schools) in an effort to balance racial ratios, stem declining enrollment and improve the quality of 
education in certain areas. Federal funding requirements for the programs establish that Magnet Programs or schools are intended to promote desegregation; programs are supposed to recruit students so that the resulting school population distribution reproduces the district's ethnic distribution. Exceptions may be granted in order to further desegregation of the receiving school's total population. Officially, no more than 80 percent of the students can be of any single race in a Magnet Program.

Three of the schools in the sample offer magnet programs: Franklin, Darwin and Russell High. Franklin offers an International Baccalaureate (I.B.)/ International Affairs (I.A.) program, a demanding academic program with academic performance prerequisites. ${ }^{24}$ Students are recruited into the program at $9^{\text {th }}$ grade. During the first year of the study, Franklin was a $10^{\text {th }}$ to $12^{\text {th }}$ grade high school, and only pre-I.B. students did $9^{\text {th }}$ grade at Franklin. The following year (1997-98), ninth graders from the regular feeder pattern began attending Franklin. ${ }^{25}$ In addition to the I.B./I.A. program, Franklin offers vocational training programs in Cosmetology and an Allied Health Assisting program.

Darwin High offers an Engineering magnet program; it is also the only school in the sample with a gifted program, where students who have been tested take classes called "gifted Honors." While Franklin focuses its recruitment efforts on White students in order to balance its majority Black population, Darwin focuses its efforts on Black students, to

${ }^{24}$ In order to apply for the program students must have completed Algebra I and Physical Science - only students who were advanced did so- in $8^{\text {th }}$ grade with a grade of A or B. Letters of reference from teachers and counselors are also required.

${ }^{25}$ This change was a result of a county level decision changing the composition of middle and high schools. The $6^{\text {th }}$ grade, which used to be part of elementary school, became part of middle schools, joining $7^{\text {th }}$ and $8^{\text {th }}$ grades. Ninth graders were transferred from middle schools to senior high schools. The School Board opted for the change in response to purely practical considerations of space, and not due to any pedagogical or curricular consideration. 
offset its highly Hispanic concentration. Russell High offers a program in International Business (Academy of International Business- AIB), which has been funded by a federal grant of limited duration, after which the program is expected to be self-sufficient in terms of funding. Russell also offers a program in Nursing that includes working in hospitals and may lead to a nurse's aid or a practical nursing registration. At the time of the research, students for that program were also recruited from out of the boundary zone, even though the program was originally intended for the in-school population. Lincoln High offers a Health careers program (three courses) and a Home and Family Education option.

Schools also offer shared time programs with vocational schools. All four schools offer a Junior Reserve Officers' Training Corps Program (JROTC) focusing on leadership skills. The program does not require any commitment to military service. All high schools offer Cooperative education programs, where students take only the core courses and go to work in place of many of the electives. All schools offer courses in Business Technology such a keyboarding and computer skills.

Schools' Curriculum Bulletins included information on DCT (Diversified Cooperative Training) and OJT (on-the-job training). In addition, the county has also established Tech Prep programs. According to Darwin High's Curriculum Bulletin, the program is supposed to chart career courses for "Middle Majority" high school students. 


\section{Student Membership}

The district uses three, four, five, or six racial/ethnic categories, depending on the purpose of document or the mandate it is responding to when collecting the data. ${ }^{26}$ Information concerning the race and ethnic composition of every school is shown with six different categories: White, Black, Hispanic, Asian, American Indian and Multiracial. Information regarding Magnet Program enrollment classifies students as Hispanic, Black, or White/ Other, although the School Board Rule mentioned above only refers to Black/Non-Black proportions. Information on participation in advanced level placement courses students classifies students as Black (non-Hispanic), White (non-Hispanic), Hispanic, Asian / Other. Information regarding student achievement on standardized tests, truancy, and drop out rates refer only to Black, White, or Hispanic, with a breakdown by gender. The district mixes "racial" and ethnic categories in one classification system; a "Hispanic" student can be of any "race" as long as they come from a Spanish speaking country, while a "Black" student can be Haitian and speak Creole or French, AfricanAmerican, African, or English-speaking Caribbean. The inconsistencies in the classification categories and the lack of availability of information on national origin associated to class placement render many of these statistics practically meaningless. ${ }^{27} \mathrm{~A}$

\footnotetext{
${ }^{26}$ Nationality information is collected on the aggregate level for LEP students and reported to authorized users of the district's data. The public has access to the District and School Profiles and the Statistical Highlights. Those documents also use the categories mentioned above in a non-uniform way.

${ }^{27}$ To find out the nationality of a student, a researcher needs to either interview the student personally or use the emergency cards used by the school, which include country of origin of students. National origin information is not available in any documents with statistics on classroom placement. Aggregate information on national origin is available only for those with authorized access to the county's computer system. This aggregate information is reported to the State and published in the Annual State Report.
} 
careful examination of the course credit analysis of one sub-sample of the project's subjects, a group of 30 Haitian students, yielded three students classified as Hispanic. Students or parents are allowed to mark whatever racial/ethnic category they feel appropriate, and no one has the authority to question that choice.

All of the schools in the project underwent population changes over the last 15 years. At Franklin, a population that 20 years ago was suburban white middle class youth with a large Jewish component gradually became mostly African-American. In the past five years, the proportion of students of Haitian descent has been increasing. The academically selective I.B. program at Franklin brings some non-Black students to the school, and these I.B. students make up the vast majority of the Advanced Placement and Honors classes. Lincoln High has a similar history of moving from a predominantly white middle class school to mostly African-American, and then shifting to a majority of students of Haitian descent. In the past few years, an increasing number of immigrant Haitian, West Indian, and Hispanic students have entered both schools. Haitian students now make up an estimated 40 percent at Franklin and above 80 percent at Lincoln.

Darwin High's population also has gradually changed from a predominantly white, upper middle-class with a significant Jewish component, to predominantly Hispanic and blue collar. Signs of the community's population change can be found, for example, in the Jewish motifs that still decorate the windows of a synagogue that is now a church located near the school. Russell High's population is the school where the population change has been most recent and most drastic: A hurricane in 1992 severely damaged a nearby military installation, leading to the re-location of a Federal Government airbase. Thus, the school has lost the part of its student body that tended to be the majority of its high achieving 
population. Due to its semi-rural location, the school has always had a high number of migrant students that is reflected in its high mobility index (Table 3). Of the schools in the project, the only school with a higher mobility index was Lincoln High, and this fact is explained by the extreme change in housing arrangements of the incoming Haitian student population. Many of these students do not live with their parents, but with other relatives, and changing living arrangements are frequent.

Table 4 Student Membership by Race and Ethnicity October 1997

\begin{tabular}{|c|c|c|c|c|c|c|c|c|}
\hline \multirow[b]{2}{*}{ Location } & \multicolumn{2}{|c|}{$\begin{array}{c}\text { White } \\
\text { (Non-Hispanic) }\end{array}$} & \multicolumn{2}{|c|}{$\begin{array}{c}\text { Black } \\
\text { (Non-Hispanic) }\end{array}$} & \multicolumn{2}{|c|}{$\underline{\text { Hispanic }}$} & \multicolumn{2}{|c|}{$\frac{\text { Asian/Indian/ }}{\text { Multiracial }}$} \\
\hline & $\mathrm{N}^{\mathrm{O}}$ & $\%$ & $\mathrm{~N}^{\mathrm{O}}$ & $\%$ & $\mathrm{~N}^{\mathrm{O}}$ & $\%$ & $\mathrm{~N}^{\mathrm{O}}$ & $\%$ \\
\hline Franklin & 207 & 6 & 2,566 & 76 & 540 & 16 & 77 & 2 \\
\hline Franklin I.B. ${ }^{a}$ & 112 & 42 & 84 & 31 & 74 & 27 & $\mathrm{~N} / \mathrm{A}^{\mathrm{a}}$ & $\mathrm{N} / \mathrm{A}^{\mathrm{a}}$ \\
\hline Lincoln & 12 & 1 & 2,211 & 92 & 173 & 7 & 1 & 0 \\
\hline Russell & 308 & 12 & 981 & 37 & 1,287 & 49 & 43 & 2 \\
\hline Darwin & 259 & 7 & 179 & 5 & 3,449 & 88 & 32 & 1 \\
\hline County H.S. & 12,270 & 14 & 27,851 & 32 & 44,345 & 52 & 1,359 & 2 \\
\hline County Total & 44,946 & 13 & 115,735 & 33 & 179,484 & 52 & 5,696 & 2 \\
\hline
\end{tabular}

Note:

a-Counted with White population. Information provided by Lead teacher in program.

\section{The School Staff}

Although schools in the district have achieved a certain level of diversity in their staffs, they are far from reflecting the ethnic composition of the student body. In addition, 
the presence of African American counselors or teachers does not necessarily solve the language problem or ease cultural differences in schools where the Black population is predominantly Haitian, as is the case at Lincoln High, and to some extent also at Franklin. At Franklin, for example, where 76 percent of the population was Black, only one assistant principal was Black at the time of the study. The principal and two assistant principals were white, and a fourth assistant principal was Hispanic. Classroom teachers in all schools were mostly White; 40 percent of the teachers at both Lincoln and Darwin High were White. At Franklin and Russell High, approximately 57 percent of the teachers were White.

Guidance counselors, together with several other professionals such as the Occupational Placement Specialist and the CAP Advisor, are part of the Comprehensive Student Services Program. The program is meant "to address the educational, career, and personal/social needs of all students in the county." The program's ultimate goal is for students to graduate with the competencies necessary to make self-directed, realistic and responsible decisions and to be successful contributors to society.

Guidance counselors are supposed to help students with their subject selections, to ensure students fulfill all of their credit requirements, and that there are no "repeatability violations" (if a student takes the same course twice, no credit is awarded for the second time). Responsibilities of counselors include discussing students' course choices in relation to their career aspirations, dealing with course changes during the year, and mediating between students and teachers when problems occur. Counselors are also expected to contact parents when students have disciplinary or academic problems and meet with parents who have questions or concerns about their children. Many of these responsibilities require filling out forms and other paperwork. An important part of a high school 
counselor's job is to make sure that $12^{\text {th }}$ graders fulfill the requirements for graduation. These include:

a) Completing all the required credits in each specific category (students may have more than 24 credits and still not have the half credit in fine arts, or practical arts, for example),

b) Having a G.P.A. above the required minimum (at the time of the research this minimum was changing from 1.5 to 2.0$),{ }^{28}$

c) Completing the community service report. Requirements vary depending on the type of certification the student is applying.

d) Passing the High School Competency Test (HSCT), a test offered five times between junior and senior years. There are two parts to the HSCT: math and English.

${ }^{28}$ During the second semester of the 1997-98 school year, the district changed GPA requirements for graduating students, generating an amount of uncertainty over the graduation prospects of many students whose GPA was between 1.5 and 2.0. For several weeks, counselors did not know what to tell these students regarding their graduation prospects. 


\section{Chapter IV}

\section{FINDINGS}

This chapter relates the main findings concerning tracking practices ${ }^{29}$ in the schools according to four of the concepts suggested in Tierney's framework for the analysis of organizational cultures (see Table 1, Chapter 2). The chapter focuses on the concepts of environment, mission, strategy and information. Information regarding leadership and socialization that was relevant for tracking practices is reported in the context of the four concepts.

\section{Environment}

To answer the question of how the organization defines the environment in the schools, it was necessary to separate the answer in two levels: One level concerns how school cultures define the environment outside the school, i.e., the educational system and society in general, and the second concerns how the school cultures define their in-school environment. Each of these definitions has implications for the maintenance of tracking practices in the schools. Tierney' framework also poses a question regarding the attitude toward the environment. The analysis of the data led me to look at the discourse that is considered acceptable or not in the schools as an indication of the prevalent attitudes towards the environment in the schools. While keeping the focus on tracking practices, the description of the school environment that follows focuses on these three issues: How the

\footnotetext{
${ }^{29}$ Since tracking officially has no existence in the schools, the practice of placing students in different level classes is referred to as "placement." For this reason, this study uses placement and tracking practices interchangeably.
} 
culture of the schools defines the external environment, how it defines the internal environment, and what this organizational culture considers acceptable discourse.

\section{The Outside Environment: The Educational System and Society in General}

The ways in which these school cultures define the external environment are extremely similar in the four school sites. From the point of view of the culture of the schools, the contrast between the espoused values of the larger society about education and what is practiced in the schools is glaring. People in the schools are keenly aware of the disparity between the stated goals-excellence, high standards-and a pattern of resource distribution that leads to growing class sizes, inappropriate teacher-student and counselor-student ratios, and even insufficient textbooks. As a result, the environment in these schools is characterized by a certain level of skepticism towards society's expectations of the educational system. A certain level of distrust directed mostly at policy makers and district administrators - normally referred to as "downtown"-is pervasive. While everyone is able to recite the espoused values that the wider society holds for education - equality of opportunity, excellence, and preparation for the world of work - the dominant attitude is one of disenchantment. In a conversation about immigrant students, one counselor explained:

(...) A lot of those kids are set up to fail. But nobody hears us. Those people, who make the policy, most times have not even been in the classroom. Of course, there's no excuse. Everybody should be in school, everybody can learn. True. Given the right tools. (31297/39-Head Counselor). 
The perception is that people who make educational policies do not know enough about the reality of the schools in order to make these decisions. From the point of view of the people who need to implement these policies, they make no sense.

The people who design policies are so far removed from the reality of the schools that they have no clue of what is happening here. Nobody is really thinking critically about what is happening in the schools. Why things are the way they are. The system can't fulfill the needs of the students. There is a huge gap between what the students need, and the expectations from the system. Students in the elementary school, supposedly if there is a problem, such as a learning disability, teachers should find this and get them help. But a lot of times students fall through the cracks, there are so many students that are not average. This is a mass education, and it is geared toward an average student. But the problem is that 99 percent of the students in this school are not average. In this particular school, most of the students have problems that affect them far beyond the average. It becomes very hard for this system to be responsive to them. (11398/15-16 TRUST counselor).

Constantly changing policies and regulations reinforce perceptions that educational policy-makers do not understand the subject, and do not think through the consequences of each new rule. Changes in graduation requirements for example, resulted in a period of confusion in the schools, as described by one counselor:

(...) and then you have, as I mentioned before, people who were never in a classroom, making decisions, and I think they need to really include teachers, so that way teachers will own this environment, so they will have something to do with this, and they will want to do it, because I don't think that that's occurring. All of these changes, there's so many changes that they don't know what to expect from one minute to the next. All of these requirements that you need to pass, they're changing from 1.5 to 2.0 at a time when they are lower in their academic ability. Which to me doesn't make sense. I think it should have remained at a 2.0, but it did not, but now when they are doing worse to put it up, you're going in the opposite direction, it doesn't make sense. I understand expectations and stuff, but it doesn't make sense. (32497/34 Counselor) 
Indeed, changes in policies with far reaching consequences for both schools and students are quite frequent. Some of the changes taking place between 1996 and 1999 included:

1) The number of standardized tests students are required to take continued to grow with the addition of the FCAT.

2) The minimum Grade Point Average (GPA) required for graduation was gradually increased from 1.5 to 2.0 .

3) The number of correct questions in the High School Competency (HSCT) test required to obtain a passing grade was increased.

4) "F" grades started counting in the GPA calculations, something that did not happen before.

5) A new "five-point rule" was enacted, requiring students to receive five points in each semester. Thus, students with a passing final grade who do not have a minimum of five points in each semester fail the course.

6) The Florida Writes exam was substituted by the FCAT (Florida Comprehensive Assessment Test) as one of the two tests - the second is the HSCT-used to determine whether a school should be placed in the list of low performing schools.

In the case of the GPA, the district decided to implement the policy before the actual date mandated by the state. For over a month, counselors did not know what would happen to students who had the 24 credits, had passed the HSCT, but whose GPA was below 2.0. In a meeting with guidance counselors, the district representative had no answers to counselors' questions. Would students be required to come back to school? 
Would they be required to retake core courses to increase their GPA? The district had increased the minimum GPA requirement without offering solutions for the practical implications of the decision.

Ms. Y. told me she hasn't been sleeping well and she thinks this is because she is "taking home problems from students." The county has decided to implement the 2.0 GPA requirement for this year. Seniors this year either must have maintained a cumulative 2.0 (for the past four years) or must have 2.0 for this year. Students knew this was going to happen, but what changed, according to Ms. Y., is that F's are now included in the calculations, which they weren't before. The county still hasn't decided what to do with the students who have the 24 credits and an average between 1.5 and less that 2.0. Ms. Y. went to a meeting downtown last week to discuss this issue. At this point she has on her desk the paperwork for half of the seniors in her caseload (100 students), all with a GPA below 2.0 , or an exact 2.0. She has been trying to talk to the teachers to see if they are willing to raise a point here or there. She has been trying to figure out ways for these kids to graduate. Her main concern is with those kids who are not going to college or any other school, and it doesn't look like they will receive a high school degree. That is a big problem. (42198/245-268 Fieldnotes, Lincoln High).

These frequent changes are especially detrimental to guidance counselors, whose job is to give students information that will help them make decisions regarding their future. Guidance counselors have learnt that information that is correct today may be incorrect tomorrow. Moreover, each one of these changes means more time spent on paperwork and less time spent on the actual process of counseling students, since counselors need to go over students' records, find out who are the senior students who will now be at risk of not graduating, call them and try to find a solution for each of these students.

The environment created by increasing graduation requirements affects tracking practices in yet another way. These changes reinforce perceptions that it is "safer" for 
students to take easier, i.e., lower level, classes, since by decreasing the risk of failure and low grades students have a better chance of graduating. The increase in graduation requirements leads the culture of the organization toward a short-term view of the school's mission. Curriculum Bulletins often include a letter of introduction where the principals emphasize the school's commitment to academic challenge:

Perhaps no other decision is as important as the selection of subjects during one's high school years. The subjects that you select will influence future decisions that you will make regarding your post-high school education or the world of work.

\section{PLEASE DO NOT UNDERESTIMATE YOURSELF! (Capital} letters in the original)

It is very important that all students be challenged to take the most advanced work that they can successfully handle.

All students are urged to compete academically.

The operative criterion in subject selection procedures, however, is the need to graduate. During subject selection for students going into their senior year, students whose GPA was between 2.0 and 3.0 were often encouraged to sign up for the two required courses (English IV, the $12^{\text {th }}$ grade English course, and Government and Economics, two half-credit courses offered in consecutive semesters) and then "go to work." Fieldnotes from a day spent with a counselor at Darwin High working with $11^{\text {th }}$ graders during subject selection noted: 


\begin{abstract}
All the advice she gives seems like sound advice for them to finish. What is missing here is she is asking very, very, few students what their plans are. If the students asked her, "What do you need to go to college?" she told them. Otherwise, to most of the 11 th graders going into 12th grade she would say: "Well you need English and government and do you want another math? Do you want another science?" To which students invariably said, "No." Then she asked them if they preferred to go to work at 9:30 or at 12:30, and signed them up for the work program. There was no discussion of their career plans. (32999/3-4 Fieldnotes)
\end{abstract}

When students needed to attend night school to receive credit for an elective class they had failed, the counselors' suggestion was usually a course called "Peer Counseling." Students are active participants in this short-term view of the goal of education; a frequently asked question during subject selection was "Is this a hard class?"

Students' behavior during subject selection relates to the second component of the definition of the environment in the schools: Perceptions of the school's achievement level, its "track record." This record is related to definitions and perceptions school staff have of the student body, perceptions that are also related to the maintenance of tracking practices.

\title{
The Internal Environment
}

Definitions of the internal environment in the schools were largely determined by the kinds of perceptions school staff had of the student body. Other elements that shaped how people in the schools defined their internal environment included perceptions counselors had of the administration and of teachers. Despite the existence of some differences in schools' definitions of their internal environment, similarities outweighed the differences among the schools in the sample.

Counselors' and teachers' perceptions of the students involved contradictory basic assumptions, particularly regarding the influence of the environment and of "ability" on 
student achievement. The espoused value states that the environment has a greater influence over achievement than nature (genetics, heredity). Nevertheless, findings pointed to the existence of basic assumptions about "ability" - a word widely used in the schools, but never specifically defined. Most of the time, ability was used to describe a student's ability to learn new material and understand new concepts. As used in everyday conversation in the schools, "ability" is not preceded by qualifiers, such as "verbal" or "mathematical." Course placement decisions were influenced both by perceptions of the students' home environment as well as by perceptions of student "ability."

Regarding the influence of the environment, counselors are quite aware of what Michael Apple calls "the degradations of poverty" (Apple 1996:41). This is particularly true at Lincoln, which has the highest percentage of students in the free/reduced lunch program, as well the highest percentage of Limited English Proficient students in the sample.

The kids here don't have a plan, they don't have a goal, even the smart kids, even the very capable ones. They are so concerned worrying about where they are going to spend the next night, and whether there is going to be a roof over their heads, or where they are going to have their next meal, that they can't have a plan for their lives. So everything is kind of last minute. They are not trained to think in terms of long term planning, and career, and stuff like that. (11398/20, Counselor)

Although students at Lincoln are probably the group facing the hardest conditions, the description fits many students in the sample. Many students live in non-traditional family arrangements, with grandparents, other family members, and in the case of recent immigrants, even with family acquaintances. School cultures in general recognized that 
students' personal lives were difficult and many of them lacked support in their home

environment.

Counselors noted that students are unable to make the connection between where they want to get (usually college or a profession), and what is needed to get there (according to counselors, studying and working hard at school).

Students lack exposure: They don't consider college a realistic option; they are not exposed early in their life. Some kids aspire to college, but don't see the connection between wanting to go to college and working to go to college. Many kids go to college and have to do lots of remedial work (2498/ 667 Teacher).

Despite this recognition that students "lack exposure," school cultures seem to be at a loss when they need to deal with the effects of this environment, namely students' perceived lack of motivation and persistence. Perplexity is one of the most common feelings expressed by both counselors and teachers. In contrast to what is often described in the literature, the problem with students' behavior was seldom defined as one of negative academic orientation. Interviews with teachers in particular are filled with pauses, sighs, and sad smiles accompanied by "I don't know."

Well, I don't know for sure what. It could be they have no one to motivate them. So, they don't know how to motivate themselves. It could be that they are bored in school. The curriculum is not interesting, teachers are not making it interesting and they want to be entertained. And it could be that, I believe, quite a few, some kids, it's problems that they have at home that are weighing them down, depressing them, and they don't have the energy. Or the desire, or they feel that they wouldn't get a fair shake in life so "why lose time anyway?" Those are some of the factors I believe that come into play in terms of their not coming to school. Some of them have babies; sometimes they just end up with the wrong crowd. They don't have, parents either, don't have the time, because they are working one or two jobs, or they don't feel educated enough to help and so they pretty much, just let the kids run the show (Franklin, 32497/70). 
This idea that parents "let the kids run the show," or that "many of our students are raising themselves" was prevalent in the two schools where the majority of the students were of Haitian origin, Lincoln and Franklin. Although this particular perception was not found in the other two schools, where students were mostly of Hispanic origin, counselors shared perceptions that the home environment of the majority of their students was not supportive of academic success. One counselor mentioned visiting students' homes and noticing that students did not have enough lighting to study, and that the TV and the radio were on at all times. The counselor interpreted this as proof that these parents did not know how to create an environment that supported learning. This perception of lack of parental support may be an additional underlying factor in the tendency to steer the majority of students away from higher-level courses, since without parental support students will not be able to succeed in the more demanding courses. One incoming principal clearly asserts the importance of parental involvement as an espoused value of the school culture in a message in the Curriculum Bulletin:

The research is clear and consistent: effective schools have higher levels of family involvement. The single most important determinant of a child's success in school, and ultimately throughout life, is not family status, education level, income or IQ. It is whether a child's family is involved in his or her education.

The discourse in the school asserts its confidence in the importance of the environment, emphasizing the element over which parents can exercise some control. At the same time, the belief in the existence of a fixed trait called "ability" plays a crucial role in how placement decisions are made and tracking practices maintained. The ability level of students is what creates the school's record of achievement in the standardized tests, the ultimate measure of a school's success. The same vocabulary used to define the schools- 
high and low performing or achieving - is also used to define individual students. Thus, the characteristics of the students expand to define the school as well. Despite the fact that schools are not supposed to use results of standardized achievement tests (the SATs given to students during elementary and middle schools, measured in stanines), the information is available in the computer system, and counselors use it when they deem appropriate. When asked to describe the student placement process, a department head responded:

Well you have your various standardized tests. They have had tests from elementary to middle school. They have had the Stanford Achievement Test, which gives them an ability level score. Then they have IQ tests. If they are gifted, they have had different IQ tests. Then they have teacher recommendation and a lot is relied on teacher recommendation-cause a lot of kids aren't test takers. You have some kids who are test takers but who do poorly in a class. So, we look at all of those different variables and put them together to see where a kid should go. (EDH99/49)

Assumptions regarding ability as a fixed trait contribute to the existing resistance to upward mobility in class level. The belief in the existence of "ability" leads counselors and teachers to define students by their previous performance, as in "John is not Honors material, or "Mary is a C student." This use of language not only reifies an originally abstract concept of "ability" into a concrete reality, but also makes this reality unchangeable. It follows that regular students "do not belong" in Honors classes," and viceversa. Some counselors and teachers used expressions such as simply 'low' or 'high' to describe students, without any noun attached to it, as in "see how low these kids are?’(031099/3 Fieldnotes, Darwin High).

An incident at Russell illustrates the workings of the assumption regarding fixed ability: 
Following a teacher's recommendation, a counselor convinced Jessica, a student who had done extremely well in several of her regular classes, to attempt Honors English in the following year. On the first week of class, the teacher of the Honors class called the counselor several times to let her know that this student "did not belong" in the class. The teacher insisted Jessica was not "Honors material." By mid-week, the teacher also complained that the Jessica "had an attitude." Ms. Waters, the counselor, said she believed the teacher was setting Jessica up, and she did not believe Jessica had the emotional resources to avoid falling into the trap. Jessica came in by the end of the week, begging to be downgraded to the regular class. Unhappy, but not wanting to have the student as a pawn in a power struggle between herself and the teacher, Ms. Waters finally caved in to the request. Jessica had a good GPA, and Ms. Waters did not want to risk lowering it in the $11^{\text {th }}$ grade. To make matters worse, those first two weeks during which the teacher's phone calls occurred were hectic at Ms. Water's office. There were constant lines of students at her door who needed schedule changes, and new students were coming in to register and receive schedules. (Fieldnotes998, Russell).

This incident was not unique. Counselors in the other schools also complained about teachers who opposed the placement of students who had been moved into higherlevel courses in their classes. Some teachers in Honors and Advanced Placement classes spent much time and energy trying to convince a counselor that the student was not Honors or Advanced Placement "material" and the placement was inappropriate. Teachers' resistance to student upward mobility was based on the use of previous achievement as a definitive marker of the students "ability." This use of the concept of ability, as a fixed measure that can predict a student's future achievement, even across subjects, is a crucial element in explaining maintenance of tracking in high schools.

The majority of students arrive at the high school already tracked, since middle schools already offer different levels of Language Arts classes (Regular and Honors, and sometimes Remedial). Middle schools also offer different levels of math: Students in the 
advanced track take Algebra I in $7^{\text {th }}$ grade, and sometimes even in $6^{\text {th }}$ grade, while the majority of students is exposed to their first Algebra course in $9^{\text {th }}$ grade. Since students in these so-called "accelerated programs" are entitled to summer advancement courses, many of these students arrive in high school having already completed the three courses that the other students take in high school: Algebra I, Geometry and sometimes even Algebra II. In addition to math and English, middle schools began tracking students in science as well; students in the "accelerated" track take Physical Science in $8^{\text {th }}$ grade, while the majority takes it in $9^{\text {th }}$ grade. Courses that are sequential in nature, as is the case in the math and science curriculum, pose an additional obstacle to upward mobility in class level, since a student who does not start in the accelerated track in middle school would need to "accelerate" in night school to make up for more advanced courses. Night school, however, does not offer "Honors" or Advanced Placement classes.

Even when students take higher-level classes in middle school, high schools tend to push students to lower level classes as they enter $9^{\text {th }}$ grade. Franklin had a particularly strong tendency to downgrade class levels for incoming $9^{\text {th }}$ graders. When the subject selection cards from the incoming students arrived, I volunteered to put them in alphabetical order. While doing that, I noticed that many students had been placed in regular classes despite the middle school recommendation for Honors placement.

Some students have all of their classes in honors sections. Others have only one -usually science-. In some of these cases, the counselor did not follow with a recommendation for chemistry honors, but for regular chemistry, so the student is basically not going to be in any honors classes anymore, even when the teacher recommended the honors class. Students who took Algebra I were going to geometry. Again, in several cases the teacher recommended honors classes but the counselor chose regular 
geometry. In all the cases that I saw the counselor not marking the course the teacher recommended, they were downgraded, never upgraded. In most of the cases where students didn't have a sheet, work experience was one of the options. Students in 9th grade seem to already be quite set into a course of mediocrity or honors classes. Students who took honors classes usually picked more academic electives - a foreign language, maybe some art, and maybe a keyboarding class. These students did not choose work experience, business systems or family dynamics.

(Fieldnotes4997/5-8)

When I asked the head counselor why this happened, she explained that "middle school teachers and counselors are not familiar with high school courses, and high school counselors know better." In other cases, although students had been recommended for Geometry, they were placed in Algebra I. Again I inquired for the reason for the change, and the head counselor explained: "Algebra I in middle school is not the same as in high school."(Fieldnotes41097/21) At Franklin, the Curriculum Bulletin establishes that Algebra I is the pre-requisite for Chemistry. The implemented policy however, is that Algebra II is the minimum level of math required (that means two more years of math before a student can enroll in a chemistry course). This limited the science courses the majority of students in the school could take to those that are "non-sequential"-Environmental Science, Anatomy and Physiology, and Marine Biology - and that are not the preferred courses colleges are looking for. When I asked a counselor the reason for the discrepancy between the information provided in the Curriculum Bulletin and the practice, she explained that one year of Algebra did not prepare students for chemistry, and this prevented students from failing the course.

Only one of the schools had a policy forcing school practice to follow the espoused value of providing students with academic challenge. This policy was the result of an effort 
by Darwin High's principal to increase the level of challenge, by automatically enrolling students who received high grades (A's or B's) in the next level class for that subject. When the rule was implemented, it faced criticism from both counselors and teachers.

Well, he (the principal) wants the school to look good, and bumps up a lot of students. You end up with those mixed classes and it's horrible. (031999-2).

Classes that do not have any "bumped up students" are considered "true Honors classes," and some teachers, as well as counselors, commented on how easily one could feel the difference. The counselor's comment hints at one of the consequences of the existence of different levels of classes in the schools: One of the ways schools are judged is by the number of higher level classes offered. By "bumping up" students, the principal increased the number of classes the school was offering at higher levels, and made the school "look good." Several aspects of the organizational culture of the school can be used in analyzing the policy and the reaction to it. The principal justifies the policy by referring to the mission of the institution, to challenge students to achieve at higher levels. The policy is criticized because it violates basic assumptions about fixed ability. From this point of view, the policy is explained as a strategy used by the principal to make the school "look good."

\section{Acceptable and Unacceptable Discourse in School's Organizational Cultures}

Despite the general agreement that a large percentage of the student body is "low," school cultures set limits in terms of what can be said. Violating this unspoken rule about what is acceptable to say can lead to criticism as much as the decision to "bump up" students to higher level classes 
Some kids in the school are ill served by some teachers. The best teachers are trying to build up motivation. Others say that they are "teaching the city's future housemaids and lawn men" (2498/ 667 Department head).

A teacher at Russell High echoed the same criticism of those who say they are teaching "future housemaids of town." The comment indicates the existence of shared assumptions across schools regarding the connection between students' socio-economic background, their academic ability, and their future opportunities. In both sites, counselors considered this type of comment inappropriate. While comments such as "the majority of our students is not college material" are acceptable, comments that flatly deny the possibility of a college education for any student is supposedly beyond the acceptable discourse in the schools. Only two of the thirty counselors in the sample, one at Franklin and another at Darwin High, reported that they saw it as their obligation to make students become "more realistic" in their expectations for post-secondary education. Comments such as "I tell it to them as it is, not everyone goes to college, not everyone should go to college" and "I don't want to create false expectations and illusions for the students," were criticized by other counselors who made a point of letting me know that they did not share that philosophy (Fieldnotes 21097/27).

Findings concerning what counselors define as beyond the limits of what can be said to students about the opportunities available to them goes to the essence of the issue of tracking in a system that officially does not track students. Despite the absence of formal tracks, the kind of courses students take in high school still impose limitations on postsecondary options open to students. Discussion of these limits, however, is generally not acceptable, particularly in face of the existence of a local community college with an "open 
registration" policy. Since by definition anyone with a high school diploma can register in the community college, even when this means several semesters of remedial courses and no college credit, the organizational culture of the school can afford to de-legitimize discussion on the implications of high school course taking patterns.

\section{Mission}

The concept of mission addresses questions regarding how the organization's mission is defined, how it is articulated in the organization, and whether or not the official mission (the espoused value) is really used as a basis for decisions in the organization. In the case of high schools, mission relates to how the school system defines its purpose, and how people in the schools articulate the school's purpose.

How Is the Mission Defined?

The official discourse is about education, about each student learning at his or her own level of ability and motivation, as well as about excellence, and educational opportunity. According to County documents,

A good senior high school program provides the best possible educational opportunity for all of its students. Offerings include strong college preparatory courses as well as applied technology courses.

Our vision is to promote academic excellence at each school site through the creation of "communities of learners" made up of professional educators, students, parents, and community members in order to prepare students to be productive citizens of Eastville County. 
The mission of Eastville County Public Schools is to support the improvement of student achievement by strengthening instructional leadership, by launching innovative systemic initiatives, and by disseminating resources that enhance curriculum and instruction.

\section{How Is Mission Articulated? Accountability and Tracking}

Analysis of the county's documents shows the official mission of the schools is defined as educating all students to become productive members of society. The way the school's mission is articulated in the principal's discourse points in a different direction. Principals' interviews followed a similar pattern: They all began by describing how the school's student population had changed over time, and the school had "lost" mainstream, college-bound students and their student population is now mostly minority. That introduction was followed by a description of how they had improved in this or that standardized test. Interviews with three of the four principals centered on the school's ratings in standardized achievement tests; particularly passing rates in the HSCT. The subject was introduced by the principals, in response to a question by the interviewer asking them to "describe your school, tell me about it, what is special about this particular school." The responses showed principals are concerned mostly with students' passing rates and achievement in standardized exams, particularly those that can place or remove a school from the dreaded "list of critically low performing schools."

These responses indicated discrepancies between the stated mission of these high schools and the manner in which the mission is articulated inside the schools, particularly by the leadership. Many counselors are aware of the problems generated by the focus on standardized tests and the implications of this kind of articulation for the priorities established by the leadership in the school: 
I think they ought to do away with tests. We need some tool to measure how they (students) are doing, but tests... Teachers, like you say, instead of teaching they spend time preparing for that, and that's because principals insist, because they have a status set by the region, or by the county where you must get this score or you are on that critically low list or whatever. I don't know, I just, seems like everything is set up for the kids to fail. To me, that's what it seems like (32497/ 40 counselor).

The fact that the school's mission is articulated in terms of passing rates, results in standardized tests, and percentages of students going to college, is described by counselors as problematic, particularly for the large percentages of "non-college bound" students in the schools. Veteran counselors often noticed that the school lacked a clear mission when it came to the vast majority of its clients, the "average students."

What I am more concerned is with the use of stanines for example to deny access to an Honors class for a student who is motivated or who could be motivated. If a student has a 9 stanine and a high IQ and still doesn't want to do something, there is something there surely! And I understand the county's concern with trying to figure that out and not waste talent. But I mean the stanine by definition is a bell curve thing right? The percentile by definition... by definition the majority of the students are going to be in the middle because that's the way a percentile is calculated so...my biggest concern is with the ones in the middle. You know, what are we doing for them? What is being offered for these guys who are (in the middle)...? (0399/ 219 head counselor)

This uncertainty regarding the schools' mission in relation to those students not perceived as college bound is fundamental to understanding schools' organizational cultures. Some teachers noticed the shift in the school's mission from teaching to graduating, by noting how students are encouraged to take the easier courses, instead of wrestling with the learning process: 
There was a change in philosophy. It used to be that kids need to fail at their own level. Now, if you flunk Honors, you are placed in regular. Honors is coveted space. There are only two sections of AP class with more or less 50 students in each class. In $9^{\text {th }}$ grade, there are 3 sections in Honors, with about 75 students, and in 10th grade there are only 60 students in Honors (11098/639 department head).

The change in philosophy mentioned by the teacher, where Honors classes became "coveted space" did not necessarily result from an intentional strategy to prevent minorities and poorer students from enjoying equality of opportunity and guarantee social reproduction. In these schools, the change in philosophy referred to above makes sense in face of overcrowding and the need to ensure that the majority of students receive credit for each course in order to graduate in four years. Students who need to spend more than four years in the school further increase overcrowding. These practical constraints have an impact on tracking practices. Honors and Advanced Placement classes are limited to smaller sizes than regular classes. Overcrowded schools need to restrict access to these classes to keep them within the permitted numbers. In addition, the prevailing notion is that average students have more chances of succeeding in easier classes. Therefore, making sure that only "Honors students" take Honors classes, schools is seen as a way to prevent "regular students" from failing courses that are too hard for them.

\section{High School Mission as College or "Other"}

In addition to passing rates in standardized exams, other publicized measures of school success include the percentage of students going to college, the number of Advanced Placement exams taken and passing rates, and the amount of dollars awarded in college scholarships. Other measures used to make schools accountable to the district 
include attendance rates, dropout and truancy rates, frequency of violent incidents, and suspension and expulsion rates. These accountability measures have a stronger influence on the goals and strategies adopted by administrators than the stated mission or the organization. A questionnaire to be completed by students in May of their senior year illustrates the county's priorities:

One of the questions is "What kind of school do you plan to attend?"

The list of options includes:

State Junior College, Private Junior College

Four-year College, Public

Four-year College, Private

Trade School,

Military...

Option No. 9 is Other. Since there is no option for "work" counselors tell students to choose the "other" option if they are going to work. (52499/21-28 Fieldnotes).

It would be unfair however, to place responsibility for the "college or none" conception of high school's mission entirely on the educational system. In this case, the wider culture plays an important role, and the message from the wider society is quite clear that college is the preferred option. Doctors and lawyers in particular are portrayed nightly on TV shows as leading exciting lives and making hefty salaries. The college option is constantly reinforced as the highest rated option for high school graduates both inside the schools, in the majority of students' homes, and by the wider society.

Although these schools are called comprehensive and their mission statements (espoused values) describe providing students the "best possible educational opportunity," the operative mission (the manner in which the mission is articulated) states that college attendance is the only option associated with success. 
The analysis of the environment has shown that the four schools in the sample defined large parts of their student body as "not college material." Given that the operative mission of schools defines college attendance as the only acceptable option, we now need to examine the strategies that schools develop to deal with this operative mission, and what effects these strategies have on tracking practices.

\section{Strategy}

Questions addressed through the concept of strategy include which strategy is adopted, who defines the strategy, and what are the penalties for bad strategies. The organization's definition of environment, both external and internal, and the perceptions of the school's mission were features of the organizational culture of schools shared by the majority of people in the school. The strategy concept, however, requires us to look at strategies adopted by different groups in the schools. Although available strategies are limited by the organizational culture of the schools, and strategies adopted by one group affect all other groups in the organization, a strategy favored by one group, for example teachers, may interfere with the strategy favored by another group, such as counselors or administrators. Moreover, particular strategies may support or undermine the organizations stated mission.

Funding practices, an issue outside the control of the schools, emerged from the data as having a strong impact on the strategies available for leadership at the schools.

\section{Funding Policies and Strategies}

State and the County decisions do not appear to take into adequate consideration specific characteristics of schools. Funding is one example of how schools receiving large 
numbers of immigrant students, as was the case with the schools in this sample, are placed at a disadvantage when policies are designed with "normal" conditions in mind. School funding is based on the "October head count" and schools do not receive extra monies for students registering after that date. Schools that have a constant influx of students, many of them with special needs such as Limited English Proficiency or are coming from war torn countries where they have not been in school for extended periods, ${ }^{30}$ are clearly at a disadvantage.

Funding for summer school is an example of how the district establishes priorities in the use of resources. Each year the district informed the schools that funding for summer school would be limited. As a result, principals told counselors that only students who had failed a course and were missing credits would be able to enroll for summer courses. The funding strategy helped failing students who otherwise would need to stay in high school longer, while offering nothing to the average student. Even though later the county released extra funds for more summer courses, by that time many students did not get the information and did not register. This process happened yearly, for the three consecutive years of data collection in this project.

A different source of funding for summer school was available for "qualified" students who wanted to advance in math and science courses. Access for these "accelerated" programs was granted only to students who were already taking courses above grade level in math or science. Thus, funding practices ensure that students

${ }^{30}$ The county offers a program called New Beginnings, for students who have not been in school. Students can attend it for a limited amount of time and then are required to join the mainstream of high school students, something for which the majority of them are not ready. 
previously labeled as "college material,"-those taking classes defined as college preparatory-are not affected by lack of resources in the same way as "average students." Funding decisions made outside the school, therefore, support the maintenance of tracking. Moreover, if an "Honors student" wanted to "accelerate" during the summer, but the course requested would be offered only in the regular program (for repeaters), counselors recommended against it. The argument was that even though the course title might be the same, for example Algebra II, the course was not taught at the Honors level as would be the case in the accelerated program, and that would be detrimental for them in the future. The practice of letting students know that summer courses for repeaters would not provide them the required skills in the subject also ensured that even when students of different ability levels took the same course, they did so in different classes. This is yet another characteristic of tracked systems; students in different tracks do not meet in any of their classes (Lucas 1999).

\section{Vocational Programs}

Given that the stated mission of the schools includes providing either academic or vocational education, but the operative mission focuses on one option, college, as the findings have indicated, what are the strategies available for people in the schools concerning vocational education?

All comprehensive schools offer vocational programs, and the schools in this sample are no exception. All four offered some kind of vocational program. Information about these programs, however, is not "marketed" to students. The information provided in the Curriculum Bulletins mentions several programs without a clear explanation of the 
differences between them. When I asked guidance counselors, most were not able to explain the differences between many of the programs. Diversified cooperative training, On-the-Job-Training (OJT), Tech Prep and School to Work, Vocational and Cooperative Education, are all names of programs in the Curriculum Bulletins. While some of these programs (Tech-Prep) actually provide students with marketable skills without affecting their chances of attending college after graduation, others (OJT, School-to-work) simply allow students to receive credit for elective classes while earning some money at work.

Despite the general attitude of "college or none" emphasized by the county and the culture of the wider society, teachers in the Tech Prep programs are enthusiastic about the programs. Some of these programs are also selective; the Business program at Russell is selective in terms of students' grades (they had to be at least B's and C's), attendance, and behavior. I asked the lead teacher if they also considered standardized tests

No. Because we have found that a lot of what most people want to call your average student, when they get into something that they're really interested in, they, there is a big change, they can go from average to being the top. So, no we don't, it's there, it's part of the record, but it's not something that we look at and say, Well, we're not going to take this child because his stanine is only 3 , that is not true. Because there is not always a direct correlation between that and what they can actually do, and students with stanines 9 don't always perform, there's the motivation there (100198/22 Tech prep teacher).

This lead teacher reported that all students in the Tech-Prep programs had passed the latest State test, and many of the graduates had gone to good colleges. Tech-Prep teachers saw the potential in these programs to be part of a lifetime learning process, where the school mediates between a student and the job market, and then the student is free to follow their interest and motivation and pursue further education, in either college or other 
type of educational institution. These teachers strongly believed in the need for more

commitment and financial investment in these programs. Whether I formally elaborated the question or not, I heard the same comments from lead teachers:

Q: So you needed more vocational teachers and classes, you would say?...

A: If you consider the size of this school and the number of students that are here...yes. And there is enough to go around for everybody.

Another lead teacher initiated the subject without any prompting

Dora! This school, we need more vocational classes. I hope I am not saying something... We have lost vocational classes in the school and one reason is because of "Harris" Tech, which is down the street, which is all vocational. So what that has done is taken some of our classes away from us and taken them down there. But we need more vocational classes, because these students need to learn something while they are in school so when they get out, cause they are not all going to be college-bound. They are not all college bound a lot of them. (...) Because a lot of students want to stay here with their friends in the school and not be transported to (the Technical Schools in the area). They would rather be here. We used to have an automotive shop, a great automotive shop here. Students could leave that and really have a skill as far being a mechanic. That's been taken out $(061099 / 215$ Tech-Prep lead teacher).

Tech-Prep teachers and Lead teachers, however, were almost alone in marketing their programs for students. Regarding principals, the system does not enforce any types of reward for supporting vocational programs for students, nor seems to be interested in making lack of support for such programs a problem. Thus, principals' priorities are dominated by achievement in standardized tests, critically low performing lists, the achievement of college-bound students, and other non-academic activities that also are rewarded within the system such as sports, band competitions. One principal described how 
his priorities had been affected since moving from the middle school to the high school

principalship:

One of the things that's happened, and it's been a learning process for me, is that the large amount that I spent with the curriculum process at the middle school, I just don't have the time. I try to do that, and I find that's burning me out. There is so much to do. You just don't have the time, with the athletics, and sports, and clubs, and people work, and meetings (112796/33).

The main reason why most guidance counselors do not actively "market" vocational programs to students is that anything that is perceived as "not college" tends to be rejected by students and parents alike. Most counselors feel that merely suggesting a vocational program is a risky proposition.

I can sit here and counsel kids and say, "Look. You only have a 2.0..." And I have done that, but I have to get to know the kid first. If I have a student that I have somehow gotten a good rapport with, if the student has maybe a $\mathrm{C}$ or less than a $\mathrm{C}$ average and has aspirations of going to college, yes, I can say to that student, "Look honey, why don't you try first of all going to a vocational training school. We have many at the secondary, post-secondary level. There are some that even give financial aid. Why don't you try because it doesn't mean that you will never get to college but it means that you have to make a stop first." I could do that. But how many students do you think would accept that? These kids have illusions of grandeur. It's hard to say that: "Look. You are not prepared." So, for that reason we have many students who get all the way up to grade 12 and drop out. Because it is by that time that they realize they have not...It dawns on them: "I am not going to be able to go to college so I am just going to drop out." They don't look at it from the perspective that maybe I can't go to college but I can do something else. (031099/95)

Counselors are afraid of being misinterpreted if they suggest a vocational program.

They fear being accused of telling students "there are things they cannot do." In an organizational culture dominated by the "college or none" philosophy, where students are not formally tracked, it is politically incorrect to tell a student to consider an option other 
than college, even when this option might actually be in the best interest of the student at that point in time.

Everybody wants to be a pediatrician. They all believe that if you want it hard enough it will happen. It is not politically correct to point out the difficulties in the way. It is easier to say "fine." $(0197 /)$

Some counselors considered the existence of open enrollment in the community college as detrimental for students, since it created an illusion that the student is in college when in fact, counselors have seen many of them spend their limited financial aid resources in remedial courses that could have been completed in high school

You see, how am I going to motivate you to go to college, when no matter what grades you get in high school, no matter what you know, you can still go. The only difference is, is you'll be in a remedial class, which is not earning credit and not be in a real class, But you try to tell these kids a remedial class doesn't mean nothing, "but we're still going to college." So the goal is to what? Go to college? They're going. But they're not getting any credit (32097/38).

The problem, according to the counselor, is that students do not opt for a vocational program that can give them marketable skills, because they believe they are going to college. At the same time, students do not see the need to put more effort and take harder courses in high school, because they know they will get into the community college regardless of the type of courses they take and even regardless of the grades they get, as long as they graduate. In this way, the "college or none" philosophy hurts both those students who actually go into the community college without the necessary skills to succeed, and then has to pay tuition to get these skills, as well as those students who do not go to college, and did not receive vocational training in high school. 
Parents ask: "Why is my child being trained to work in an office?" Unrealistic. You can call it I am being unrealistic, illusions of grandeur-anything, but this is what happens. It's a counselor and the people who work closely with the parents and the students who know this. In other words if you see a kid, if I had to do it all over

again, I would start out in elementary school cause I really feel that I could have made probably a much bigger difference at the elementary school level. These kids need...in other words, you don't want to project a child's life but they need goal setting very early on in life. And children need to be told, cause if you ask, " What you want to be?" "I am going to be a fireman. I want to be this. I want to be a lawyer. I want to be a doctor." Then they should start working with children from that perspective very early on in life. You know they need science and math (0399/117 head counselor).

The comment of this veteran counselor points to a very important element in the maintenance of tracking practices in the schools: The availability of information regarding career planning, and the need to ensure that information is offered early on in the student's academic career. The counselor goes even further than middle school, asserting that if she had to "do it all over," she would become a counselor in elementary school.

\section{Information}

The concept of information led to questions such as: What constitutes information in the school? Who has access to what kinds of information? How is information disseminated? In the particular case of tracking practices, information emerged as a crucial category.

\section{Physical Access to Information}

Regarding the Student Services offices, the location, and accessibility of the guidance counselors' offices to students and parents is symbolic of how the school culture 
defines these services. At Franklin, the guidance counselors' area is close to the main office. A tall counter separates a long, narrow waiting area from an open central space occupied by several secretaries and student office aids. Doors to the offices of the five counselors and two assistant principals for discipline line the walls of this central area. A few chairs lined up against the wall in the waiting area provide parents and students a place to sit while waiting to be called in by the counselor or assistant principal. Students standing at a counselor's door are generally told to go back to the waiting area or to class if they don't have an appointment. The CAP advisor's office is close by, between the waiting area and the entrance to the entire Student Services department, while the TRUST counselor's office is in a completely remote area of the building, inside the library.

Darwin and Lincoln's students services areas present similar physical arrangements, with an entrance door leading to a small waiting area with some chairs and a small counter. Counselor's offices are located past the counter. At Lincoln, the general area of students' services contained the offices of one Assistant Principal, the registrar, five guidance counselors, the TRUST counselor, the CAP advisor, and the Occupational Placement Specialist. The area includes a small lunchroom where several of the counselors usually ate together. I was invited to join them at lunch several times, which I did. The lunchroom is also used for meetings with college representatives.

At Darwin High, the student services area contains the offices of all eight guidance counselors, the CAP advisor, and the lead teacher of the Engineering Magnet Program. The area includes a conference room used for meetings with college representatives (the "rep") with a small refridgerator and microwave. While this area is much larger than the one in Lincoln, counselors at Darwin do not eat lunch together, usually going out of the school or 
eating in their own offices. Secretaries at the entrance in both sites exercise little or no control over students' access to counselor's offices, even though at Darwin High there is another door between the waiting room and the secretaries' area behind a small counter that was controlled electronically. Students working as student aids in the secretaries' areas would always press the button that opened the door for other students. Parents waiting to see counselors are the only people who are left to use the waiting room. Nevertheless, while I witnessed a few incidents of parents complaining that they had spent long periods waiting to be seen at Franklin - and indeed, a few times I witnessed parents waiting for more than an hour-such incidents did not seem to occur at Darwin High.

Russell is the exception to the physical arrangement of the three other schools, since it does not have enough space to have all of its counselors in the same area. Thus, the College Advisor's office is located close to the main office area, while the four guidance counselors in the school occupied similarly located areas in two floors. Two guidance counselors occupy offices on one floor, adjacent to the offices of the Head of the Special Education Program/Testing Chairperson, while the other two guidance counselors' offices share an area with the offices of the TRUST counselor and the Migrant Student Advisor, a job that only Russell High has, due to its semi-rural location.

In sum, the physical plant of the school interacts with elements of the school culture, in this case, the degree of openness of the students services' staff, to determine the level of access students have to counseling in each school. While Russell had the least favorable physical arrangement, with counselors spread throughout the building, guidance counselors at the school tended to be more accessible than at Franklin, where counselors were the least accessible. Although all schools had policies requiring appointments to see 
the counselors, only Franklin actually enforced them regularly. This was due to a combination of the physical plan with the availability of secretaries in the area who made a point of enforcing these rules and counselors who complained when the rule was not enforced. Russell's counselors enforced the appointment rule only when there were secretaries available in the reception area, which seldom happened. When it was possible, the rule was enforced. At Lincoln, guidance counselors had very little clerical help to exercise control regarding access to the counselors' offices, so that the existence of a physical plan that would enable access control did not matter. In addition, counselors were not concerned with the rule concerning requests for appointments. In fact, I never even saw a request form at Lincoln High. Darwin High, on the other hand, had both the physical plant and the clerical help that would allow for access control, and had the requests printed, but rarely enforced the rule. Counselors at Darwin did not complain to the secretaries when several students came into their offices at once, or lined at their doors. At Darwin, this was accepted as the nature of things.

Despite these differences in the physical environment and how it interacted with each individual school's definition of how much access students should have to counselors, in general the size of counselors' caseloads in all the schools severely limited the quantity and quality of counseling available to students in all four sites.

\section{Subject Selection Procedures}

The list of requirements for graduation is easily accessible in high schools. The list, with its 24 credits and how they are divided, passing the HSCT, the hours of community service, is a ubiquitous presence in all four schools. It hangs from wall in hallways, is in 
most counselors' offices, and is in the Curriculum Bulletin. On the other hand, information that is important for acceptance to the more competitive colleges is selectively distributed. During an "articulation" meeting with $9^{\text {th }}$ grade students in the Honors gifted English class at Darwin, for example, the counselor started very formally by informing students: "You are about to embark in a totally new high school agenda." Ms. S. told them that in tenth grade they would need to take English II Honors Gifted, leading the teacher reminded her these are "gifted kids," implying that "they know that." Ms. S. proceeded to tell the students:

I am assuming all of you already have three math credits. You should take as many math, language arts, social studies electives as they can possibly take. If you are college bound, you need to take the more academic electives. For scholarships, you need to take Honors and A.P. classes, if you can do that. The more science electives you have, the better equipped you are. (...) Elective classes considered academic in nature include: Psychology, Sociology, Literature, and Social Studies (...) The State University System will accept academic electives with A's to substitute for a core class with a C. You need to boost your GPA with academic electives; colleges and universities use 15 subjects to calculate the GPA. How many of you want to take a four-year college? If you are college bound, you need academic electives, don't take a bunch of junk. Don't go around telling the electives teachers I told you not to take electives, but if you are college bound, you need to take academic electives (030999/ 16).

Subject selection is a mass production process in all four schools in the sample.

Students receive information about available courses for the coming school year in their classrooms during English period, since this is one class where the school knows that all students in the class belong in the same grade level. (District policy requires students to enroll in English class according to their grade level. If the student failed English in the previous year, the student is required to make up the missing credit at summer or night 
school, but takes the English class with grade peers. Most other classes in a high school include students from different grades.) In schools where students are assigned to counselors by grade level, students have a greater chance of receiving information from their own guidance counselor. In school as large as Darwin, two counselors are assigned by grade level, reducing in half the chance of receiving information from the student's assigned counselor. Where students are assigned to guidance counselors by alphabetical order, as was the case in the three other schools in this sample, it becomes impossible to attempt any type articulation meeting with one's own counselees. In these schools, students only meet with their assigned counselors if they come to the counselor's office, since the probability that a student's assigned counselor will do the articulation meeting in that student's class is random.

Students receive the Curriculum Bulletin and the subject selection sheet, and have a few days to collect teachers' signatures for classes where a teacher recommendation is necessary (any Honors, gifted, Advanced Placement class). With the exception of Franklin High, where the cards were handed in the cafeteria, students need to take the completed card to the counselor's office. In general, students have very little time to discuss their selection with the counselor, and this is normally done with several students around waiting to hand in their cards. Although the Curriculum Bulletin in all four schools mentions the importance of parental input, in reality it is not considered an important factor in the decision-making process for the majority of students.

District policy establishes that parents have the right to override the teacher's recommendation regarding placement. None of the Curriculum Bulletins examined contained this information. Neither was it mentioned during the meetings counselors had 
with students. The only way a parent would find out about this right would be by directly asking the question. Parents who know about this right and consider the possibility are informed of the policy stating that when parents override the school's placement recommendation, the student is not allowed to transfer out of that course.

Information on subject selection issues tended to be confusing. After a counselors' meeting in preparation for subject selection, to be held the following week at the cafeteria at Franklin, the head counselor asked the counselors: "Are you confused enough already?" and everybody laughed. On the following week, however, when students filled an extremely cold cafeteria with their subject selection cards in hand, the behavior of the counselors implied that everything is simple and obvious. It is the students' fault that they could not understand instructions.

The students sat at the long cafeteria tables, two or three classes at a time. They would ask questions of any adult passing by. When they were ready, they would go to the line in front of their counselor-counselors at Franklin were assigned according to the alphabetical order of students' last name-and stand in line until their turn. That meant that each student had a few minutes alone with the counselor at a point in time when the counselor already expected the student to have made up his or her mind, and also that the student always had a few other students standing closely behind them in the line, waiting for their turn. (Fieldnotes, Franklin 397).

In the case of subject selection, there are huge discrepancies between what schools say they do and what they do. Curriculum bulletins and principals always mention career planning and guidance. A conversation with Nelly, a Black student who in November had been accepted to one of the top universities in the State, was prompted by the CAP advisor telling us about a phone call she had just gotten from a student. The caller, apparently inspired by a TV serial whose protagonist is a freshman at NYU ("Felicity") had decided 
she wanted to apply to that school. The counselor talked about her surprise at the student's lack of understanding of the competitiveness and the entire application process, and I used this as an opportunity to ask Nelly about her sources of information.

I asked her how did she know that she had to apply early. How did she know that she had to have high SAT's and a high GPA? And she said, "Well from my parents who are both professionals." Her mother has just graduated with an MBA while working fulltime.(...). I asked Nelly if the information was there in school. She said, "Well you know when we were freshmen the CAP advisor came in and the counselors told us what we needed for graduation," but they don't really give the details...the specifics of how much SAT you want. She said she knew that she had to apply early because her SAT's weren't so good but her GPA was high and they balanced each other out, but she knew that if she left it to the end and there was a lot more competition it would be harder. So she said she knew from the beginning and she applied very early. The counselor then added that on the first day of school, even before school started, there were a bunch of kids knocking on her door and that these were definitely the top students in the school. "These guys who already know what they want and know where they were going" (32599/7-10).

In practice, even the principals admit that there is no time for any serious counseling, and counselors mostly "push paperwork." The issue of disagreement over definitions of the guidance counselor's role is related to the issue of student access to information. When a principal does not see the role of the counselor as one that involves providing effective guidance, counselors find themselves in a position where they have very few resources - time being the main resource lacking - to offer students.

Counselors' caseloads are too large -500 to 700 students in each of the schools-to enable time for building meaningful relationship with the majority of their counselees. Veteran counselors are more aware of the change in their role definition, noting at one point or another that "we used to be able to do real counseling." Although the complaints 
are similar in all schools, it was more clearly elaborated at Russell. The principal at Russell had no problems in admitting that the guidance counselor's job in the high school is mostly to do scheduling:

most of the time they do paper work, for the most part they don't do counseling, paperwork, subject selection, registration, by the time, middle of the year, you know, we start subject selection for next year, and continuous, you know, getting kids credits for graduation. That's basically what they do. The whole idea of a counselor is a misnomer, they don't counsel.

Although in the interview this principal said the county allocates one counselor for every 435 students, the school actually had four guidance counselors for over 2400 students, reaching a caseload of approximately 600 students per counselor. During a student services' staff meeting later that year, counselors complained bitterly about the fact that this principal had "cashed in" the position-meaning the money went to his discretionary fund and is used for something else —of a fifth counselor who had retired, therefore increasing the caseloads of the remaining counselors. Counselors disagreed with the principal's priorities, which was noticeable in the way he allocated funds and other resources (e.g. space, his own time) in the school. As mentioned before, this principal had said that the hardest thing for him when transitioning from middle school to a high school had been to back off from curricular issues. "The athletics, sports, the clubs," all required time and resources.

The limited information available and the lack of support of the role of guidance counselor negatively affected students who did not have access to information on educational options and the importance of subject selection outside of the school. Students 
with cultural capital had access to this information from their college educated parents or other family members, and thus the strategy did not impact them to the same extent.

\section{Overview of Findings}

What are the elements of the organizational culture of these four schools that supported the maintenance of tracking practices despite an official commitment of the school system to not track students?

\section{The Centrality of the Concept of Ability}

Using Schein's (1992) distinction between espoused values and basic assumptions, the organizational culture of schools contains contradictions between espoused values and practices that are based on unspoken, but deeply held basic assumptions. The analysis of the school documents shows that schools espouse values such as excellence and equal opportunity. Placement practices, however, are based on unspoken basic assumptions that conceive "ability" as a fixed measure of intellectual capacity. This unspoken assumption restricts access to higher-level courses to students who have already been defined as "high" through their previous placement and achievement. It is this operative but unspoken assumption about ability that legitimizes the maintenance of tracking practices that reinforce differential educational attainment by social class and ethnicity in a system that does not formally track students.

Overcrowding, Resource Distribution, and Differential Access to Information

Overcrowding has important ramifications for the organizational culture of schools. Schools functioning over capacity tend to adopt strategies that further contradict their 
espoused values: Student Services personnel are supposed to provide students with personal, academic, and career counseling. Average caseloads of 600 students, however, tend to limit most contact between counselors and students to scheduling issues. Consequently, it is natural that students in the extremes of the achievement distribution have a better chance of receiving personal attention. In overcrowded schools, time with counselors is a scarce resource, and the lack of time for counseling restricts students' access to information.

Access to information was found to be a key element in the maintenance of tracking practice, particularly for schools with high percentages of students with lower socioeconomic status or recent immigrants. The home environment of these students often is unable to provide the information needed to make decisions with long-term implications, making them more dependent than other students on the information provided by the school. By restricting access to information, overcrowding differentially affects students from different social backgrounds, with a negative effect on the placement of lower status or immigrant students. Students from lower socio-economic backgrounds and recent immigrants lack reliable sources of information on the importance of course placement, which starts already in middle school. For these students, the absence of formal tracks might be detrimental, because they lack the information that would allow them to understand that course placement decisions made by the school reduce their ability to compete for the more selective colleges.

Despite the fact that schools in the sample differed somewhat, the data indicates that these schools shared many important characteristics. In all four schools, overcrowding combined with an educational system that frequently changes graduation requirements and 
with a perception that the majority of the student body has "low ability." This combination resulted in a tendency to steer students towards less demanding courses. While Darwin High's principal contributed some variation to this pervasive tendency, the criticism directed at the policy underscores the similarity of the mechanisms supporting the maintenance of tracking practices across schools.

In the absence of formal tracks, and in an environment (both inside and outside of schools) that defines college as the only measure of success, the mission of the high school is defined as helping high achieving students to get to college, and making sure the other students graduate from high school. These characteristics of the organizational cultures of schools mentioned until this point are shared by the majority of people in the schools. These elements of the culture can be understood as coming from an integrated perspective. Not all elements of school culture were so widely shared across groups in the schools, and a different perspective is required in order to expose these differentiated elements (Martin 1992).

The differentiated perspective provides a better understanding of the different strategies adopted by people with different roles in the schools. Despite the fact that schools espoused career and personal counseling as a stated value, schools were either financially unable or unwilling - a distinction the available data does not allow me to make- to commit the necessary resources to increase students' access to counseling. This contradiction between espoused values and practice was a source of frustration and skepticism on the part of the counselors. Guidance counselors' caseloads prevented them from providing the individual counseling they felt was needed, particularly because the population in these schools was defined as especially "needy." The large percentages of 
minority students and their lower socio-economic background contributed to counselor's perceptions that the needs of the student body were above average. From the perspective of many of the counselors, the difficulties faced by some of their students in their daily lives, "whether there is going to be a roof over their heads, or where they are going to have their next meal" (page 93) made concerns about the effects of taking regular versus "Honors" level courses seem unimportant.

In this context, the differentiated perspective allows us to understand the priority given to graduating and receiving a high school diploma, and the resulting strategy of selecting less demanding courses for most students. The strategy adopted, however, results in a strengthening of tracking tendencies in the schools.

\section{The Influence of the External Environment:}

The measures of accountability imposed by the county on the schools led principals to focus on getting schools out and keeping them off the critically low performing lists. These measures of school effectiveness determined by the State and district established priorities for the leadership that ran against one of the school's espoused values: Preparing students for the world of work. Neither the wider culture nor the district's measures of school effectiveness prioritize vocational education. The wider culture in fact delegitimizes vocational educational, and this affects the school through both parents and students. As a result, fewer resources are invested to improve the quality of these programs. For those students who overcame social pressure against enrolling in a vocational program, the small number of places available in the few programs that truly trained students for skilled jobs made these programs selective, and not all students could be accepted (page 
110-11). Given the maintenance of tracking practices in the schools and the restricted number of places in the few desirable vocational programs, most students attending these schools in fact have three "track" options available:

1. The college prep track: Students are placed in mostly college preparatory classes, and select academic electives, as emphasized by Ms. S. (page 118)

2. The regular track: Students are placed in regular classes that lead to a high school diploma. Graduates leave high school unprepared for college and with no vocational skill.

3. Students realize they will not be able to go to college and drop out during $12^{\text {th }}$ grade (page 112 ).

\section{Summary}

The analysis of the data indicates that often times a combination of practical organizational imperatives with deeply ingrained underlying assumptions determines the strategy to be adopted by people in the schools. Mission statements (espoused values) have little influence on day-to-day activities of these schools. Organizational imperatives and basic assumptions combine to create situations where the strategies actually violate some of the stated values of the organization.

Findings point to the existence of deep-seated beliefs prevalent in the wider society and in schools regarding ability as fixed. Other findings indicate the existence of operational definitions of school success: graduation rates, passing rates in competency tests, scores in standardized tests, numbers of college-bound students, college scholarship monies offered to students, and success in athletic and other non-academic competitions. 
Operational definitions of school failure also impact schools such as absenteeism, suspension and expulsion rates, and the incidence of violence. These operational definitions of success and failure bear little resemblance to the espoused values of the schools and the school system, as suggested by the content analysis of school documents.

When combined with basic assumptions about ability and prevalent perceptions regarding the levels of the majority of students, these operational definitions determine most of the strategies adopted in the schools. These strategies tend to support the maintenance of tracking practices in the schools, because steering students towards easier classes is seen as a way to guarantee that students will receive credit for the courses they take and graduate. Only students with proven records of high achievement are steered towards the more demanding courses. 


\section{CONCLUSION}

After the "Unremarked Revolution": Organizational Culture

and the Maintenance of Tracking

\section{Indicators of the Maintenance of Tracking}

Despite the county's assertions that there are no tracks in its comprehensive schools, students are in fact being tracked. The language used in the schools expresses the available tracks: College-bound students are A students or Honors students, regular students are those who are able to go to the local community college or to some other postsecondary training. Finally, at-risk students - those who do not drop out, or, in McDermott's words, are not pushed out (1987)—can go to vocational schools—but not the Tech Prep programs, since these require good attendance records (page 110), something that students at-risk lack-and work-study programs.

The de facto elimination of tracking should imply two possibilities (Lucas 1999):

1. Mobility in class levels: Students should be able to change class levels if their achievement or motivation changes.

2. Discrepant class levels: Students should be able to occupy discrepant places in different subjects according to their motivation and ability for each subject. Placement in each subject should be independent of performance in other subjects. 
According to these definitions, the schools in this sample have maintained tracking practices. High schools tended to place students in classes at the same level, as shown by the subject selection cards of the incoming $9^{\text {th }}$ graders at Franklin High (page 98).

\section{Emic and Etic Perspectives on the Use of the Concept of "Ability"}

From an emic (insider, or "native") perspective, students are encouraged to take classes where they can be successful, receive the credit, and graduate. This emic perspective results from a combination of overcrowding, which converts smaller classes into a scarce resource, with basic assumptions that regard ability as a fixed characteristic of each individual student. When the priority is passing the course, receiving the credit, and graduating, and not the learning process, average or low "ability" (as demonstrated by academic achievement or in "ability" tests, the results of which are available to guidance counselors) are legitimate reasons to avoid challenging courses that increase the risk of failure.

From an etic (outsider) perspective, the concept of "ability" is understood (though not formally defined) as rigidly determining what students are and are not able to learn and achieve academically. The use of the concept of ability in these schools matches Gould's (1996) description of Alfred Binet's worse fears:

Alfred Binet, the French inventor, not only avoided a hereditarian interpretation of his test, but explicitly (and fervently) warned against such a reading as a perversion of his desire to use the tests for identifying children who needed special help. (Binet argued that an innatist interpretation would only stigmatize children as unteachable, thus producing the opposite of his intent - a fear entirely and tragically justified by later history.) (Gould 1996:29). 
The use of the concept of ability in these schools, although not specifically an "innatist" interpretation, is an interpretation that stigmatizes students defined as "low" as unteachable, because it defines ability as fixed. Regardless of whether heredity or environment are blamed for the low level of ability, Binet's fears of the misuse of ability tests appear to have materialized in these schools. While Binet developed an entire program to improve the learning ability of students who scored low in his tests, remedial education in America consists of teaching less material at a slower pace.

"Ability," which in its everyday use becomes synonymous with previous or demonstrated achievement, is then used to discourage students from both attempting more challenging courses and from occupying discrepant places in the different subjects. Lack of math skills is used to prevent students from enrolling in higher-level science courses, as in Franklin High. The sequential nature of the more prestigious science and math courses precludes upward mobility for most students who were not placed in accelerated programs in middle school. Furthermore, when upward mobility in course level is possible (in Language Arts, and sometimes Social Studies), it tends to be discouraged, as illustrated by the incident with Ms. Waters, Jessica, and the Honors English teacher (page 129).

\section{The Unifying Role of Comprehensive Schools}

The maintenance of tracking practices and the avoidance of discrepant placements by the schools prevents the majority of students from socializing with students who take classes at different levels. Consequently, Wraga's (1999) ideal of the unifying function of comprehensive school does not occur in these schools: Students attending the same school actually have very different experiences and socialization. Regular students in the school 
encounter larger classes and are defined a priori as "non college material." Students in the Honors and Advanced Placement classes receive more attention, and usually smaller classes. Society's expectation of comprehensive high schools, that the heterogeneity of the student body would lead students from different environment to know each other better (Conant 1967) is undermined by the maintenance of de facto tracking.

\section{The Stigmatization of Vocational Education}

The widespread - and justified - criticism of tracking practices that led to the "unremarked revolution" (Lucas 1999) also resulted in a process of stigmatization of vocational education (page 112). Although vocational classes are available, these comprehensive schools offer few vocational programs (page 111). In such an environment, suggesting programs that offer real skills is perceived as insulting to the student, and risky to the counselor. As one counselor said, she would only suggest such a program if she had already established rapport with that student. In overcrowded schools, too many students never really establish rapport with their counselors. An additional reason why students do not receive "first-class vocational education" (Conant 1967:4) is that these programs have limited capacity. Despite the success achieved by some of these programs, as reported in the interviews with Tech-Prep lead teachers at both Darwin High and Russell High (page 110), principals do not support their growth, usually claiming that the school lacks the physical space and funds to hire more teachers to increase program capacity. The reward system established by district and State policies determines priorities that undermine one of the official missions (i.e.: espoused value) of comprehensive schools, namely, providing preparation for the world of work to students who are not ready to go to college. 


\section{The Role of Information}

Observations of the process of subject selection in the high school support the idea (Lucas 1999) that access to information is a key category in the new "transparent" track system. The signposts that indicate the career expectations for students were not present in these schools. Students who do not receive the kind of information provided by Ms. S. to the "gifted honors" freshman (page 118) and do not have access to this information at home, do not find out that colleges value "academic" electives until it is already too late. The data in this dissertation supports Lucas' (1999) hypothesis that access to information became a key issue after the "unremarked revolution."

Why is information so selectively distributed? Social reproduction theory would argue that this is how the system works to keep the dominant class in power. Organizational theory provides a different, less conspiratorial, insight. The belief in ability as a fixed trait (Erickson 1987, Tye 2000) accounts, at least in part, for the scarcity of information available regarding the importance of class placement and subject selection. Telling students about the importance of taking courses where they, by definition, "do not belong" and are perceived as not having the ability to succeed would be a waste of time. Therefore, the information is not given to those students. Furthermore, counselors who try to convince students they think are capable to try harder courses find out that if the teacher disagrees with their assessment, they will need to change the class assignment, as was the case with Ms. Waters and Jessica. For counselors are busy with large caseloads and population with needs perceived as greater than those of the mainstream the idea of additional schedule changes can act as a deterrent. 
Within the organizational culture of these schools, the top of the list of counselors' priorities is occupied by "making sure all students have what they need to graduate in time." The available strategy is to take the path of least resistance. The emic perspective is that counselors help students achieve their goal, and this goal is defined as graduation from high school. From an etic perspective, however, the result is that the vast majority of students do not receive enough information regarding what colleges are looking for, until it is already too late. Adequate information of what is needed to be successful in college, or in the workforce, is absent for the most part. Although many students graduate from high school without the level of knowledge to be successful in college, and without the skills that would enable them to find employment, the discourse in the schools states that "the opportunity was there."

The findings support Lucas' (1999) suggestion that the removal of the formal signposts of school tracks has actually left students from non-dominant groups in a worse position. When students were formally assigned to tracks, they knew what the result would be (vocational or academic preparation), and they could question the assignment. Although they may have lacked the power to change the assignment, there was a clear notion of "who is doing what to whom." In the new system, the result of subject selection is not clear. Two elements make the results of subject selection far from obvious: 1) students allegedly have choices in each course, and not a program, as was the case with formally tracked schools, and 2) students can always feel that the community college option is open. In theory, the community college is always available. In practice, unprepared students are accepted in the community colleges, but many spend their financial aid in remedial courses without ever receiving a degree (page 113). 
From the point of view of the majority of students and their parents, the hegemonic discourse, in truly Gramscian fashion, legitimizes social reproduction and places responsibility squarely on the shoulders of the students. The emphasis placed on college and the stigmatization of vocational educational stand in the way of the formation of a class identity by those who chose to attend these programs.

\section{$\underline{\text { School Mission }}$}

Findings suggest that the elimination of formal tracks and the maintenance of $d e$ facto tracking may negatively impact schools serving predominantly minority populations such as those in this sample. Due to the stigmatization of vocational education and the emphasis on college, a comprehensive high school serving large numbers of students of working class or minority background who may not be college-bound finds itself an organization without a mission. The literature on organizational culture establishes that goals and purposes are defining characteristics of organizations (Shafritz and Ott 1987). The literature on schools asserts it is quite normal for educational organizations to "lack consensus on describing the desired product," and that schools have problems in specifying desired outcomes (Cuban 1995:6).

One problem caused by this lack of mission is illustrated by the disparaging comments regarding educating "the future housemaids." The comment is considered unacceptable by some, but it represents the perceptions of one subgroup of school professionals regarding the mission of the organization. In this case, the organization's lack of clear mission for a large number of its students underlies much of the 'non-teaching' that goes on in the schools that sets counselors and students against teachers (page 101-2). 
The Focus on College and the Organizational Culture of Schools

This finding can also be understood as a manifestation of the separation of spheres (Hurst 1991). The administrator's function of controlling the body of the student remains relatively unchanged, regardless of the mission of education. Whether the student plans to attend college or dropout, the administrator's obligation is to make sure the student is at the right place on the right time, dressed appropriately. The counselor's role, although not addressed in Hurst's model, can be accommodated by the fact that the counselor needs to ensure the students do all that is required to graduate, and may even be able to provide some personal guidance with pressing personal problems, as many counselors did. The teacher, responsible for educating the mind but not the spirit, is left without a role if the organization defines the mission in terms of college or failure. In schools where the percentage of students going to college is estimated at 15 to 20 percent, such as these, the teacher's role is the most affected by the college or none strategy adopted by schools.

Theoretical Implications:

Social Reproduction or Social Mobility

Saha's (1987) theory regarding the relationship between social mobility and social reproduction can be applied to explain the findings from this study. The existence of the social mobility model in fact allows for the maintenance of social reproduction. The mobility option is selectively made available to a few members of the non-hegemonic group; because of this, it is possible to maintain a discourse where individuals are responsible for their own success or failure, regardless of whether the opportunity for each particular individual existed in reality. The fact that social mobility is an option offered 
only for those perceived as having "ability," and that the definition of ability used is rigid and culture bound is never mentioned.

The Effects of Tracking: Unequal Selectedness and Meritocracy

The schools in the sample illustrated well the workings of Bourdieu's concept of "unequal selectedness." The social mobility option is only available to some minority students. They are those who demonstrated high ability, through achievement in standardized tests- - tests that are known for being biased against minorities (Gould 1996) - as well as their motivation and persistence, through perfect attendance and good behavior. These are, without a shred of doubt, the modern equivalents of "best genius and superior parts" (Conant 1963). Many of the counselor's descriptions of their "success stories," stories of students who managed to be high achievers despite the odds against them, showed that these students are indeed gifted in more than one way.

\section{Educational Policy and School Change}

Wilcox (1988) notes that it would be unreasonable to expect schools to be places disconnected from the wider society of which they are an integral part. That does not need to be construed as an indictment of schools, a condemnation to the eternal role of agents of social reproduction. The majority of the people I met while working in this project truly care for students. The strategies available to them, however, are limited by the characteristics of the system, particularly overcrowding and lack of resources. Radical critical pedagogy theorists, such as McLaren (1995), have suggested that teachers need to actively engage in the transformation of schools into agents of social change that will work against global capitalism. McLaren's approach suggests that through a process of 
"conscientização," people placed in charge of socializing children will collectively engage in the radical transformation of the institutions that employ them and of the society of which they are members. Such expectation seems unrealistic from the perspective of educational anthropologists, a perspective that understands education as part of a process of socializing children to adult life done by every society, whether in the form of an educational institution or not (Spindler 1955; 1988; Wilcox 1988). In other words, it is unrealistic to expect people who are the products of a stratified society to socialize students to an egalitarian society.

Smircich' (1983) distinguishes between the deeper definition of culture that sees organizations as cultures, and the more superficial definition of culture as something organizations have. Her perspective suggests that school cultures can and often do change at the more superficial level of espoused values and reward structures. From this perspective, educational policy has the potential to change the priorities of schools, since it has control over the measures used in the evaluation of school effectiveness. Educational policy has control over the definition of successful education outcomes. As long as this outcome continues to be defined in percentages of college-bound students, passing rates in standardized tests, school practices will follow that definition. These practices, according to Binder (2000), can be changed if policies establish different outcome definitions. Whether it is possible to change school cultures at the level of their basic underlying assumptions about ability is a different question. Assumptions concerning "ability" seem to be part of the sacred norms of schools (Corbett, Firestone and Rossman 1987), those norms that are the hardest to change. 
Research on resistance to detracking shows that teachers perceive these efforts as changing the distribution of power in the schools (Datnow 1997; Finley 1984). In the case of Darwin High, the principal's decision to "bump up" students in fact took away some of the control teachers and counselors had over student placement, by automatically enrolling students who did well in a higher-level class for the following year. Although the change is much smaller than detracking, it still generated a negative reaction. While the strategy worked to some extent in that particular school, it is quite clear that not all principals would be in a similar position to implement such a policy without generating too much resistance in the organization.

The analysis of the organizational culture of these schools shows that an understanding of schools' everyday life is only possible if it includes serious consideration of the role of concepts such as Honors, college-material, "high" (ability), and their less desirable opposites Regular, Remedial, not college-material, and "low." Despite the elimination of formal tracks and the denial of tracking, tracking practices continue to play a central role in the organizational culture of these schools. Underneath the maintenance of tracking practices is a narrow and practically uncontested definition of ability. In addition to this deeply ingrained assumption regarding ability, two organizational factors help maintain tracking practices: 1) limited resources, resulting in limited access to counselors and information, and 2) organizational goals that stress efficiency (graduation), leading to the perception that schools cannot afford the risk of challenging students academically. The elimination of de-facto tracking and of its negative effects on access to equal opportunity depend on the ability of educational policy to address these organizational imperatives and underlying assumptions which enable the maintenance of tracking in American schools. 
Achor, Shirley, and Aida Morales. 1990. "Chicanas Holding Doctoral Degrees: Social Reproduction and Cultural Ecological Approaches." Anthropology and Education Quarterly 21:269-285.

Alexander, K., M. Cook, and E. McDill. 1978. "Curriculum Tracking and Educational Stratification." American Sociological Review 43:47-66.

Apple, Michael W. 1996. Cultural Politics and Education. New York, N.Y.: Teachers College Press.

Apple, Michael W., and Lois Weis. 1983. "Ideology and Practice in Schooling: A Political and Conceptual Introduction." Pp. 3-34 in Ideology and Practice in Schooling, edited by Michael W. Apple and Lois Weis. Philadelphia: Temple University Press.

-. 1986. "Seeing Education Relationally: The Stratification of Culture and People in the Sociology of School Knowledge." Journal of Education 168:7-34.

Argyris, C., and D.A. Schon. 1974. Theory in Practice: Increasing Professional Effectiveness. San Francisco, CA: Jossey-Bass.

-. 1978. Organizational Learning. Reading, MA: Addison-Wesley.

Barr, Rebecca, and Robert Dreeben. 1983. How Schools Work. Chicago: University of Chicago.

Bernstein, Basil. 1975. Class, Codes and Control. London: Routledge and Keagan Paul.

Beyer, Landon E., and Michael W. Apple (Eds.). 1998. The Curriculum:Problems, Politics and Possibilities. Albany, N.Y.: State University of New York Press.

Binder, Amy. 2000. "Why Do Some Curricular Challenges Work While Others Do Not? The Case of Three Afrocentric Challenges." Sociology of Education 73:69-71.

Bobbio, Norberto. 1982. Gramsci e la Concezione della Societa Civile. Rio de Janeiro: Edições Graal.

Bourdieu, Pierre. 1979. Outline of a Theory of Practice. Cambridge, U.K.: Cambridge University Press.

Bourdieu, Pierre, and J.C. Passeron. 1977. Reproduction in Education, Society and Culture: Sage Publications. 
Bowles, S., and H. Gintis. 1976. Schooling in Capitalist America: Educational Reform and the Contradictions of Economic Life. N.Y.: Basic Books, Inc.

Carey, Nancy, Laurie Lewis, and Elizabeth Farris. 1998. "Parental Involvement in Children's Education: Efforts by Public Elementary Schools.": National Center for Education Statistics.

Cole, Michael. 1988. Bowles and Gintis Revisited: Correspondence and Contradiction in Educational Theory. London: Falmer Press.

Conant, James B. 1963. Thomas Jefferson and the Development of American Public Education. Berkeley, CA: University of California Press.

-. 1967. The Comprehensive High School: A Second Report to Interested Citizens. New York: McGraw-Hill.

Cooper, Robert. 1996. "Detracking Reform in an Urban California High School: Improving the Schooling of African American Students." Journal of Negro Education 65:190208.

Corbett, H. Dickson, William A. Firestone, and Gretchen B. Rossman. 1987. "Resistance to Planned Change and the Sacred in School Cultures." Educational Administration Quarterly 23:36-59.

Cuban, Larry. 1987. "Cultures of Teaching: A Puzzle." Educational Administration Quarterly 23:25-35.

—. 1990. "Reforming Again, Again, and Again." Educational Researcher 19:3-13.

-. 1995. "The Hidden Variable: How Organizations Influence Teacher Responses to Secondary Science Curriculum Reform." Theory into Practice 34:4-11.

—. 1998a. "How Schools Change Reforms: Redefining Reform Success and Failure." Teachers College Record 99:453-477.

—. 1998b. "Unchanging Public Opinion." The American School Board Journal.

Cusick, Phillip A. 1987. "Introduction." Educational Administration Quarterly 23:11-24.

Datnow, Amanda. 1997. "Gender as a Defensive Strategy." Anthropology and Education Quarterly 28:204-228.

DeVos, George. 1980. "Ethnic Adaptation and Minority Status." Journal of Cross Cultural Psychology 11:101-124. 
DiBella, Anthony J. 1994. "Applying concepts of Corporate Culture to International Business Management." in Anthropological Perspectives on Organizational Culture, edited by Tomoko Hamada and Willis E. Sibley. Lnaham: University Press of America.

Enomoto, Ernestine K. 1994. "The Meaning of Truancy: Organizational Culture as Multicultures." The Urban Review 26:187-207.

Erickson, Frederick. 1987. "Conceptions of School Culture: An Overview." Educational Administration Quarterly 23:11-24.

Finley, Merilee K. 1984. "Teachers and Tracking in a Comprehensive High School." Sociology of Education 57:233-243.

Fleischman, H.L., and P. J. Hopstock. 1993. "Descriptive Study of Services to Limited English Proficient Students." Arlington, VA: Report to the U.S. Department of Education, Office of the Undersecretary. Development Associates, Inc.

Freedman Lustig, D. 1997. "Of Kwanzaa, Cinco de Mayo, and Whispering: The Need for Intercultural Education." Anthropology and Education Quarterly 28:574-592.

Freire, Paulo. 1987. Pedagogia do Oprimido. Rio de Janeiro: Paz e Terra.

Gamoran, Adam. 1987. "The Stratification of High School Learning Opportunities." Sociology of Education 60:135-55.

Gamoran, Adam, and Mark Berends. 1987. "The Effects of Stratification in Secondary Schools: Synthesis of Survey and Ethnographic Research." Review of Educational Research 57:415-35.

Geertz, Clifford. 1973. The Interpretation of Cultures. N.Y.:Basic Books.

Gibson, Margaret A., and John U. Ogbu (Eds.). 1991. Minority Status and Schooling: A Comparative Study of Immigrant and Involuntary Minorities. New York: Garland.

Giroux, Henry. 1992. Border Crossings: Cultural Workers and the Politics of Education. N.Y.: Routledge.

Gollub, W.L., and Earling Sloan. 1978. "Teacher Expectation and Race and Socioeconomic Status." Urban Education 13:95-106.

Gottfredson, Denise C. 1981. "Black - White Differences in the Educational Attainment Process: What Have We Learned?" American Sociological Review 46:542-557.

Gould, Stephen Jay. 1996. The Mismeasure of Man. New York: Norton. 
Hallinan, Maureen T. 1994. "Tracking: From Theory to Practice." Sociology of Education 67:79-84.

Hamada, Tomoko. 1994. "Anthropology and Organizational Culture." in Anthropological Perspectives on Organizational Culture, edited by Tomoko Hamada and Willis E. Sibley. Lanham: University Press of America.

Hayes, Floyd W., III. 1990. "Race, Urban Politics, and Educational Policy-Making in Washington, D.C.: A Community's Struggle for Quality Education." Urban Education 25:237-57.

Hurn, Christopher J. 1993. The Limits and Possibilities of Schooling: An Introduction to the Sociology of Education. Boston: Allyn and Bacon.

Hurst, Leslie. 1991. "Mr. Henry Strikes a Deal: Negotiated Teaching in a Junior High School." Pp. 183-202 in Ethnography Unbound, edited by Michael Burawoy. Berkeley: University of California Press.

Kalmijn, Matthijs, and Gerbert Kraaykamp. 1996. "Race, Cultural Capital, and Schooling: An Analysis of Trends in the United States." Sociology of Education 69:22-34.

Karabel, Jerome, and A.H. Halsey. 1977a. "Educational Research: A Review and An Interpretation." Pp. 1-85 in Power and Ideology in Education, edited by Jerome Karabel and A.H. Halsey. N.Y.: Oxford University Press.

Karabel, Jerome, and A.H. Halsey (Eds.). 1977b. Power and Ideology in Education. New York: Oxford University Press.

Kelly, D. 1975. "Tracking and Its Impact on Self-Esteem: A Neglected Dimension." Education 96.

Kliebard, Herbert M. 1995. The Struggle for the American Curriculum: 1893-1958. New York: Routledge and Kegan Paul.

- 1998. "The Effort to Reconstruct the Modern American Curriculum." Pp. 21-33 in The Curriculum: Problems, Politics and Possibilities, edited by Landon E. Beyer and Michael W. Apple. Albany, N.Y.: S.U.N.Y. Press.

Kohl, H. 1994. I Won't Learn from You and Other Thoughts on Creative Maladjustment. N.Y. The New Press.

Kuhn, Thomas. 1962. The Structure of Scientific Revolutions. Chicago: University of Chicago Press. 
Lazerson, M. 1974. Origins of the Urban School. Cambridge: Harvard University Press.

LeCompte, Margaret D., and Jean J. Schensul. 1999. Analyzing and Interpreting Ethnographic Data. Walnut Creek, CA: Altamira Press.

Lucas, Samuel Roundfield. 1999. Tracking Inequality: Stratification and Mobility in American High Schools. New York, N.Y.: Teachers College Press.

Martin, Joanne. 1985. "Can Organizational Culture Be Managed?" Pp. 95-99 in Organizational Culture, edited by Peter J. Frost and et al. Beverly Hills: Sage Publications Inc.

-. 1992. Cultures in Organizations: Three Perspectives. New York: Oxford University Press.

McDermott, Raymond P. 1977. "Social Relations as Contexts for Learning." Harvard Educational Review 47:198-213.

-. 1987. "Making Dropouts." Pp. 16-26 in What do Anthropologists Have to Say About Dropouts? The First Centennial Conference on Children at Risk, edited by Henry T. Trueba, George Spindler, and Louise Spindler. University of California at Santa Barbara: The Falmer Press.

McDonough, Patricia M. 1998. "Structuring College Opportunities: A Cross-Case Analysis of Organizational Cultures, Climates, and Habiti." in Sociology of Education: Emerging Perspectives, edited by Carlos Alberto Torres and Theodore R. Mitchell. Albany: State University of New York Press.

McLaren, Peter. 1995. "Critical Pedagogy in the Age of Global Capitalism: Some Challenges for the Educational Left." Australian Journal of Education 39:5-21.

-1998. Life in Schools: An Introduction to Critical Pedagogy in the Foundations of Education. New York: Longman.

McQuillan, Patrick James. 1998. Educational Opportunity in an Urban American High School: A Cultural Analysis. Albany: State University of New York Press.

Mehan, Hugh, Lea Hubbard, Angela Lintz, and Irene Villanueva. 1994. "Tracking Untracking: The Consequences of Placing Low Track Students in High Track Classes."San Diego: University of California.

Merelman, Richard M. 1980. "Democratic Politics and the Culture of American Education." The American Political Science Review 74:319-332. 
Moore, Donald R., and Suzanne Davenport. 1988. "The New Improved Sorting Machine.". Madison: University of Wisconsin-Madison, School of Education, National Center on Effective Secondary Schools.

Moore, Larry F. 1985. "How are Organizational Cultures and the Wider Cultural Context Linked?" in Organizational Culture, edited by Peter J. Frost, Larry F. Moore, Meryl Reis Louis, Craig C. Lundberg, and Joanne Martin: Sage Publications.

Mosca, Gaetano. 1939. The Ruling Class. N.Y: McGraw Hill.

Nord, Walter R. 1985. "Can Organizational Culture Be Managed? A Synthesis." in Organizational Culture, edited by Peter J. Frost, Larry F. Moore, Meryl Reis Louis, Craig C. Lundberg, and Joanne Martin. Beverly Hills: Sage Publications.

Oakes, Jeannie. 1981. "Tracking Policies and Practices: School by School Summaries: A Study of Schooling in the United States." Los Angeles: University of California at Los Angeles Graduate School of Education.

-. 1982. "The Reproduction of Inequality: The Content of Secondary School Tracking." Urban Review 14:107-120.

-. 1983. "Tracking and Ability Grouping in American Schools: Some Constitutional Questions." Teachers College Record 84:801-819.

-. 1985. Keeping Track: How Schools Structure Inequality. New Haven, CT: Yale University Press.

-. 1986. "Tracking Inequality, and the Rhetoric of Reform: Why Schools Don't Change." Journal of Education 168:60-80.

—. 1987. "Tracking in Secondary Schools: A Contextual Perspective." Educational Psychology 22:129-153.

-. 1990. "Multiplying Inequalities: The Effects of Race, Social Class, and Tracking on Opportunities to Learn Math and Science." Santa Monica, CA: Rand Corporation.

-. 1994. "More than Misapplied Technology: A Normative and Political Response to Hallinan on Tracking." Sociology of Education 67:84-89.

—. 1995. "Two Cities' Tracking and Within-School Segregation." Teachers College Record 96:681-690.

Office of Bilingual Education and Minority Language Affairs. 1997. "About Us!" http://www.ed.gov/offices/OBEMLA/aboutus.html. 
Ogbu, John U. 1974. The Next Generation: An Ethnography of Education in an Urban Neighborhood. New York: Academic Press.

-. 1990. "Minority Education in Comparative Perspective." Journal of Negro Education 59:45-57.

Pallas, Aaron M., Doris R. Entwisle, Karl L. Alexander, and M. Francis Stluka. 1994. "Ability-Group Effects: Instructional, Social or Institutional?" Sociology of Education 67:27-46.

Peshkin, Alan. 1988. "The Researcher and Subjectivity: Reflections on an Ethnography of School and Community." in Doing the Ethnography of Schooling: Educational Anthropology in Action, edited by George Spindler. Prospect Heights, IL: Waveland Press.

Raywid, Mary Ann. 1999. "On the Viability of the Comprehensive High School: A Reply to Professor Wraga." Educational Administration Quarterly 35:305-310.

Riordan, Cornelius. 1997. Equality and Achievement: An Introduction to the Sociology of Education. New York: Addison-Wesley.

Rippa, S. Alexander. 1997. Education in a Free Society: An American History. White Plains, N.Y.: Longman.

Rist, Ray. 1970. "Social Class and Teacher Expectations: The Self-Fulfilling Prophecy in Ghetto Education." Harvard Educational Review 40:411-451.

Rosenbaum, J. 1976. Making Inequality: The Hidden Curriculum of High School Tracking. New York: Wiley.

Rosenthal, Robert, and Lenore Jacobsen. 1968. Pygmalion in the Classroom. New York: Holt, Rinehart and Winston.

Rumberger, Russel W., and Katherine A. Larson. 1998. "Toward Explaining Differences in Educational Achievement among Mexican American Language-Minority Students." Sociology of Education 71:68-93.

Saha, Lawrence J. 1987. "Social Mobility versus Social Reproduction: Paradigms and Politics in the Sociology of Education." New Education 9:14-28.

Sapon-Shevin, Mara. 1993. "Gifted Education and the Protection of Privilege: Breaking the Silence, Opening the Discourse." in Beyond Silenced Voices. Class, Race, and Gender in United States Schools, edited by Lois Weis and Michelle Fine. New York: State University of New York Press. 
Sarason, Seymour Bernard. 1996. Revisiting "The Culture of the School and the Problem of Change". New York, NY: Teachers College Press.

Schein, Edgar H. 1992. Organizational Culture and Leadership. San Francisco, CA: Jossey-Bass Inc, Publishers.

Shafritz, Jay M., and J. Steven Ott (Eds.) 1987. Classics of Organization Theory. Chicago: The Dorsey Press.

Silva, Tomaz Tadeu da. 2000. "The Curriculum as Fetish." Taboo. The Journal of Culture and Education 4:19-44.

Sirotnik, Kenneth A. 1998. "What Goes on in the Classroom? Is This the Way We Want It?" in The Curriculum: Problem, Politics, and Possibilities, edited by Landon E. Beyer and Michael W. Apple. Albany, N.Y.: State of New York University Press.

Siskin, Leslie Santee. 1994. Realms of Knowledge: Academic Departments in Secondary Schools. Washington, DC: Falmer Press.

Smircich, Linda. 1983. "Concepts of Culture and Organizational Analysis." Administrative Science Quarterly 28:339-358.

Smith, Vicki. 1993. "Approaching Organizational Culture versus Cultural Approaches to Organizations: Let's Close the Gap." Contemporary Sociology 22:417-421.

Spindler, George. 1955. Education and Anthropology. Stanford,CA: Stanford University Press.

- (Ed.). 1988. Doing the Ethnography of Schooling. Educational Anthropology in Action. Prospect Heights, IL: Waveland Press.

Spindler, George, and Louise Spindler. 1988. "Cultural Process and Ethnography." in Education and Cultural Process: Anthropological Approaches, edited by George Spindler. Prospect Heights, IL: Waveland Press.

Stepick, Alex. 1995. "The Academic Orientation of Minority Adolescents." in Prospectus of Research Proposal Funded by the National Science Foundation.

Stevenson, D.L., K.S. Schiller, and B. Schneider. 1994. "Sequences of Opportunities for Learning." Sociology of Education 67:184-198.

Tierney, William G. 1988. "Organizational Culture in Higher Education: Defining the Essentials." Journal of Higher Education 59:2-21. 
Trueba, Henry T. 1987. "The Ethnography of Schooling." Pp. 1-13 in Success or Failure: Linguistic Minority Children at Home and in School. New York: Harper and Row.

Tye, Barbara Benham. 2000. Hard Truths: Uncovering the Deep Structure of Schooling. New York, N.Y.: Teachers College Press.

Vanfossen, Beth E., James D. Jones, and Joan Z. Spade. 1987. "Curriculum Tracking and Status Maintenance." Sociology of Education 60:104-122.

Wells, Amy Stuart, and Jeannie Oakes. 1996. "Potential Pitfalls of Systemic Reform: Early Lessons from Research on Detracking." Sociology of Education:135-143.

Wilcox, Kathleen. 1988. "Differential Socialization in the Classroom: Implications for Equal Opportunity." in Doing the Ethnography of Schooling. Educational Ethnography in Action, edited by George Spindler. Prospect Heights, IL: Waveland Press.

Willis, Paul. 1981. Learning to Labor: How Working Class Kids Get Working Class Jobs. New York: Columbia University Press.

Wraga, William G. 1998. "The Comprehensive High School and Educational Reform in the U.S.: Retrospect and Prospect." The High School Journal 81:121-126.

-. 1999. "Repudiation, Reinvention, and Educational Reform: The Comprehensive High School in Historical Perspective." Educational Administration Quarterly 35:292304.

Zehler, A.N., Paul J. Hopstock, Howard L Fleischman, and Cheryl Greniuk. 1994. "An Examination of Assessment of Limited English Proficiency Students." Arlington, VA: Special Issues Analysis Center Development Associates, Inc. 
DORA ACHERMAN-CHOR

$\begin{array}{ll}\text { April 2,1960 } & \text { Born, Rio de Janeiro, Brazil } \\ 1984 & \begin{array}{l}\text { B.A. Sociology and Anthropology } \\ \text { Tel Aviv University, Israel }\end{array} \\ \text { 1996-1999 } & \begin{array}{l}\text { Research Assistant } \\ \text { Florida Int'l University } \\ \text { Miami, Florida }\end{array} \\ & \begin{array}{l}\text { Teaching Assistant } \\ \text { Florida Int'l University } \\ \text { Miami, Florida }\end{array} \\ & \begin{array}{l}\text { M.A. Comparative Sociology } \\ \text { Florida Int'l University } \\ \text { Miami, Florida }\end{array} \\ & \begin{array}{l}\text { Research and Program Coordinator } \\ \text { The Academy for the Art of Teaching }\end{array} \\ & \begin{array}{l}\text { Florida Int'l University } \\ \text { Miami, Florida }\end{array}\end{array}$

PUBLICATIONS AND PRESENTATIONS

Acherman-Chor, D. (1997). The Implementation of Evaluation and Placement Policies for Immigrant Students in Dade County. Paper presented at the $42^{\text {nd }}$ meeting of the Florida Educational Research Association (FERA), Orlando, Florida.

Acherman-Chor, D. (1997). Educational Policies that Affect LEP Students and their Effects on Immigrants. Paper presented at the $96^{\text {th }}$ meeting of the American Anthropological Association, Washington, DC.

Acherman-Chor, D. (1998). Multiculturalism in Educational Discourse. Paper presented at $97^{\text {th }}$ meeting of the American Anthropological Association, Philadelphia, PA.

Acherman-Chor, D. (1999). The Implementation of Equity Policy for LEP Students: A Qualitative Evaluation. Working Paper \#5, Immigration and Ethnicity Institute, Florida International University.

Acherman-Chor, D., Aladro, G. and Dutta-Gupta, S. (2000). Minorities and Math: What is Behind the Failure Rates? Paper presented at meeting of The Mathematical Association of America, Gold Coast Section, Miami, FL. 